\title{
14. Cardiología clínica
}

\subsection{Correlación entre estatura o superficie corporal y tensión arterial entre menores de 18 años}

Acoltzin Vidal Cuauhtémoc, Rabling Arellanos Elizabeth, ${ }^{\ddagger}$

Marcial Gallegos Leticia ${ }^{\ddagger}$

* Universidad de Colima. ${ }^{*}$ Clínica Cardiológica privada.

Tipo de estudio: Prueba diagnóstica

Introducción: Aunque se han descrito cifras de tensión arterial en menores de 18 años, observamos que algunos con estatura elevada tienen cifras de tensión arterial mayores que las esperadas. Objetivo: Buscar correlación entre estatura, tensión arterial sistólica (TAS), diastólica (TAD) y superficie corporal (SC), pues el criterio diagnóstico se basa en cifras sin diferenciar las características somatométricas. Metodología: Se midieron estatura, tensión arterial, peso y se calculó SC de menores de 18 años sanos. La tensión arterial se midió con esfigmomanómetro automático calibrado. La estatura y el peso con una báscula mecánica calibrada antes de empezar el procedimiento. Se hicieron pruebas de correlación y coeficiente de determinación. Resultados: Son 150 casos. Hubo correlación con r mayor de 0.5 entre estatura y TAS: 0.53 , determinación: $0.29(p=0.000000)$; SC y TAS: 0.529 , determinación $=0.28(\mathrm{p}=0.000000)$; y edad y TAS: 0.51, determinación: 0.27 ( $p=0.000000$ ) (Tabla 14.1.1). Los percentiles 90 y 95 para TAS fueron 130 y $140 \mathrm{mmHg}$ y para TAD 77 y $80 \mathrm{mmHg}$. No hubo diferencia significativa entre sexos. Discusión y conclusiones: Entre más corpulentos mayor TAS, aunque por edad sean menores. Esto deberá cambiar el criterio diagnóstico de hipertensión arterial en estas etapas de la vida.

\subsection{Síndrome de Tietze y cardiopatía isquémica: la importancia de prestar atención a los detalles}

Radillo Alba Hugo Alberto

Hospital Civil de Guadalajara «Fray Antonio Alcalde».

Tipo de estudio: Reporte de casos clínicos con revisión de fuentes

Introducción: El síndrome de Tietze o costocondritis consiste en la inflamación de las articulaciones de la parrilla costal. Este diagnóstico corresponde a uno de los principales diagnósticos diferenciales del dolor precordial causado por la isquemia cardiaca. Dada su frecuencia, la costocondritis se sobrediagnostica en contextos de urgencias y se enmascaran casos de dolor precordial cardiaco. Descripción del caso:
Hombre de 49 años, obeso, diabético, hipertenso y fumador ingresado en tres días distintos a lo largo de nueve días a un Servicio de Urgencias por dolor precordial, concluyéndose por médicos generales diagnóstico de costocondritis. En el cuarto ingreso, es valorado por residente, quien deriva a hospital de tercer nivel por contar con evidencia clínica y analítica de cardiopatía isquémica. Metodología: Se realizó una búsqueda por referencias cruzadas sobre los tópicos relacionados con costocondritis, cardiopatía isquémica crónica, síndromes coronarios agudos y su relación con periodos de atención y desenlaces, dado el final ominoso del caso en cuestión. Resultados: Según estadística publicada desde 1960 y hasta 2019, la mayoría de los síndromes coronarios agudos son atendidos, en primera instancia, por médicos generales de primer contacto en consultorios privados y hospitales comunitarios en donde no se cuenta con un especialista familiarizado en reconocer presentaciones atípicas de dichos síndromes. Refrendar la importancia del análisis clínico es menester para el especialista. Discusión: Se analiza el torpe proceso diagnóstico que se replica en múltiples comunidades del país, en donde un síndrome coronario agudo no se sospechó desde el inicio, pese a la presentación clínica del paciente. El caso culminó en la muerte del paciente abordo de una ambulancia. Podemos proyectar la preocupación del especialista en obtener de forma expedita el diagnóstico de cardiopatía isquémica.

\subsection{Endocarditis tricuspídea asociada a marcapasos con embolismos pulmonares y sistémicos}

Arias Rodríguez Sergio, Núñez-Méndez José Gilberto,

Núñez-Méndez Rodrigo, García-Saldivia Marianna Andreina,

Moreno-González Agustina, Lupercio-Mora Karina,

Almeida-Gutiérrez Eduardo

Hospital de Cardiología del Centro Médico Nacional Siglo XXI.

Tipo de estudio: Reporte de casos clínicos con revisión de fuentes

Introducción: La endocarditis infecciosa asociada a dispositivos cardiacos es más frecuente por el aumento en la colocación de dispositivos intracardiacos, se presenta en el 2\% en los primeros cinco años después del implante y puede involucrar los cables del dispositivo y la superficie endocárdica circundante. Cuando se presentan embolismos, son en el sistema venoso y rara vez en el arterial. Descripción del caso: Hombre de 52 años con antecedente de bloqueo AV-completo desde el 2008 con colocación de marcapasos bicameral, cambio de generador en marzo de 2020; exteriorización del dispositivo en junio de 2020. Pre-

Tabla 14.1.1.

\begin{tabular}{|c|c|c|c|c|c|c|}
\hline Dato & Q0 & Q1 & $\mathbf{Q} 2=\mathbf{M}$ & Q3 & Q4 & Mo \\
\hline Estatura & 0.70 & 1.17 & 1.42 & 1.66 & 1.85 & 1.65 \\
\hline TAS & 60 & 90 & 110 & 120 & 150 & 110 \\
\hline TAD & 40 & 55 & 60 & 70 & 90 & 110 \\
\hline SC & 0.42 & 0.80 & 1.26 & 1.63 & 2.17 & 1.36 \\
\hline
\end{tabular}

TAS = tensión arterial sistólica; $\mathrm{TAD}=$ tensión arterial diastólica; $\mathrm{SC}=$ superficie corporal 


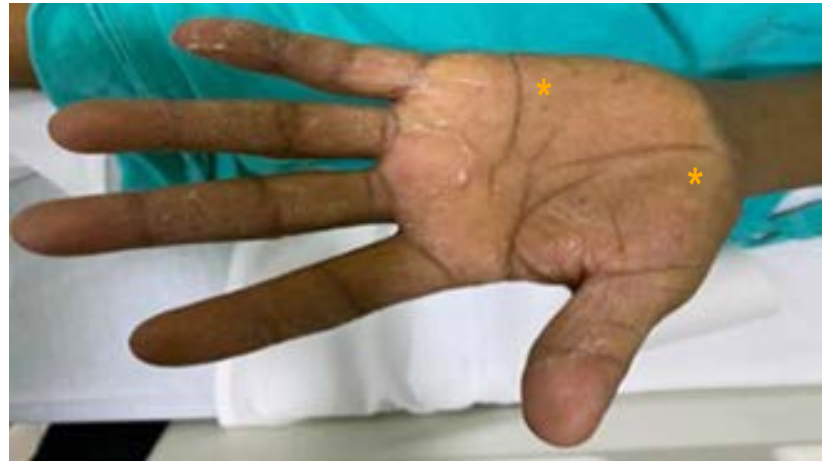

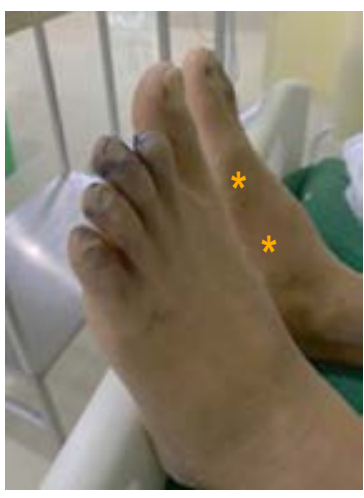

* Necrosis distal

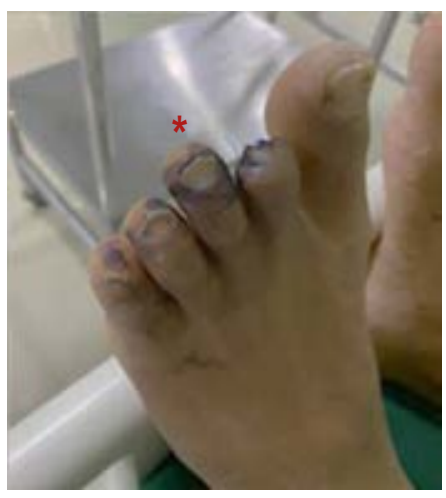

* Lesiones de Janeway
Figura 14.3.1.

sentó dos semanas antes fiebre y nuevo soplo holosistólico tricuspídeo, insuficiencia cardiaca derecha, lesiones de Janeway, necrosis distal de extremidades inferiores y embolismo pulmonar. Diagnóstico bacteriológico: Staphylococcus aureus (Figuras 14.3.1 y 14.3.2). Metodología: Se realizó búsqueda en bases de datos de revistas indizadas con factor de impacto (PubMed y Cochrane) y en bases de datos de publicaciones arbitradas sin factor de impacto (Google Scholar). Se eligieron los artículos de revisión, guías de práctica clínica y series de casos que mostraran información relacionada con nuestro caso. Resultados: El embolismo sistémico se presenta en el $25 \%$ de los casos de endocarditis infecciosa; sin embargo, es muy poco frecuente en la endocarditis de cavidades derechas. En este contexto clínico, usualmente existe un foramen oval permeable o endocarditis de cavidades izquierdas concomitante que se estudió en nuestro paciente y se excluyeron ésta y otras posibilidades de cortocircuitos. Discusión: La endocarditis infecciosa asociada con dispositivos cardiacos ha aumentado en los últimos años y es una condición de incidencia variable y alta mortalidad. La endocarditis de cavidades derechas, por lo general, se ve asociada solamente a embolismos pulmonares. Presentamos un caso atípico de endocarditis tricuspídea asociada con marcapasos complicado con embolismos sistémicos.

\subsection{Síndrome de Wellens: un patrón electrocardiográfico de muy alto riesgo}

Núñez Méndez José Gilberto, Núñez-Méndez Rodrigo,

Almeida-Gutiérrez Eduardo, Lupercio-Morta Karina

Hospital de Cardiología del Centro Médico Nacional Siglo XXI.

Tipo de estudio: Reporte de casos clínicos con revisión de fuentes
Introducción: El síndrome de Wellens se caracteriza por la presencia de ondas $\mathrm{T}$ negativas o bifásicas encontradas en derivaciones precordiales, especialmente V2-V3, en ausencia de onda $\mathrm{Q}$, durante periodos libres de dolor torácico en un paciente con historial clínico de angina. Se asocia a una estenosis significativa del segmento proximal de la arteria descendente anterior. Descripción del caso: Hombre de 62 años, con historial de angina progresiva, electrocardiograma con ondas $\mathrm{T}$ negativas en $\mathrm{V} 3-\mathrm{V} 4$; presentó nuevamente angina prolongada, y al ingreso asintomático, electrocardiograma: ondas $T$ negativas precordiales con ondas T bifásicas en V2-V3, sin alteraciones de movilidad segmentaria en ecocardiograma y discreta elevación de biomarcadores. Coronariografía: lesión suboclusiva del 99\% en el segmento medio de la descendente anterior. Metodología: Se realizó una búsqueda binaria en bases de datos de revistas indexadas con factor de impacto (PubMed y Cochrane), y en bases de datos de publicaciones arbitradas sin factor de impacto (Google Scholar). Se eligieron los artículos de revisión, guías de práctica clínica y series de casos que mostraron información relacionada con nuestro caso. Resultados: Existen dos patrones

\section{A) Vegetación en valva anterior de válvula tricúspide}
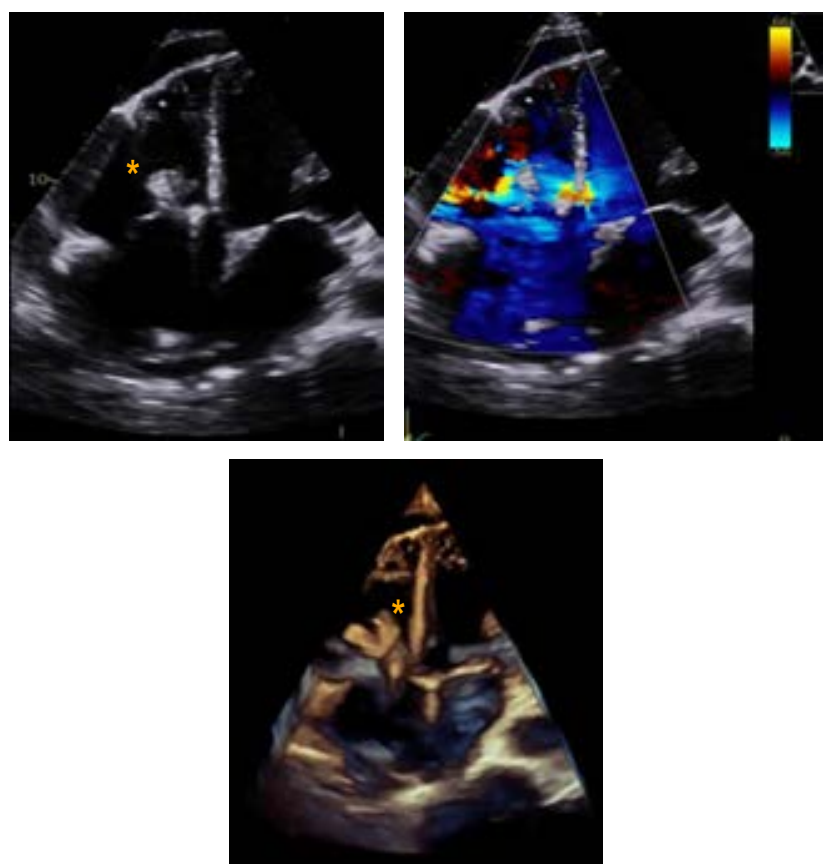

B) Embolismos pulmonares sépticos

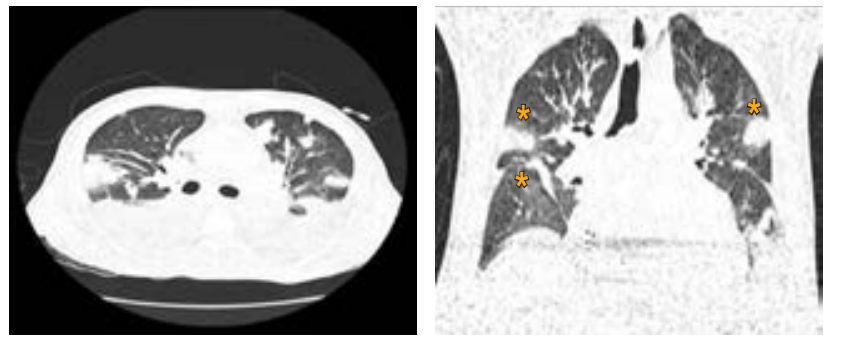

Figura 14.3.2. 

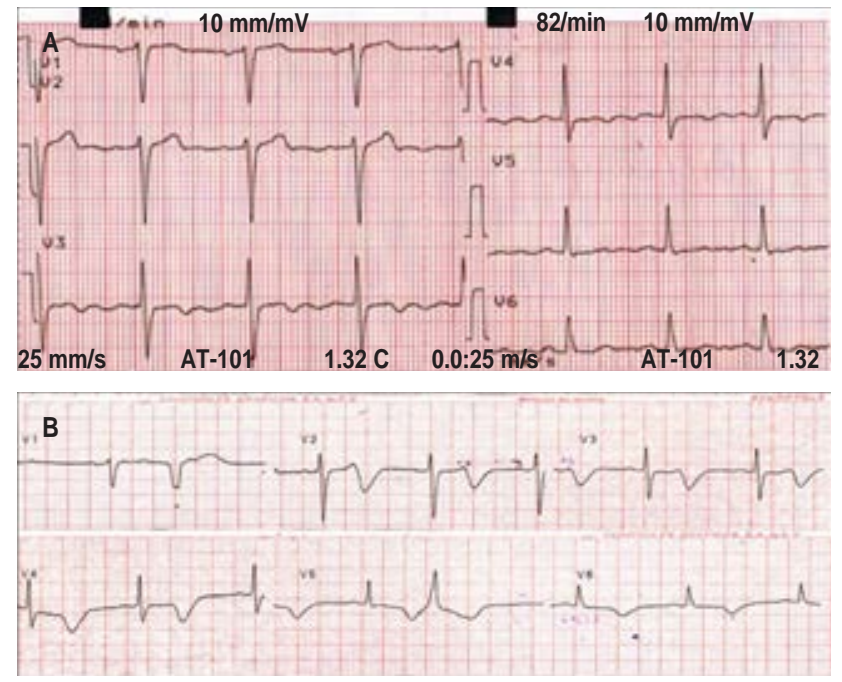

Figura 14.4.1: Electrocardiogramas-derivaciones precordiales.

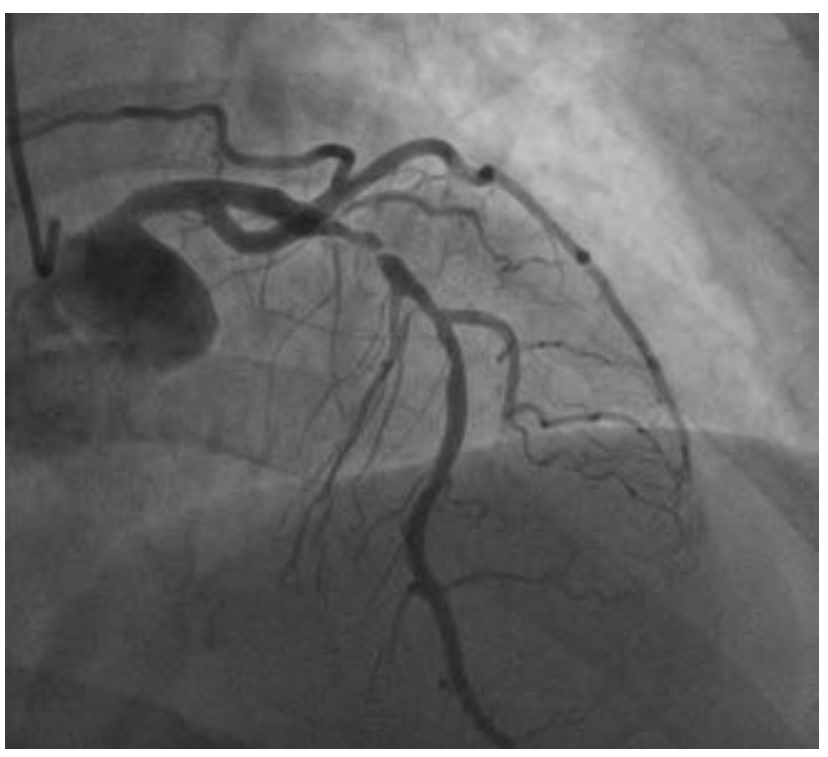

Figura 14.4.2: Angiografía coronaria-proyección anteroposterior craneal.

electrocardiográficos en este síndrome, el tipo B es el más común y ocurre en el $75 \%$ de los casos, caracterizado por la presencia de ondas $\mathrm{T}$ negativas en $\mathrm{V} 2-\mathrm{V} 3$ y el tipo A que representa el $25 \%$, caracterizado por ondas T bifásicas en V2-V3. El paciente presenta un patrón tipo A al encontrarse asintomático. Discusión: Nuestro caso representa un síndrome de Wellens de tipo A cuyos hallazgos electrocardiográficos corresponden a una lesión entre el primer y segundo ramo septal de la descendente anterior. La identificación del síndrome de Wellens es imperativa debido a que el $75 \%$ desarrollará un infarto agudo de miocardio en siete días, a menos que una intervención se realice con urgencia.

\subsection{Predictores de eventos cardiovasculares a 6 meses de intervención coronaria percutánea}

Pérez Roa Herlich Francisco, García Jiménez Yoloxóchitl

IMSS Unidad Médica de Alta Especialidad No. 14 del

Centro Médico Nacional «Adolfo Ruiz Cortines».

Tipo de estudio: Estudio Pronóstico

Introducción: El síndrome coronario agudo con elevación del segmento ST (IAMCEST) tiene una mortalidad del $21.1 \%$ en nuestra población. Existe una reducción de la mortalidad con estrategias de reperfusión de hasta 9.4\%. La intervención coronaria percutánea (ICP) es un tratamiento de elección como tratamiento inicial o dentro de una estrategia farmacoinvasiva, dentro de las 12 horas del inicio de síntomas. Objetivo: Identificar los predictores de eventos cardiovasculares mayores (ECM) a seis meses del ICP en pacientes con IAMCEST. Metodología: Estudio no experimental, cuantitativo, observacional, transversal en pacientes que recibieron ICP por IAMCEST de enero de 2018 a diciembre de 2019. Se calculó el riesgo relativo (RR) y odds ratio (OR) de muerte y hospitalización por causa cardiovascular a seis meses de la ICP. Resultados: Se incluyeron 120 pacientes: $82.5 \%$ hombres y $17.5 \%$ mujeres; edad promedio 60 años. Se realizó ICP rescate $47.5 \%$, ICP precoz $32.5 \%$ e ICP primaria $20 \%$. Se documentó $37.5 \%$ enfermedad monovaso y $35 \%$ enfermedad trivascular. La mortalidad a los seis meses fue $6.67 \%$. Los factores pronósticos de mortalidad fueron diabetes OR $2.6(p=0.042)$, clase Killip OR 2.9 ( $p=0.042)$, CC OR $2.9(p=0.035)$, FEVI menor $40 \%$ OR 2.9 ( $p=0.04)$. Discusión y conclusiones: En pacientes con IAMCEST tratados con ICP, los factores asociados a mortalidad a seis meses son diabetes, clase Killip Kimball al diagnóstico, choque cardiogénico y daño miocárdico al egreso hospitalario.

\subsection{Disfagia como primera manifestación de anillo vascular incompleto de arco aórtico en paciente adulto}

Jiménez Toxqui Maribel, García Jiménez Yoloxóchitl,

Hernández Bravo Mariana

\begin{tabular}{lcrc|} 
& OR & IC & p \\
\hline DM2 & 2.6 & $1.1-3.6$ & 0.042 \\
KK & 2.9 & $0.45-5.6$ & 0.042 \\
Choque cardiogénico & 3.2 & $0.78-5.5$ & 0.035 \\
FEVI $\leq 40 \%$ & 2.9 & $1.1-6.8$ & 0.040 \\
\hline
\end{tabular}

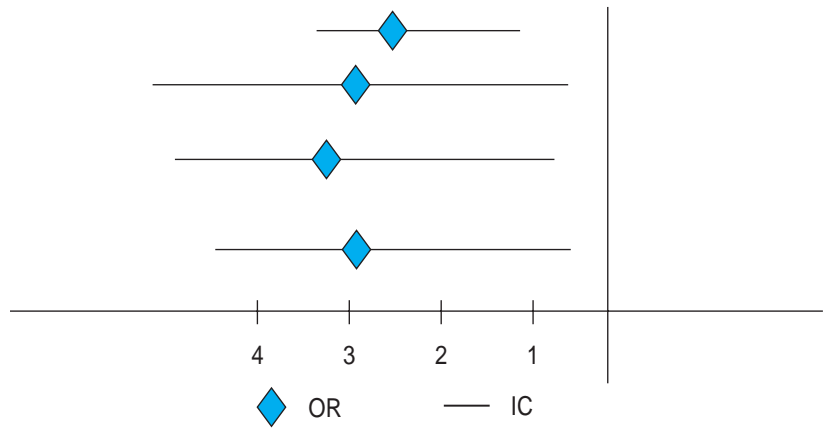

Figura 14.5.1: Riesgo de muerte cardiovascular. 
IMSS Unidad Médica de Alta Especialidad No. 14 del

Centro Médico Nacional «Adolfo Ruiz Cortines».

Tipo de estudio: Reporte de casos clínicos con revisión de fuentes

Introducción: Los anillos vasculares completos se originan por la persistencia de los cuartos arcos aórticos que rodean total o parcialmente tráquea y esófago comprimiéndolos. Defectos vasculares poco frecuentes representan el $0.8 \%$ de las cardiopatías congénitas. El término anillo vascular incluye no sólo los anillos completos, sino anillos parciales con o sin bandas, ligamentos fibrosos que también causan compresión traqueal o esofágica. Descripción del caso: Mujer de 35 años con antecedentes de hipotiroidismo de un año en tratamiento. Presenta disfagia de un año de evolución progresiva de sólidos a líquidos, con pérdida significativa de peso. Se realizó esofagograma que muestra estrechamiento del tercio medio esofágico. Endoscopia descarta patología. Metodología: Búsqueda bibliográfica de revistas indexadas en PubMed, palabras claves: anillo vascular, adultos, slings; se encontraron en su mayoría reportes aislados de esta patología, esto debido a su baja incidencia en población adulta. Resultados: Tomografía de tórax documenta anillo vascular incompleto del arco aórtico izquierdo con arteria subclavia derecha aberrante, asciende oblicuamente hacia la derecha discurriendo por detrás del esófago, lo que condiciona su obliteración parcial. Se realiza
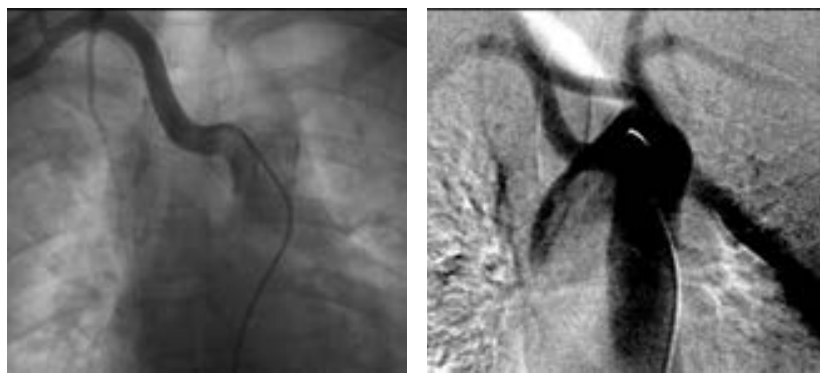

Figura 14.6.1: Angiogramas que muestran el nacimiento independiente de la arteria subclavia derecha a partir del cayado e istmo aórtico (nacimiento aberrante).

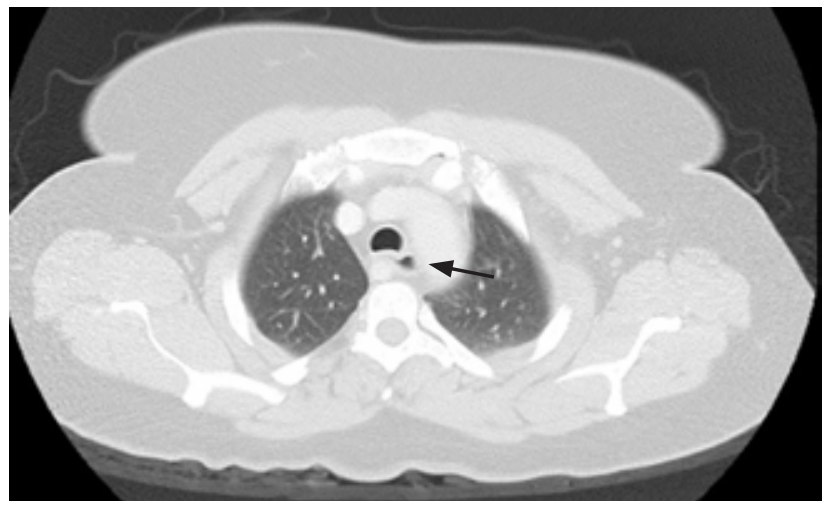

Figura 14.6.2: TAC de tórax: arteria subclavia derecha aberrante que condiciona obliteración parcial del esófago (flecha). cateterismo cardiaco con reporte de nacimiento anómalo de arteria subclavia derecha a partir del cayado e istmo aórtico. Aceptada en comité para cirugía de anillo vascular. Discusión: Se presentan en las fases tempranas de la vida. Cuando ocurre al final de la infancia o en la edad adulta, la disfagia es el síntoma predominante, principalmente en presencia de arco aórtico izquierdo y una arteria subclavia derecha aberrante. En la adultez, usualmente es asintomático, el 5\% puede tener síntomas debido al desarrollo de rigidez aterosclerótica, tortuosidad y dilatación.

\subsection{Presentación atípica de cardiomiopatía de Takotsubo}

Fernández Ochoa Aurig Fernando, Núñez Méndez Rodrigo,

Almeida Gutiérrez Eduardo, Lupercio Mora Karina

Hospital de Cardiología del Centro Médico Nacional Siglo XXI.

Tipo de estudio: Reporte de casos clínicos con revisión de fuentes

Introducción: La cardiomiopatía por estrés es un síndrome de insuficiencia cardiaca reversible agudo caracterizado por disfunción sistólica regional transitoria del ventrículo izquierdo. Actualmente se reconoce que está asociada a una tasa no despreciable de complicaciones tales como arritmias ventriculares, tromboembolismo sistémico y choque cardiogénico. Descripción del caso: Hombre de 89 años. Presenta angina atípica asociada a diaforesis y náuseas durante 20 minutos y elevación de troponina. El electrocardiograma reveló desnivel positivo del segmento-ST V2-V5. Ecocardiograma: ventrículo izquierdo no dilatado, acinesia apical. Angiografía coronaria sin lesiones angiográficas significativas y ventriculograma con discinesia anteroapical e hipercontractilidad basal anterior y posterior. Metodología: Se revisó expediente clínico y a través de método booleano se realizó búsqueda de términos MeSH Takotsubo cardiomyopathy y males en las bases de datos con repositorios de evidencia científica arbitrada indizada (PubMed) y no indizadas (Google Scholar). Resultados: La cardiomiopatía por estrés es más común en mujeres (89.9\%) y edad media 66.4 años. Hay dos subtipos, la forma secundaria es más común en varones y se caracteriza por ser desencadenado por estrés físico; presentan una mortalidad elevada (10-21\%). Presentamos a un paciente en el extremo de la vida con una presentación atípica de miocardiopatía por estrés. Discusión: Los pacientes masculinos con cardiomiopatía por estrés parecen tener antecedentes clínicos más severos, con mayor frecuencia de comorbilidades y enfermedades agudas, los cuales se asocian con peor pronóstico en la presencia de síndrome de Takotsubo secundario. Sigue sin determinarse si la forma primaria tiene un peor pronóstico en los hombres que en las mujeres.

\subsection{Validación de DAPT score y PRECISE- DAPT score en población mexicana}

Vázquez Arellano Rodrigo,* Vieyra Herrera Gerardo,* Cortez López Elyz Ariadneth, ${ }^{*}$ Rodríguez Chávez Laura Leticia,* Chiquiure Valenzuela Eduardo Julián José Roberto,* Vieyra Hernández Paola Adriana ${ }^{\ddagger}$

* Instituto Nacional de Cardiología Ignacio

Chávez. ${ }^{*}$ Universidad Panamericana.

Tipo de estudio: Registros locales o nacionales

Introducción: La terapia doble antiplaquetaria (DAPT) es actualmente el tratamiento de elección para pacientes sometidos a intervención coronaria percutánea (ICP) con colocación de stent; 
Figura 14.7.1:

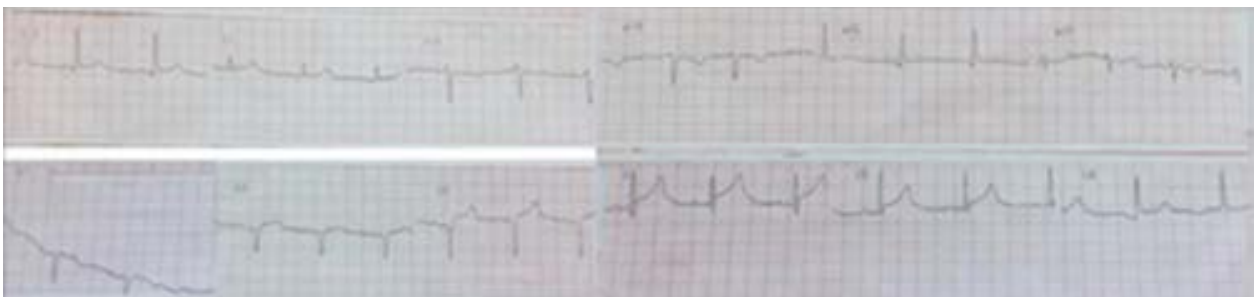

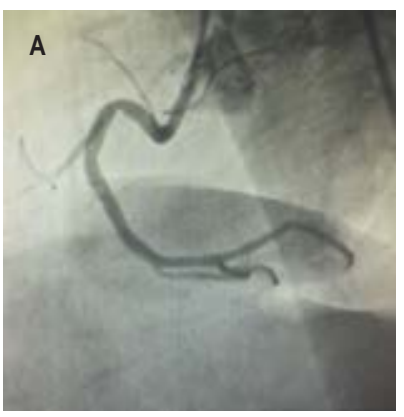
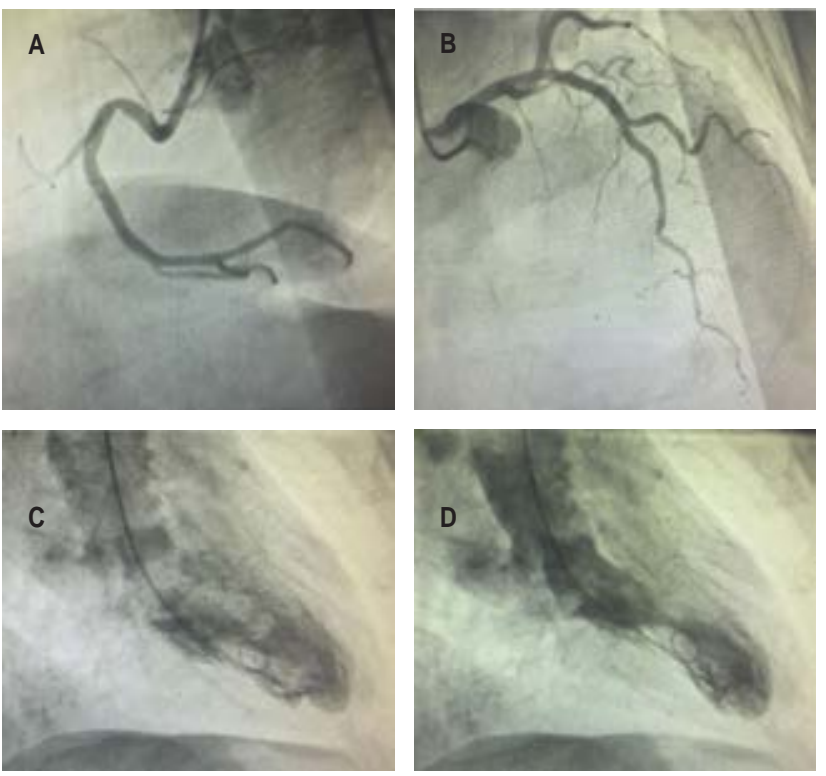

Figura 14.7.2.

sin embargo, la duración óptima ha sido tema de debate. En 2016 y 2017 surgieron dos puntajes cuyo objetivo es clasificar a los pacientes con DAPT en mayor riesgo de sangrado o isquemia. Objetivo: El objetivo de esta investigación es validar el uso de DAPT score y PRECISE-DAPT score en población mexicana. Metodología: Estudio prospectivo, longitudinal, observacional, descriptivo-analítico en un solo centro hospitalario. Pacientes mayores de 18 años, quienes fueron sometidos a ICP, en los cuales se aplicó el DAPT score y PRECISE-DAPT score, así como seguimiento a los 30 días, 6, 12 y 24 meses del egreso hospitalario. Resultados: Un total de 391 pacientes fueron incluidos en el estudio, de los cuales 35 (9\%) presentaron dolor torácico, y 8 (2\%) sangrado de moderado a mayor. DAPT score predijo 30/35 (86\%) casos de angor con puntaje $\geq 2$ y $7 / 8$ (88\%) casos de sangrado moderado a mayor con puntaje $<2$. PRECISE-DAPT score predijo 9/35 (25\%) casos de angor con puntaje $<25$, y $3 / 8$ (38\%) casos de sangrado con puntaje $\geq 25$. Discusión y conclusiones: La aplicación de DAPT score en población mexicana resultó mejor como predictivo de complicaciones en pacientes que están bajo tratamiento con terapia doble antiplaquetaria, en comparación con PRECISE-DAPT score.

\subsection{Tratamiento fibrinolítico para trombosis de prótesis mitral. Reporte de un caso}

Granados Marcelo Cristian Alí, Bocardo Galván Jessica Berenice, Almeida Gutiérrez Eduardo, Lupercio Mora Karina,

García Méndez Rosalba, Saturno Chiu Guillermo

Hospital de Cardiología del Centro Médico Nacional Siglo

XXI del Instituto Mexicano del Seguro Social.

Tipo de estudio: Reporte de casos clínicos con revisión de fuentes

Introducción: La trombosis valvular protésica es potencialmente mortal a pesar del tratamiento (mortalidad 10-25\%), con manifestaciones variables (asintomáticos, disnea, eventos tromboembólicos o choque cardiogénico) y constituye una indicación de cirugía emergente; el tratamiento fibrinolítico se recomienda cuando la cirugía no está disponible o es de alto riesgo por comorbilidades. Se presenta caso tratado con fibrinolisis con desenlace satisfactorio. Descripción del caso: Mujer de 48 años, múltiples comorbilidades, miocardiopatía hipertrófica tratada con miectomía septal y prótesis mitral. Con disnea de mínimos esfuerzos tras suspender anticoagulación cinco días. Ingresó con falla cardiaca y click protésico inaudible; INR 1.9. Ecocardiograma transesofágico: disco posterior fijo con trombo de $22 \times 14 \mathrm{~mm}$ y anterior de $7 \times 4 \mathrm{~mm}$. Se administró tenecteplasa por alto riesgo quirúrgico. Respuesta exitosa a 24 horas (sin trombo residual). Metodología: Se realizó revisión del expediente y a través de método booleano se buscaron términos MeSH prosthetic valvular thrombosis y fibrinolysis en las bases de datos con repositorios de evidencia científica arbitrada indizada (PubMed) y no indizadas (Google Scholar). Resultados: La trombosis de prótesis valvular mitral es una entidad potencialmente mortal que requiere alta sospecha diagnóstica y tratamiento oportuno. Discusión: La trombólisis es una opción terapéutica eficaz, segura, altamente disponible y de bajo costo para pacientes con trombosis de prótesis valvular izquierda en pacientes con alto riesgo quirúrgico o cuando no se cuente con disponibilidad de cirugía cardiaca; sin embargo, se requieren ensayos clínicos aleatorizados para corroborar estos hallazgos.

\subsection{Fístula coronario-cavitaria como etiología de angina crónica}

Cisneros Sánchez Nundehui, Calderón Osorio Fernando Manuel Instituto Mexicano del Seguro Social.

Tipo de estudio: Reporte de casos clínicos con revisión de fuentes

Introducción: Las fístulas de arterias coronarias con drenaje a ventrículo izquierdo son anomalías congénitas asintomáticas sin repercusión hemodinámica, detectados incidentalmente por angiografía coronaria. Es raro cuando desencadena cardiopatía isquémica. Reportamos un caso de fístula de arteria coronaria izquierda drenando al ventrículo izquierdo como causa de angina crónica. Descripción del caso: Mujer de 69 años, hipertensa y diabética. Tres años con disnea y angina típica, un año en clase funcional III. 
Electrocardiograma con bradicardia sinusal. Prueba de esfuerzo positiva para isquemia inferior. Ecocardiograma transtorácico sin alteraciones de la movilidad, FEVI conservada. Coronariografía con coronaria derecha hipoplásica y primera diagonal con comunicación a ventrículo izquierdo. Metodología: Las fístulas coronarias son una comunicación directa entre arteria coronaria y cámara cardiaca o gran vaso. Son poco frecuentes con incidencia del 0.1 a $0.7 \%$ en la población adulta sometida a angiografía. Más frecuente en hombres (relación 1.9:1) entre los 30-76 años. La coronaria izquierda está involucrada en $35 \%$, con drenaje a ventrículo izquierdo en $3 \%$. Normalmente son asintomáticas. Resultados: Es un caso inusual de angina crónica secundario a fístula de coronaria izquierda a ventrículo izquierdo. Los trayectos fistulosos no son hemodinámi- camente significativos, no dan sintomatología. Y en caso de existir, la isquemia miocárdica es por «robo del flujo coronario» debido al cortocircuito a través de la fístula, donde la sangre escapa de la circulación coronaria sin irrigar el miocardio. Discusión: Se presentó caso inusual de una fístula de coronaria izquierda a ventrículo izquierdo con presentación atípica de angina crónica.

\subsection{Disección aórtica Stanford B, DeBakey IIIB secundaria a emergencia hipertensiva. Reporte de un caso}

Cabrales García Rafael,* García Jiménez Yoloxóchitl,‡ Marín Rendón Sadoc*

Figura 14.9.1.
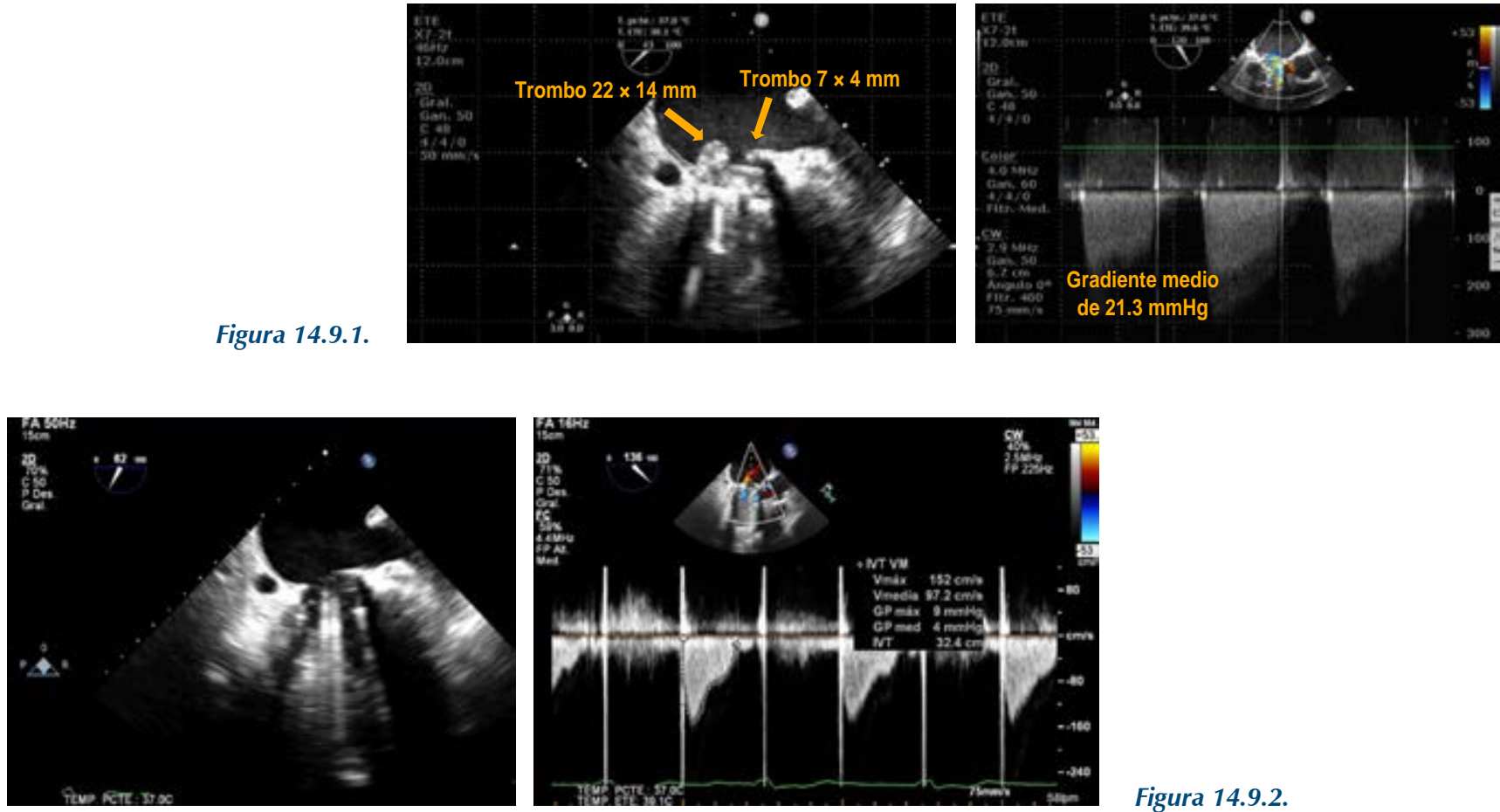

Figura 14.9.2.

Figura 14.10.1.
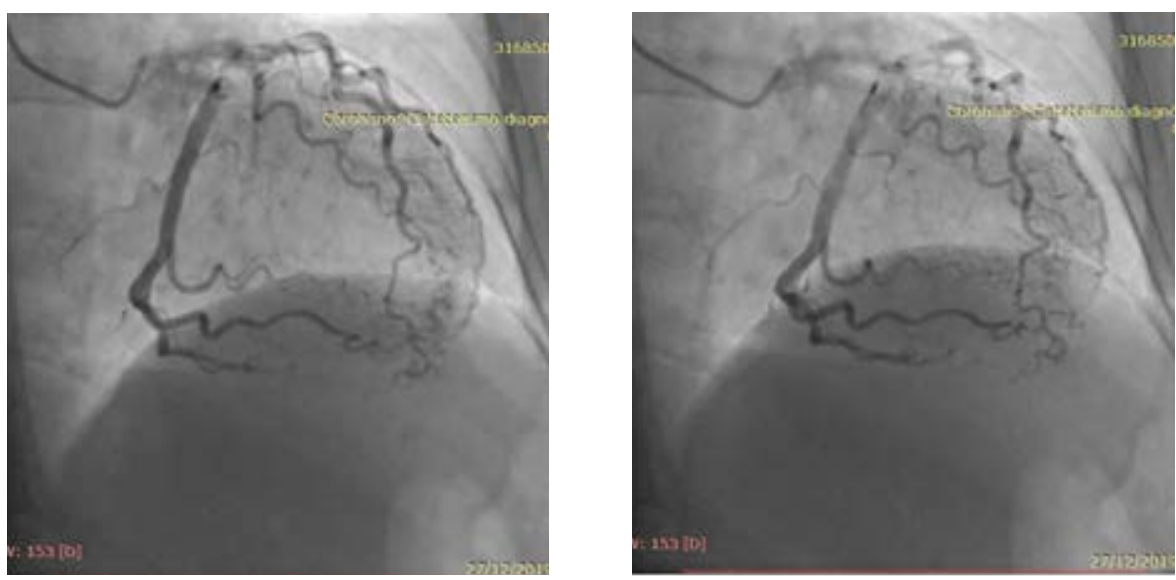

Figura 14.10.2. 
* Instituto Mexicano del Seguro Social. ${ }^{*}$ UMAE

Hospital de Especialidades No. 14, Veracruz.

Tipo de estudio: Reporte de casos clínicos con revisión de fuentes

Introducción: La disección aórtica se define como una separación de las capas de la pared aórtica debido a un desgarro de la íntima. Su etiología por emergencia hipertensiva es del $72 \%$. Su incidencia es mayor a partir de la sexta década, asociada con hipertensión y ateroesclerosis. Se clasifica de acuerdo con su extensión anatómica y esto permite definir la estrategia de manejo. Descripción del caso: Hombre de 68 años hipertenso sin control. Presenta dolor torácico súbito, documentándose TA 172/94 mmHg. En radiografía de tórax: ensanchamiento mediastinal. Electrocardiograma y enzimas cardiacas normales. Angiotomografía de tórax muestra disección de aorta posterior a la arteria subclavia izquierda hasta arterias iliacas comunes. Clasificado en Stanford B, DeBakey IIIB. Por extensión, en comité se acepta para tratamiento médico y control. Metodología: Se realiza una revisión sistemática y exhaustiva de las revistas indexadas al 2020, disponibles en la base de datos de PubMed-Medline, Science Direct, identificando las palabras claves aortic dissection, hypertensive emergency, hypertensive crisis, Stanford, DeBakey, dando relevancia al factor de impacto. Resultados: Las características clínicas y los hallazgos radiográficos no invasivos favorecen la sospecha diagnóstica, corroborándose con la angiotomografía. El electrocardiograma y las enzimas cardiacas son útiles descartando afección coronaria. El plan terapéutico fue discutido, las características de disección en apego a las guías clínicas concluyeron tratamiento médico. En seguimiento a tres meses, el paciente tiene TA 140/72 mmHg sin angina. Discusión: La supervivencia en disección tipo B es limitada, 12\% fallece en hospital y $28 \%$ antes de un año. Su manejo debe incluir el control estricto de la presión arterial y comorbilidades, evitando dilatación, expansión y futura rotura. Las opciones terapéuticas de intervencionismo o manejo médico deben ser establecidas por el Heart Team considerando la extensión y los datos de complicación.

\subsection{Presentación ECG dinámica con patrones de De Winter y Wellens en SICASEST}

Esquivel Sifuentes Ricardo Arturo, Ríos Cañas Francisco Javier Hospital de Cardiología del Centro Médico Nacional Siglo XXI. Tipo de estudio: Reporte de casos clínicos con revisión de fuentes

Introducción: Los patrones electrocardiográficos (ECG) de De Winter y Wellens son anormalidades características en el segmento ST y onda T en las derivaciones precordiales sugestivas de oclusión ateromatosa de alto grado en la arteria coronaria descendente anterior (DA) cursando usualmente en contexto de síndrome isquémico coronario agudo (SICA), con necesidad de intervencionismo coronario urgente. Descripción del caso: Hombre de 67 años, obesidad, diabetes mellitus tipo-2, hipertensión arterial, tabaquismo y angina estable clase funcional III. Presenta angina prologada, acude 18 horas después, primer ECG: patrón de De Winter, troponina T-HS: 2306 pg/mL; ECG subsecuente: síndrome de Wellens tipo B. Se diagnostica infarto agudo de miocardio sin elevación del ST de alto riesgo. Cateterismo cardiaco: suboclusión de la DA con intervencionismo exitoso. Metodología: A través de método booleano se realizó búsqueda de términos MeSH De Winter sign, Wellens sindrome y treatment en las bases de datos con repositorios de evidencia científica arbitrada indizada (PubMed) y no indizadas (Google Scholar). Resultados: El síndrome de Wellens

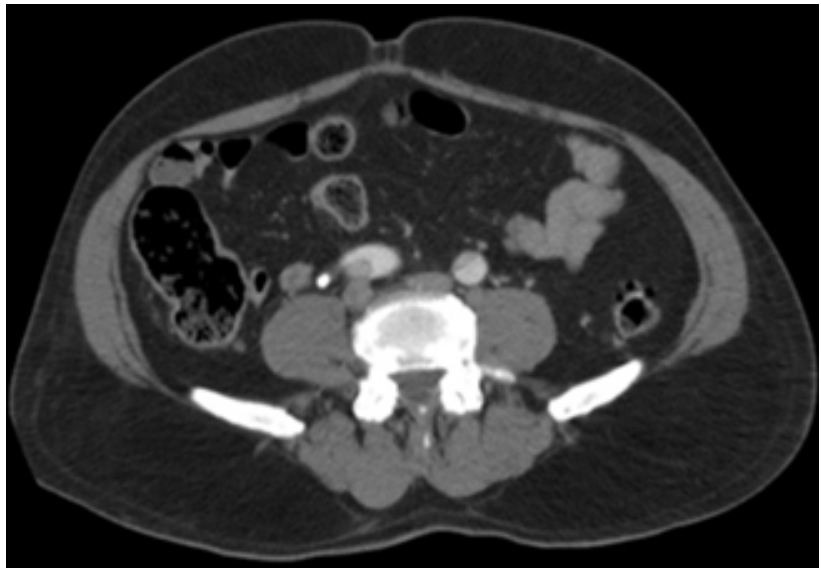

Figura 14.11.2: TAC de abdomen evidenciando disección de aorta abdominal infrarrenal que progresa distalmente con ambas luces permeables hasta arterias iliacas.

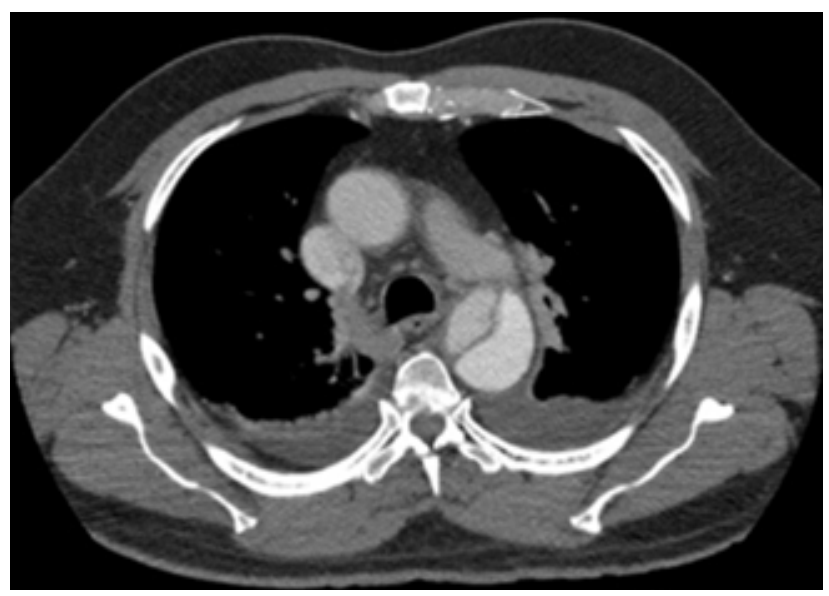

Figura 14.11.1: TAC torácica con contraste donde se evidencia un flap intimal en la aorta descendente, así como derrame pleural bilateral.

se ha observado hasta en un $15-18 \%$ del total de SICA, con riesgo de evolucionar a infarto agudo de miocardio con elevación del segmento ST hasta en un 75\%. El patrón de De Winter se ha observado en $2 \%$ de los casos de oclusión de arteria DA, más frecuente en personas jóvenes, hombres y dislipidémicos. Discusión: Los signos ECG presentados sugieren compromiso critico de la circulación de la DA, principalmente desde su segmento proximal. En nuestro paciente observamos la alternancia entre patrones De Winter y Wellens correlacionados con lesión angiográfica significativa y la decisión terapéutica favoreció la adecuada evolución y pronóstico.

\subsection{Desafiante presentación del patrón electrocardiográfico De Winter}

Esparza Pérez Denhi, Pacheco López Alejandro,

Uribe González Luis Jhonatan, Almeida Gutiérrez Eduardo, Lupercio Mora Karina 
Figura 14.12.1.
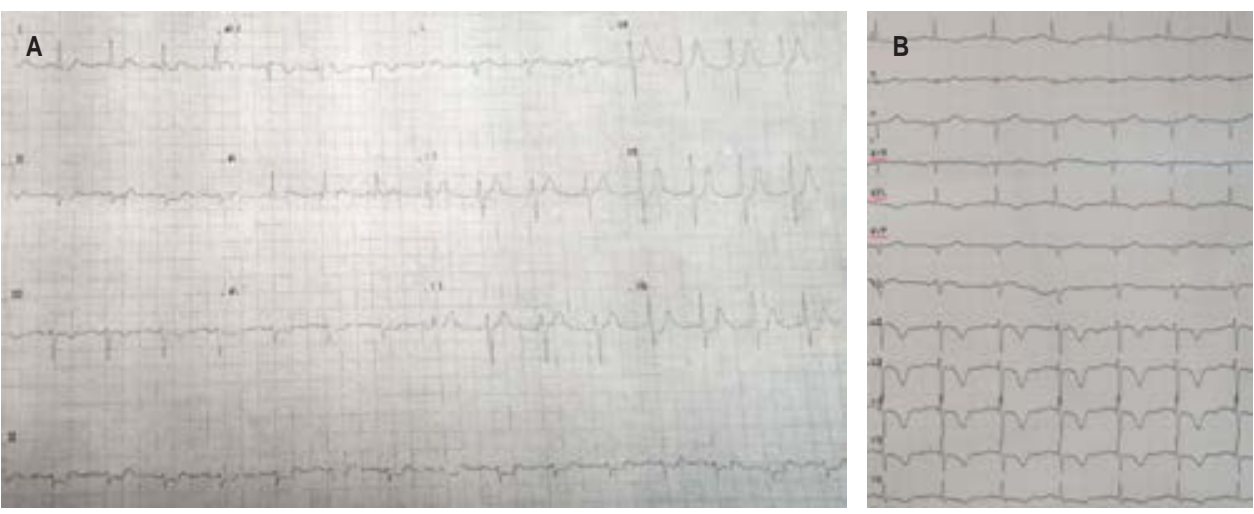

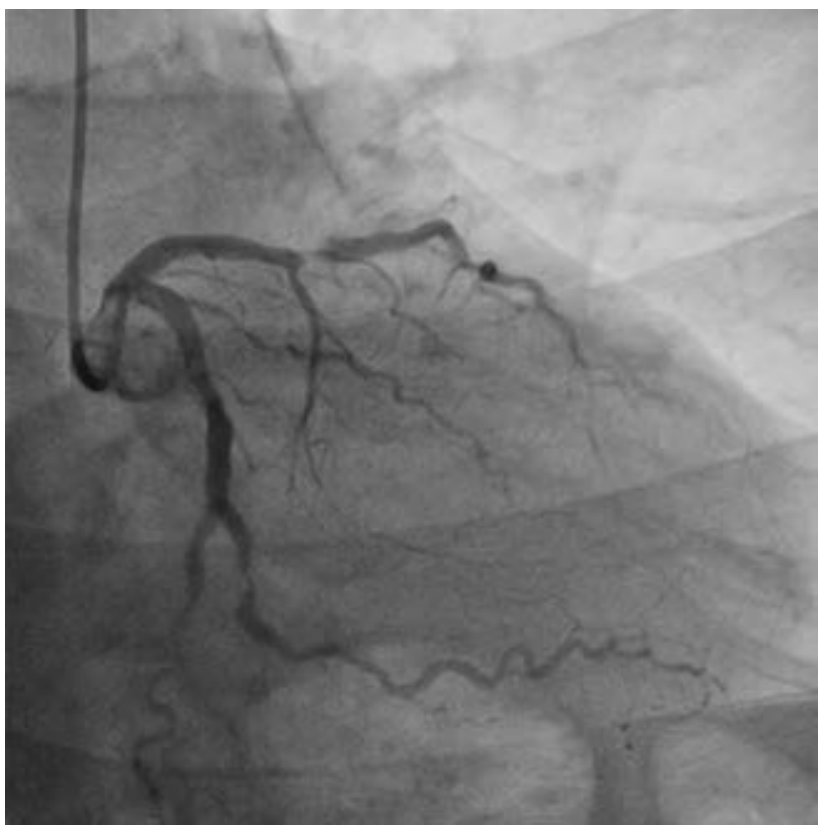

Figura 14.12.2.

Hospital de Cardiología del Centro Médico Nacional Siglo XXI, IMSS.

Tipo de estudio: Reporte de casos clínicos con revisión de fuentes

Introducción: Se ha descrito una serie de alteraciones electrocardiográficas atípicas conocidas como «equivalentes de infarto con elevación del segmento ST», que deben ser reconocidas de manera inmediata, ya que indican un riesgo elevado de presentar peores desenlaces clínicos y otorgan un pronóstico funesto; entre ellos, se encuentra el patrón de De Winter que representa alrededor del $2 \%$ de los infartos anteriores. Descripción del caso: Hombre de 46 años, consulta por dolor precordial y diaforesis de 2 horas, el electrocardiograma mostró descenso del segmento ST con pendiente ascendente de V2-V6 y desnivel positivo del segmento ST en aVR, en la exploración angiográfica se mostró lesión severa en segmento medio de la arteria descendente anterior en bifurcación con el segundo ramo diagonal se realizó intervencionismo exitoso.
Metodología: Mediante método booleano se realizó búsqueda de términos MeSH «De Winter», «infarto anterion» y «equivalentes de infarto» en las bases de datos con repositorios de evidencia científica arbitrada indexadas (PubMed, EBSCO, Ovid, ClinicalKey) y no indexadas (Google Scholar). Resultados: El patrón electrocardiográfico De Winter se expresa hasta el $2 \%$ de los infartos anteriores con una evolución promedio de 1.5 horas después del inicio de los síntomas, la explicación electrofisiológica de este patrón sigue siendo un enigma, el reconocimiento de este patrón electrocardiográfico es de vital importancia para clasificar correctamente a los pacientes e indicar tratamiento de reperfusión inmediata. Discusión: En la práctica clínica, el espectro completo de anormalidades electrocardiográficas que indican isquemia coronaria aguda u oclusión que requieren exploración angiográfica inmediata van más allá del conocido patrón de desnivel positivo del segmento ST. Mejorar el reconocimiento de estos patrones atípicos es un desafío para el clínico, ya que de su interpretación depende que el enfermo reciba el tratamiento correcto.

\subsection{Estenosis aórtica y ectasia coronaria; una relación infrecuente}

Calzada Asencio Andrés, Álvarez Salazar Bryant Andrés, Brown Gutiérrez Alejandro, Lupercio Mora Karina, Almeida Gutiérrez Eduardo

Hospital de Cardiología del Centro Médico Nacional Siglo XXI, IMSS. Tipo de estudio: Reporte de casos clínicos con revisión de fuentes

Introducción: La estenosis aórtica es la valvulopatía primaria más común. Los síntomas son angina, síncope y disnea, siendo la presencia de alguna de éstas una indicación quirúrgica. Su asociación con enfermedad arterial coronaria aterosclerosa es frecuente, por lo que debe evaluarse la presencia de la misma en personas mayores de 40 años con factores de riesgo. Descripción del caso: Hombre de 57 años, antecedente de hipertensión arterial y enfermedad renal crónica enviado por angina. Presenta soplo mesotelesistólico aórtico irradiado a vasos de cuello. Electrocardiograma: bloqueo completo de rama izquierda; troponina normal. Ecocardiograma: válvula aórtica trivalva con estenosis de grado severo. Cateterismo cardiaco: ectasia coronaria Markis I. Se realiza cirugía de implante de válvula mecánica de manera exitosa. Metodología: Se realizó búsqueda con método booleano de términos MeSH que incluyeron Coronary artery ectasia y aortic valve stenosis en las bases de datos de evidencia científica indizadas como PubMed y Cochrane 
Figura 14.13.1.
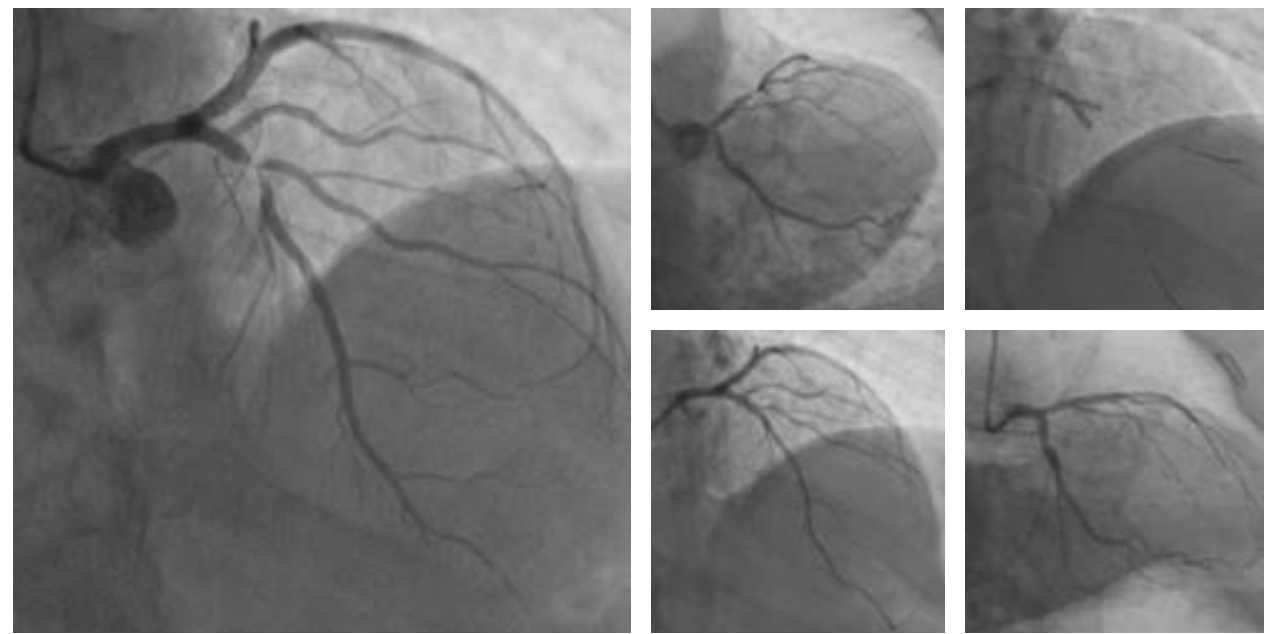

y no indizadas (Google Scholar). Resultados: La estenosis aórtica y su asociación con enfermedad arterial coronaria (aterosclerosis significativa) varía desde un 7.2 hasta un 50\%. Existen reportes de ectasia coronaria evaluada por RM en $44 \%$ de pacientes con aorta bicúspide. En nuestra búsqueda no se encontraron reportes de ectasia coronaria asociada con estenosis aórtica degenerativa. Discusión: La aorta bicúspide puede relacionarse con ectasia coronaria. Este caso es una presentación atípica de enfermedad arterial coronaria en el contexto de estenosis aórtica trivalva por tratarse de ectasia. Esto pudiera representar un obstáculo en la toma de decisión quirúrgica. La imposibilidad de revascularización no contraindica la cirugía valvular.

\subsection{Bloqueo auriculoventricular completo como manifestación inicial de síndrome de Guillain-Barré}

Salazar Vela David, Jiménez Zaragoza Pedro Ricardo,

Martínez Anaya Daniel Alejandro, Rodríguez Gómez Jaqueline,

Flores Martínez Luis Ulises, Radillo Alba Hugo Alberto,

Esturau Santaló Ramón Miguel

Hospital Civil de Guadalajara «Fray Antonio Alcalde».

Tipo de estudio: Reporte de casos clínicos con revisión de fuentes

Introducción: El síndrome de Guillain-Barré es una polirradiculoneuropatía desmielinizante inflamatoria aguda que provoca debilidad muscular ascendente y arreflexia, presentando alteraciones autonómicas de manera frecuente; sin embargo, el bloqueo auriculoventricular completo en las primeras fases de la enfermedad se considera una presentación atípica de esta enfermedad, requiriendo la colocación de marcapasos por complicaciones fatales que presentan estos pacientes. Descripción del caso: Hombre de 60 años con episodio de pérdida súbita del estado de alerta, objetivándose bloqueo auriculoventricular completo, requiriendo la colocación de marcapasos temporal. Dentro de su abordaje inicial se descartó etiología isquémica y metabólica, sospechándose etiología degenerativa; sin embargo, durante su estancia hospitalaria presentó debilidad ascendente con arreflexia, realizándose punción lumbar y electromiografía concluyentes con Guillain-Barré. Metodología: Se realizó búsqueda en PubMed según términos MeSH encontrándose únicamente un reporte de casos donde exponen un caso similar al nuestro, además

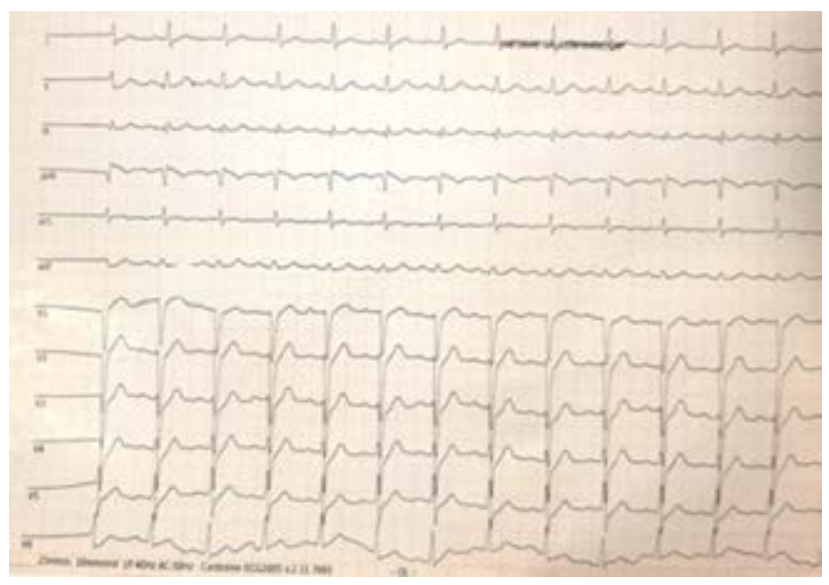

Figura 14.13.2.

de revisiones sistemáticas en Cochrane de alteraciones en ritmo cardiaco en pacientes con esta patología. Resultados: En pacientes con Guillain-Barré se reconocen las manifestaciones autonómicas como algo frecuente, aunque la mayoría de éstos se comportan de manera benigna mejorando después del tratamiento con inmunoglobulina; los pocos pacientes en los cuales se ha reportado bloqueo auriculoventricular completo debutan con paro cardiorrespiratorio con necesidad de colocación de marcapasos de manera urgente. Discusión: Entre las causas más comunes de Bloqueo auriculoventricular completo están cardiopatía isquémica y alteraciones metabólicas; sin embargo, es importante sospechar de procesos autoinmunes en aquéllos con alteraciones motoras y sensitivas, ya que estas patologías son causas poco comunes de alteraciones del ritmo, además de ser reversibles después del manejo con inmunoglobulina, sin necesidad de colocación de marcapasos definitivo.

\subsection{Endocarditis infecciosa asociada a catéter de hemodiálisis complicada con embolismos pulmonares}


Figura 14.14.1.
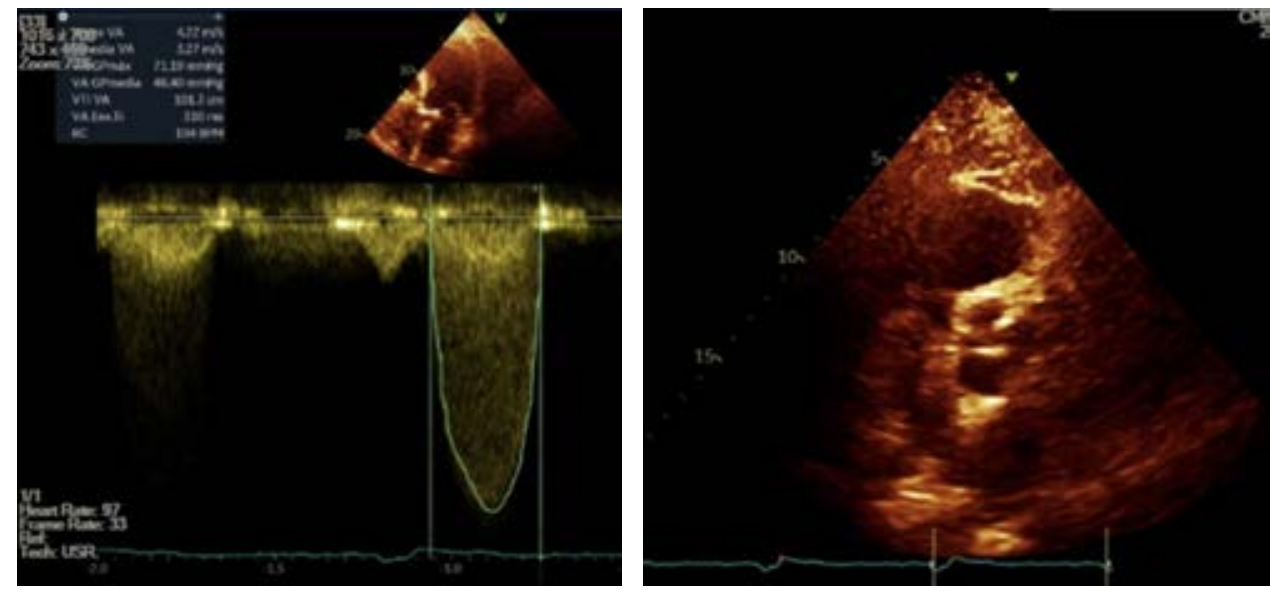
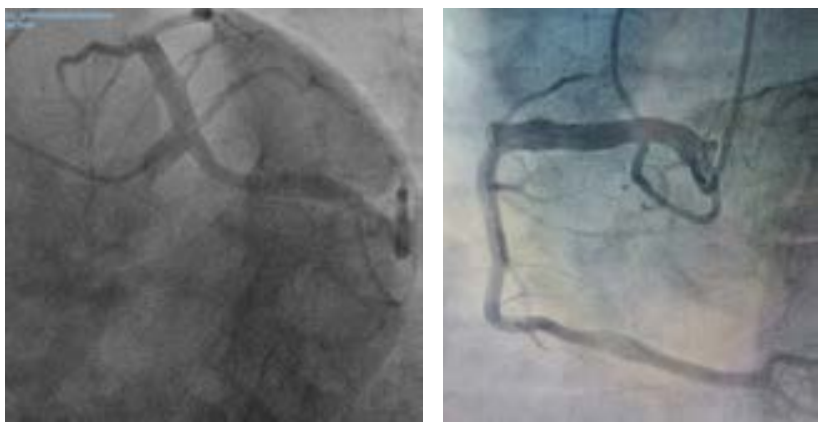

Figura 14.14.2.

Silvestre Flores Iván Israel, Fernández Ochoa Aurig Fernando, Hernández Pineda Axel Hiram, Lupercio Mora Karina,

Almeida Gutiérrez Eduardo

Hospital de Cardiología del Centro Médico Nacional Siglo XXI.

Tipo de estudio: Reporte de casos clínicos con revisión de fuentes

Introducción: La endocarditis infecciosa es una entidad con una mortalidad elevada (26.1-50\%). Pacientes en hemodiálisis crónica (HDC) tienen un riesgo significativamente mayor para desarrollarla, se ha reportado afección de válvula mitral hasta en un $25 \%$. Conlleva insuficiencia valvular (62.5\%) seguida por la perforación de la valva (25\%). Descripción del caso: Hombre de 50 años, nefrópata crónica en HDC, cáncer papilar de tiroides, fibrilación auricular paroxística y epilepsia, inicia hace un mes con fiebre, se sospecha infección de angioacceso con pobre respuesta a antibioticoterapia. Ecocardiograma: valva posterior mitral deformada con vegetación de $11 \times 25 \mathrm{~mm}$. Tomografía tórax: atelectasia redonda izquierda y nódulos cavitados bilaterales sugestivos de émbolos sépticos. Cultivo de vegetación: positivo Staphylococcus epidermidis. Metodología: Se revisó expediente clínico y a través de método booleano se realizó búsqueda de términos $\mathrm{MeSH}$ infective endocarditis y haemodialysis en las bases de datos con repositorios de evidencia científica arbitrada indizada (PubMed) y no indizadas (Google Scholar). Resultados: Los microorganismos colonizan la superficie del catéter comenzando una secreción de un exopolisacáridos que regula numerosos factores de virulencia
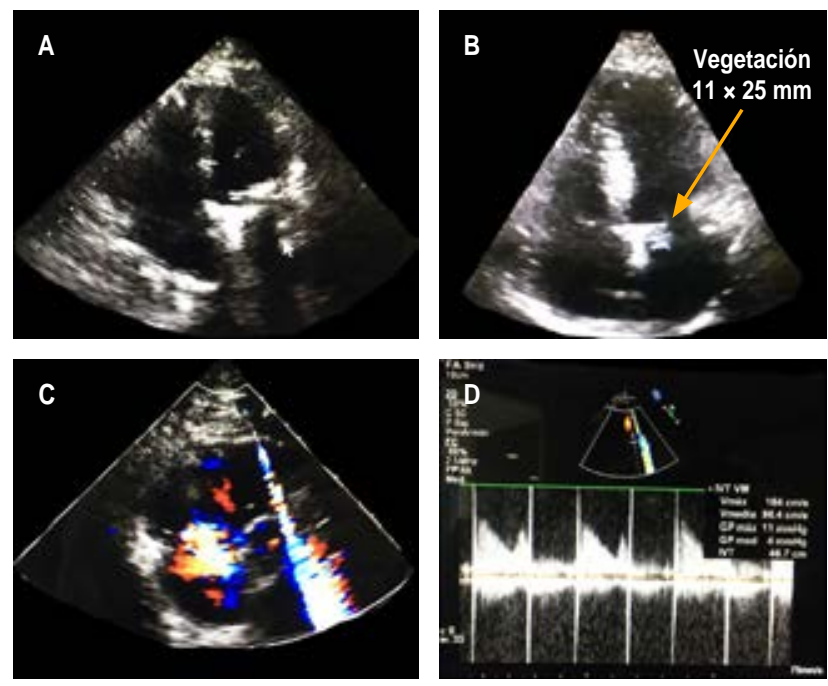

Figura 14.16.1.

Ilamado quorum sensing, algunas células pueden liberarse de la matriz y pueden diseminar la infección a localizaciones distantes. El riesgo embólico es muy alto (20-50\%). Discusión: El principal factor de riesgo para infección asociada a catéter de HDC es el tiempo con una tasa de 3.8-6.6 episodios/1,000 días, microorganismos responsables $2 / 3$ partes son grampositivos con menor incidencia de Staphylococcus epidermidis y Enterococcus faecalis. Vegetaciones $>10 \mathrm{~mm}$ tienen mayor riesgo de embolia, sobre todo por Staphylococcus spp. que afectan a la válvula mitral.

\subsection{Síndrome coronario agudo con elevación del segmento ST en un vaso principal secundario a embolismo}

Ramírez Sánchez Patricia, Macossay Santiago Sigifredo, Antezana Castro Javier, Robles Rangel Marco Antonio, García Hernández Nayeli, Mercado Rojas Gerardo Hospital de Cardiología del Centro Médico Nacional Siglo XXI. Tipo de estudio: Reporte de casos clínicos con revisión de fuentes 
Introducción: El embolismo coronario es una causa infrecuente de infarto del miocardio con prevalencia del 4 al 13\%; su aparición se ha asociado a condiciones clínicas como la presencia de prótesis valvulares en posición aórtica o mitral, fibrilación auricular, cardiomiopatía dilatada, endocarditis infecciosa, comunicación interauricular, tumores intracardiacos, neoplasias, siendo actualmente la fibrilación auricular la causa más común. Descripción del caso: Hombre de 70 años; antecedentes: doble lesión mitral reumática tratada con plastia, fibrilación auricular en anticoagulación. Acude por angina; ingreso en choque cardiogénico, electrocardiograma: bloqueo completo de rama derecha, elevación del segmento-ST anterior-extensa; ecocardiograma: FEVI 15\%; aurícula izquierda: contraste espontáneo y trombos; cateterismo: descendente anterior con trombo y oclusión total aguda en segmento proximal sin lesión aterosclerosa. Metodología: A través de método booleano se realizó búsqueda de términos MeSH coronary embolus y myocardial infarction en las bases de datos con repositorios de evidencia científica arbitrada indizada (PubMed) y no indizadas (Google Scholar). Resultados: Embolismo coronario, tres criterios mayores: evidencia angiográfica de embolismo y trombosis sin ateroesclerosis, embolismo múltiples sitios y embolismo sistémico concomitante, sin trombo en ventrículo izquierdo. Criterios menores: estenosis < 25\% con excepción de la lesión culpable, fuente embólica documentada, patología tromboembólica coexistente. Definitivo: 2 mayores, 1 mayor y 2 menores, 3 menores. Probable: 1 mayor y 1 menor o 2 menores. Discusión: Se trata de una causa inusual de síndrome coronario agudo. De acuerdo con los criterios descritos por Shibata en 2015, el paciente tiene dos criterios mayores, por lo que se considera definitivo para embolismo coronario. El abordaje intervencionista es controvertido, recientemente la trombectomía por aspiración ha demostrado ser un método factible que podría disminuir significativamente la mortalidad.
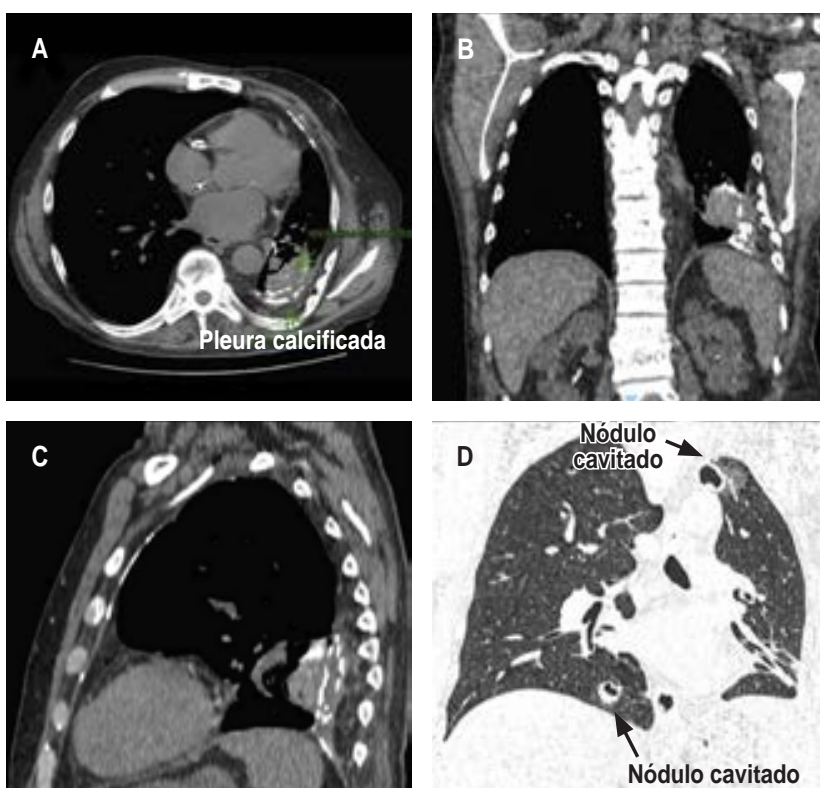

Figura 14.16.2.
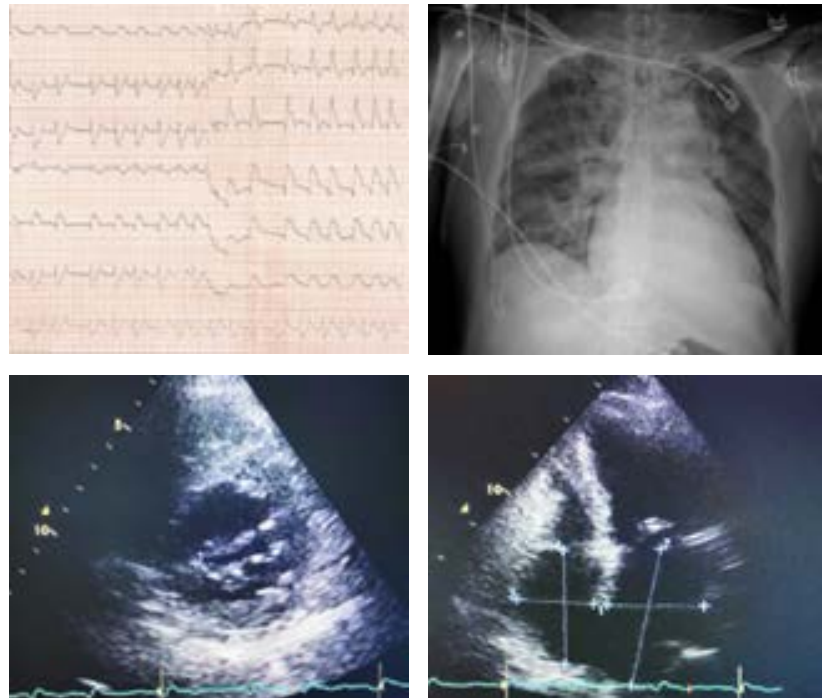

Figura 14.17.1.
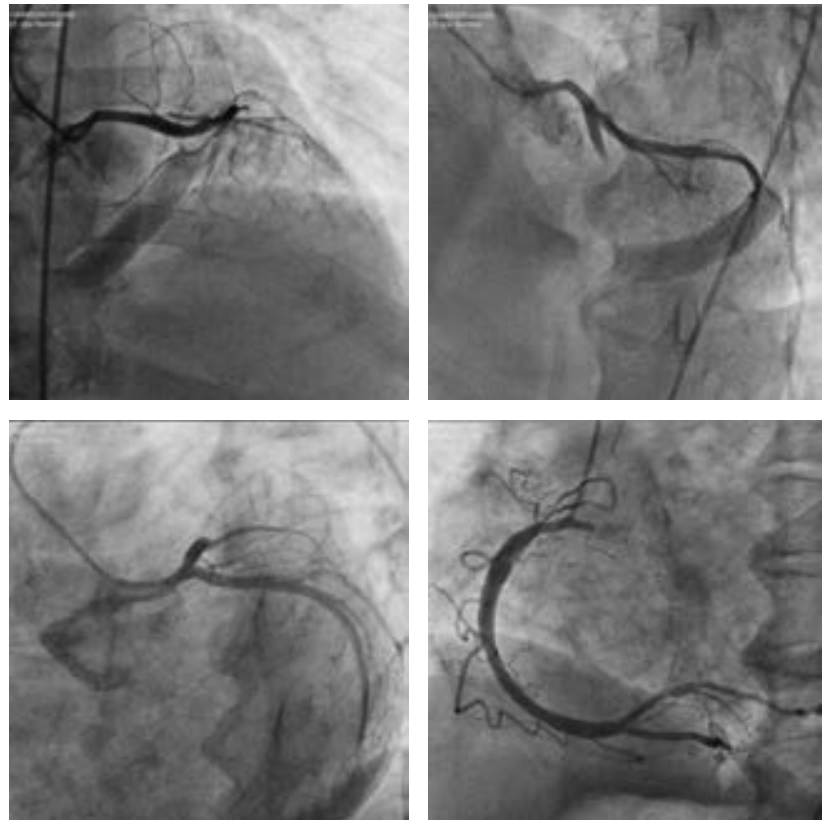

Figura 14.17.2.

\subsection{Taquicardia ventricular como presentación inicial tardía de aneurisma ventricular calcificado}

Trejo González Cosme Francisco, Meza Alvarado José Manuel,

Zavaleta Muñiz Elías Roberto, Calderón Osorio Fernando Manuel,

Wong Estrello Raúl

Unidad Médica de Alta Especialidad No. 71, IMSS.

Tipo de estudio: Reporte de casos clínicos con revisión de fuentes

Introducción: Menos del 5\% de los pacientes presentan remodelado posterior a un infarto transmural extenso con desarrollo de un 


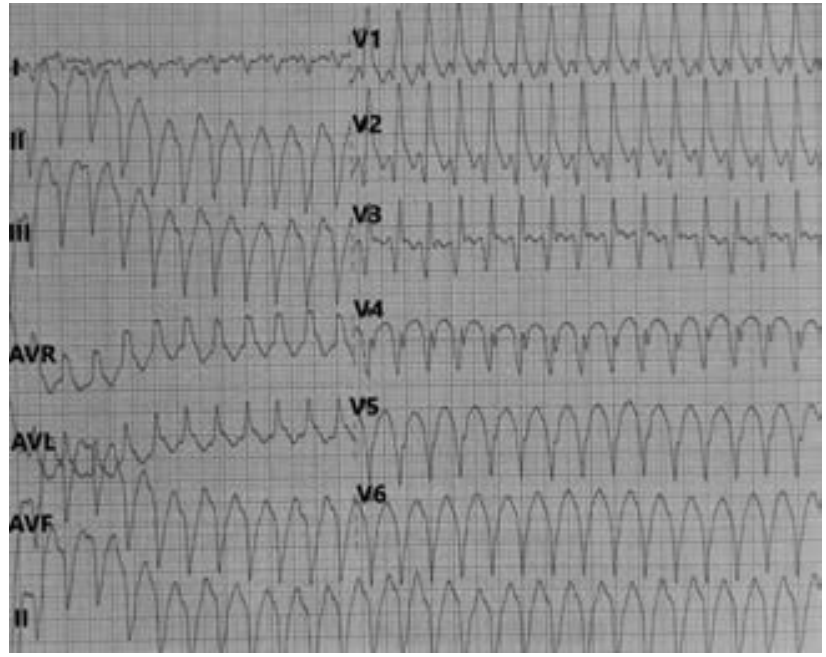

Figura 14.18.1.

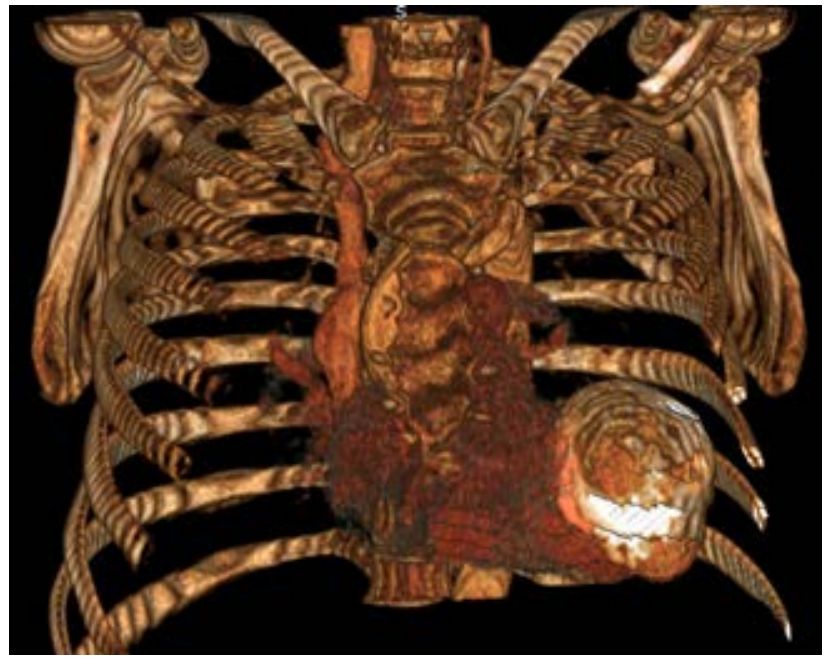

Figura 14.18.2.

aneurisma de ventrículo izquierdo, siendo éste cada vez más raro debido a los avances en fibrinólisis y angioplastia coronaria. Estos pacientes pueden cursar con arritmias ventriculares recurrentes y falla cardiaca, los cuales pueden llegar a requerir manejo con ablación o abordaje quirúrgico. Descripción del caso: Masculino de 72 años con antecedente de infarto previo hace 20 años que no recibió tratamiento. Acude por presentar sincope al esfuerzo, encontrando taquicardia ventricular a su ingreso a urgencias, requiriendo cardioversión eléctrica. En radiografía de control previo a su estudio para coronariografía se encuentra ensanchamiento mediastinal con posterior toma de tomografía, encontrando aneurisma en pared anteroseptal con material calcificado. Metodología: Se realizó una búsqueda en sitios específicos de Guías de Práctica Clínica de CENETEC, así como la plataforma de EBSCO y PubMed, utilizando los términos aneurisma, ventricular, calcificado e infarto, en inglés y español, realizando una posterior valoración de guías de práctica clínica nacionales e internacionales. Resultados: Se realiza revisión bibliográfica, no encontrando taquicardia ventricular como manifestación tardía de aneurisma ventricular calcificado en contexto de paciente que ha cursado asintomático previamente. Discusión: Se revisa bibliografía encontrando múltiples casos desde 1953 reportados de aneurismas ventriculares, encontrando como complicaciones trombos, calcificaciones y taquicardia asociada, esto en un contexto temprano. Sin embargo, nuestro paciente se ha presentado asintomático durante el curso de su enfermedad, debutando con taquicardia ventricular y encontrando como causa el aneurisma mencionado.

\subsection{Fibrosarcoma en aurícula izquierda, reporte de caso y revisión de la literatura}

Cernas Romero María Elena, Esparza Pérez Delhi, Peña Pacheco Claudia, Almeida Gutiérrez Eduardo, Lupercio Mora Karina

Instituto Mexicano del Seguro Social.

Tipo de estudio: Reporte de casos clínicos con revisión de fuentes

Introducción: Los tumores cardiacos malignos representan el 25\% de los tumores primitivos. El fibrosarcoma con incidencia de $3.6 \%$ de origen mesenquimal deriva de fibroblastos, compuesto por células fusiformes con áreas de necrosis y/o hemorragia, infiltra al miocardio. Prolifera rápidamente, el tratamiento inmediato es la resección, es recurrente, requiere quimioterapia como tratamiento adyuvante; la supervivencia promedio es de 6 a 12 meses. Descripción del caso: Mujer de 50 años que presenta disnea y lipotimia de tres meses; ecocardiograma: imagen intraauricular izquierda $23 \times 33 \mathrm{~mm}$. aspecto heterogéneo, lobulada, fija y adherida al septum interatrial con extensión a valva anterior de la válvula
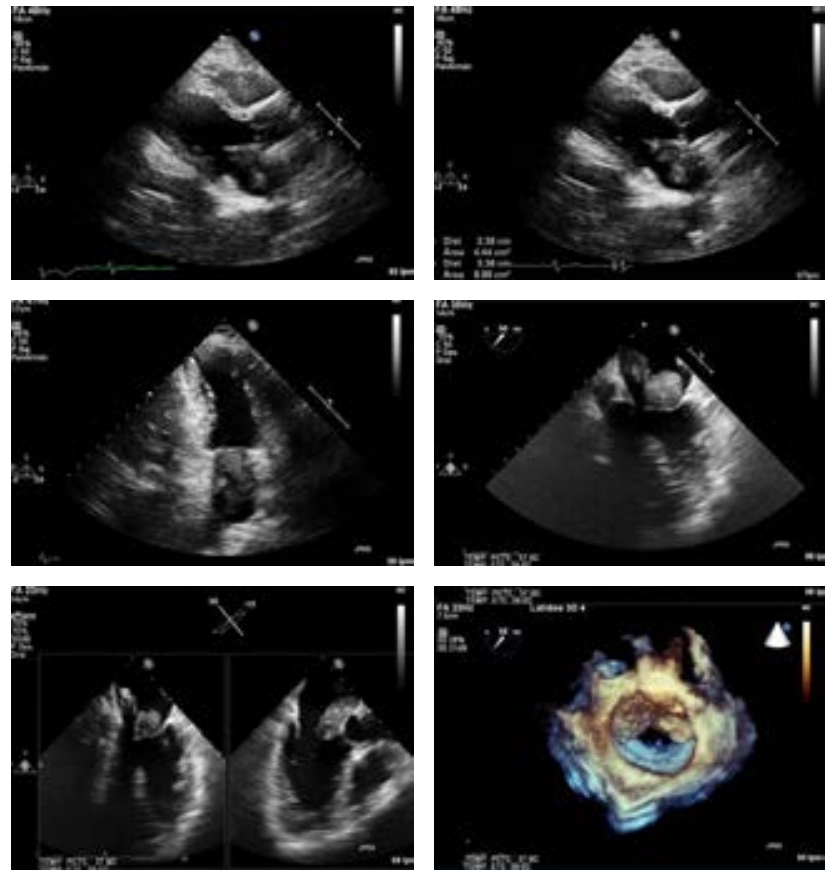

Figura 14.19.1. 

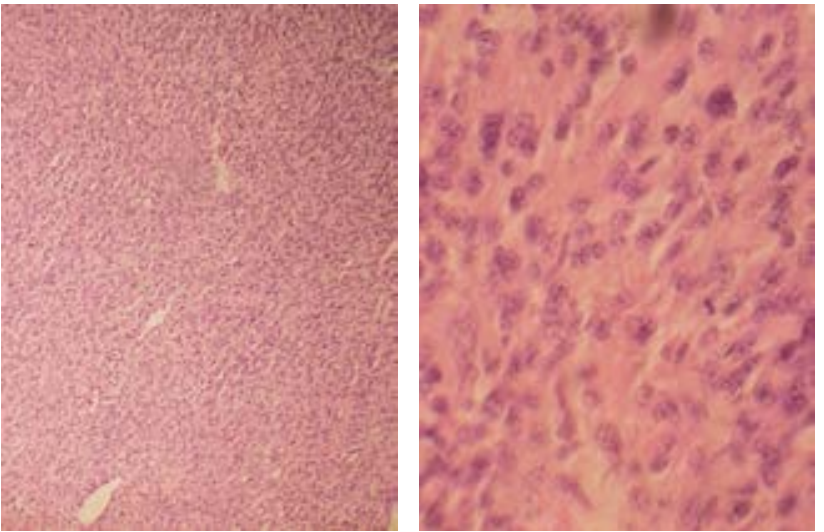

Figura 14.19.2.

mitral. Se realizó resección quirúrgica, análisis histopatológico: espécimen ovoide, irregular $5.5 \times 4 \times 3.2 \mathrm{~cm}$, superficie grisrosa, lisa, ahulada, aspecto mixoide, hemorragia focal, neoplasia mesenquimatosa hipercelular, patrón en «espinas de pescado». Metodología: Mediante método booleano se realizó búsqueda de términos $\mathrm{MeSH}$ fibrosarcoma, cardiac tumors, primary cardiac tumors y cardiac fibrosarcoma en las bases de datos con repositorios de evidencia científica arbitrada indizada (PubMed) limitada a 10 años. Resultados: El fibrosarcoma cardiaco muestra poca respuesta al tratamiento quirúrgico, es recurrente y la letalidad elevada, por lo que se exploran tratamientos adyuvantes para mejorar la sobrevida de los pacientes. Discusión: En este caso, a pesar de la topografía y características ecocardiográficas que sugerían el tumor más frecuente, mixoma, el estudio histopatológico fue fundamental para la decisión de indicar quimioterapia adyuvante, ya que es lo único que repercute de manera favorable en el pronóstico. Resulta imperante explorar alternativas terapéuticas quirúrgicas y médicas para disminuir tan desafortunada evolución.

\subsection{Cardiomiopatía de Takotsubo sin elevación del segmento ST}

Gómez González Daniel Alejandro, Pacheco López Alejandro, Ramos García Marco Antonio, Lupercio Mora Karina, Almeida Gutiérrez Eduardo, Leticia Pérez Eréndira Hospital de Cardiología del Centro Médico Nacional Siglo XXI. Tipo de estudio: Reporte de casos clínicos con revisión de fuentes
Introducción: En 1983 se reportó el primer caso, este síndrome representa $1-3 \%$ de pacientes con sospecha de infarto del miocardio. El 90\% son mujeres entre 67-70 años. Desencadenado por estrés emocional o físico, el síntoma más común es dolor torácico con elevación de biomarcadores cardiacos y cambios electrocardiográficos. Presentan disfunción ventricular izquierda transitoria con imagen de trampa japonesa de pulpo. Descripción del caso: Mujer de 60 años. Riesgo cardiovascular: tabaquismo, hipertensión arterial sistémica, diabetes mellitus tipo-2 y dislipidemia; 24 horas antes de su ingreso, presentó episodio de estrés emocional y después angina típica y descarga adrenérgica; electrocardiograma con cambios inespecíficos del ST, con elevación de troponina T (1840 pg/mL); ecocardiograma con acinesia en segmentos apicales e hipercinesia en segmentos basales. Metodología: A través del método booleano se realizó búsqueda de términos MeSH takotsubo y syndrome en las bases de datos con repositorios de evidencia científica arbitrada indizada (PubMed) y no indizadas (Google Scholar). Resultados: El Takotsubo es un síndrome relativamente nuevo, se presenta siempre con biomarcadores cardiacos elevados y diferentes cambios electrocardiográficos; la fisiopatología es por estimulación simpática, vasoespasmo coronario y disfunción microvascular. Son raros los casos que se presentan sin cambios electrocardiográficos y sigue siendo un reto el diagnóstico. Discusión: Es muy importante conocer los cambios electrocardiográficos para la sospecha diagnóstica; llama la atención este caso, ya que tiene una presentación clínica típica, pero con cambios electrocardiográficos inespecíficos, eso dificulta la sospecha diagnóstica, retrasa el tratamiento y obliga al médico a realizar otros paraclínicos que no siempre están disponibles para brindar un mejor tratamiento a corto y largo plazo.

\subsection{Frecuencia y correlación de trastornos del ritmo y conducción en pacientes hospitalizados con infección}

Rivera Santiago Carlos Antonio, Caballero Pérez Jorge Enrique, Abarca De La Cruz Nayeli, García Manuel,

Guevara Valdivia Milton Ernesto, De Los Santos García Oscar

Centro Médico Nacional La Raza, IMSS.

Tipo de estudio: Registros locales o nacionales

Introducción: Es una enfermedad respiratoria aguda causada por una infección por un nuevo coronavirus SARS-CoV-2. Los pacientes con enfermedad cardiovascular preexistente pueden ser más susceptibles a la infección COVID-19 y presentar eventos cardiovasculares, de los cuales se han descrito arritmias auriculares, ventriculares y lesión miocárdica e insuficiencia cardiaca. Objetivo: Establecer la frecuen-

Figura 14.20.1.
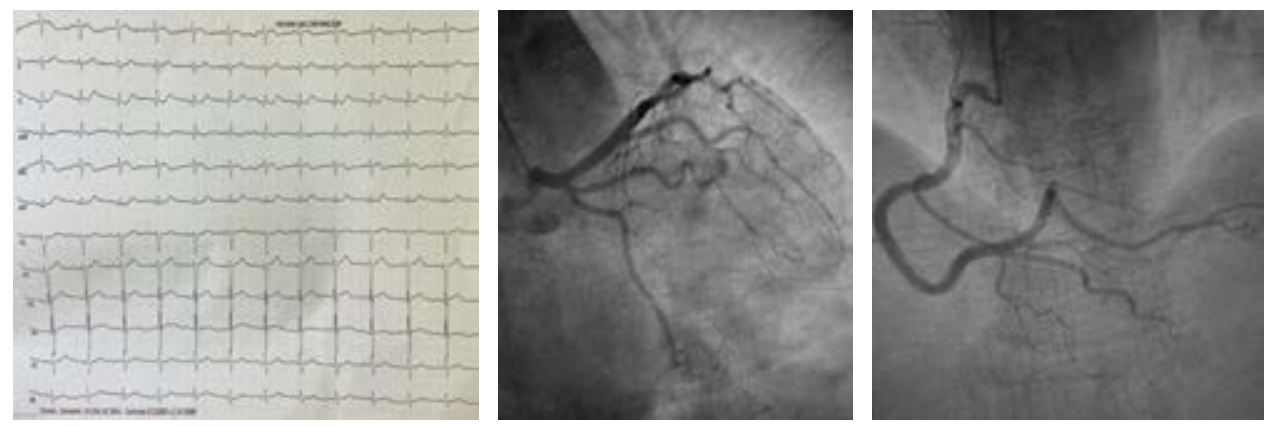
cia y correlación de trastornos del ritmo y conducción en pacientes hospitalizados con infección por COVID-19 en 30 días. Metodología: Estudio observacional, analítico y prospectivo realizado en Servicio de
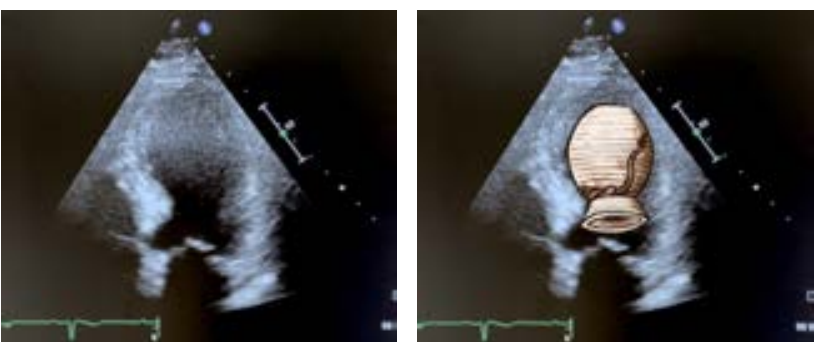

Figura 14.20.2.
Medicina Interna Área COVID UMAE Hospital de Especialidades «Dr. Antonio Fraga Mouret», Centro Médico Nacional La Raza, IMSS. Ciudad de México de julio a agosto del 2020 en pacientes con infección por COVID-19 con y sin factores de riesgo cardiovascular. Resultados: Se incluyeron 57 pacientes en el estudio, 29 hombres (50\%) y 27 mujeres (48.3\%) con una media de edad de 56 años ( \pm 18 años), de los cuales 43 fueron positivos para COVID. El riesgo cardiovascular se calculó con la escala SCORE, encontrando que el 12.1\% tenían riesgo cardiovascular bajo, $20.7 \%$ riesgo moderado, $37.9 \%$ riesgo alto y $27.6 \%$ riesgo muy alto. No se encontró una correlación significativa entre los pacientes con COVID y las alteraciones del ritmo cardiaco; sin embargo, la correlación fue significativa en pacientes con riesgo cardiovascular alto. Discusión y conclusiones: Se han descrito casos de arritmias en pacientes con COVID-19; no hubo correlación significativa en este estudio, posiblemente lo reportado obedece a interacciones con otras variables, como el riesgo cardiovascular.

Tabla 14.21.1: Correlaciones.

\begin{tabular}{|c|c|c|c|c|c|c|c|c|}
\hline & & SCORE & $\begin{array}{l}\text { Resultado } \\
\text { positivo para } \\
\text { COVID-19 }\end{array}$ & $\begin{array}{l}\text { Enfermedad } \\
\text { previa: } \\
\text { 0, HAS; 1, DM; } \\
\text { 2, ICC; 3, EAC; } \\
\text { 4, IM; 5, car- } \\
\text { diomiopatía; } \\
\text { 6, enf. vascular; } \\
\text { 7, EVC; } \\
\text { 8, renal; 9, enf. } \\
\text { pulmonar }\end{array}$ & $\begin{array}{l}\text { Si presenta } \\
\text { arritmia } \\
\text { durante } \\
\text { el estudio } \\
\text { Holter }\end{array}$ & $\begin{array}{c}\text { Arritmia duran- } \\
\text { te ECG Holter: } \\
\text { 1, EAs; 2, AF; } \\
\text { 3, AF; 4, TA; } \\
\text { 5, EV; 6, TVNS; } \\
\text { 7, TVS; 8, BAV; } \\
\text { 9, bradicardia } \\
\text { sinusal < 40; } \\
\text { 10, pausas } \\
\text { sinusales }\end{array}$ & $\begin{array}{c}\text { Uso de } \\
\text { azitromicina }\end{array}$ & $\begin{array}{c}\text { Tiempo } \\
\text { de } \\
\text { duración } \\
\text { del QT }\end{array}$ \\
\hline SCORE & $\begin{array}{l}\text { Correlación de Pearson } \\
\text { Sig. bilateral } \\
\mathrm{n}\end{array}$ & $\begin{array}{l}1 \\
57\end{array}$ & $\begin{array}{c}-0.186 \\
0.166 \\
57\end{array}$ & $\begin{array}{c}0.132 \\
0.417 \\
40\end{array}$ & $\begin{array}{c}0.270^{*} \\
0.042 \\
57\end{array}$ & $\begin{array}{c}0.082 \\
0.543 \\
57\end{array}$ & $\begin{array}{c}0.049 \\
0.719 \\
57\end{array}$ & $\begin{array}{c}0.166 \\
0.219 \\
57\end{array}$ \\
\hline $\begin{array}{l}\text { Resultado positivo para } \\
\text { COVID-19 }\end{array}$ & $\begin{array}{l}\text { Correlación de Pearson } \\
\text { Sig. bilateral } \\
\text { n }\end{array}$ & $\begin{array}{c}-0.186 \\
0.166 \\
57\end{array}$ & $\begin{array}{l}1 \\
57\end{array}$ & $\begin{array}{c}-0.033 \\
0.842 \\
40\end{array}$ & $\begin{array}{c}-0.243 \\
0.069 \\
57\end{array}$ & $\begin{array}{c}-0.091 \\
0.503 \\
57\end{array}$ & $\begin{array}{c}0.031 \\
0.820 \\
57\end{array}$ & $\begin{array}{c}0.185 \\
0.169 \\
57\end{array}$ \\
\hline $\begin{array}{l}\text { Enfermedad pre- } \\
\text { via: 0, HAS; 1, DM; } \\
\text { 2, ICC; 3, EAC; 4, IM; } \\
\text { 5, cardiomiopatía; 6, enf. } \\
\text { vascular; 7, EVC; 8, renal; } \\
\text { 9, enf. pulmonar }\end{array}$ & $\begin{array}{l}\text { Correlación de Pearson } \\
\text { Sig. bilateral } \\
\mathrm{n}\end{array}$ & $\begin{array}{c}0.132 \\
0.417 \\
40\end{array}$ & $\begin{array}{c}-0.033 \\
0.842 \\
40\end{array}$ & $\begin{array}{l}1 \\
40\end{array}$ & $\begin{array}{c}0.060 \\
0.714 \\
40\end{array}$ & $\begin{array}{c}0.029 \\
0.859 \\
40\end{array}$ & $\begin{array}{c}0.210 \\
0.193 \\
40\end{array}$ & $\begin{array}{c}-0.038 \\
0.816 \\
40\end{array}$ \\
\hline $\begin{array}{l}\text { Si presenta } \\
\text { arritmia durante } \\
\text { el estudio Holter }\end{array}$ & $\begin{array}{l}\text { Correlación de Pearson } \\
\text { Sig. bilateral } \\
\text { n }\end{array}$ & $\begin{array}{c}0.270^{*} \\
0.042 \\
57\end{array}$ & $\begin{array}{c}-0.243 \\
0.069 \\
57\end{array}$ & $\begin{array}{c}0.060 \\
0.714 \\
40\end{array}$ & $\begin{array}{l}1 \\
57\end{array}$ & $\begin{array}{c}0.868 * * \\
0.000 \\
57\end{array}$ & $\begin{array}{c}-0.031 \\
0.820 \\
57\end{array}$ & $\begin{array}{c}0.446^{* *} \\
0.001 \\
57\end{array}$ \\
\hline $\begin{array}{l}\text { Arritmia durante ECG } \\
\text { Holter: 1, EAs; 2, AF; } \\
\text { 3, AF; 4, TA; 5, EV; } \\
\text { 6, TVNS; 7, TVS; 8, BAV; } \\
\text { 9, bradicardia sinusal < 40; } \\
\text { 10, pausas sinusales }\end{array}$ & $\begin{array}{l}\text { Correlación de Pearson } \\
\text { Sig. bilateral } \\
\text { n }\end{array}$ & $\begin{array}{c}0.082 \\
0.543 \\
57\end{array}$ & $\begin{array}{c}-0.091 \\
0.503 \\
57\end{array}$ & $\begin{array}{c}0.029 \\
0.859 \\
40\end{array}$ & $\begin{array}{c}0.868^{* *} \\
0.000 \\
57\end{array}$ & $\begin{array}{l}1 \\
57\end{array}$ & $\begin{array}{c}-0.063 \\
0.641 \\
57\end{array}$ & $\begin{array}{c}0.388^{* *} \\
0.003 \\
57\end{array}$ \\
\hline $\begin{array}{l}\text { Uso de } \\
\text { azitromicina }\end{array}$ & $\begin{array}{l}\text { Correlación de Pearson } \\
\text { Sig. bilateral } \\
\text { n }\end{array}$ & $\begin{array}{c}0.049 \\
0.719 \\
57\end{array}$ & $\begin{array}{c}0.031 \\
0.820 \\
57\end{array}$ & $\begin{array}{c}0.210 \\
0.193 \\
40\end{array}$ & $\begin{array}{c}-0.031 \\
0.820 \\
57\end{array}$ & $\begin{array}{c}-0.063 \\
0.641 \\
57\end{array}$ & $\begin{array}{l}1 \\
57\end{array}$ & $\begin{array}{c}-0.120 \\
0.372 \\
57\end{array}$ \\
\hline $\begin{array}{l}\text { Tiempo de } \\
\text { duración del QT }\end{array}$ & $\begin{array}{l}\text { Correlación de Pearson } \\
\text { Sig. bilateral } \\
\text { n }\end{array}$ & $\begin{array}{c}0.166 \\
0.219 \\
57\end{array}$ & $\begin{array}{c}0.185 \\
0.169 \\
57\end{array}$ & $\begin{array}{c}-0.038 \\
0.816 \\
40\end{array}$ & $\begin{array}{c}0.446 * * \\
0.001 \\
57\end{array}$ & $\begin{array}{c}0.388 * * \\
0.003 \\
57\end{array}$ & $\begin{array}{c}-0.120 \\
0.372 \\
57\end{array}$ & $\begin{array}{c}1 \\
57\end{array}$ \\
\hline
\end{tabular}

* La correlación es significativa en el nivel 0.05 (bilateral). ${ }^{* *}$ La correlación es significativa en el nivel 0.01 (bilateral). 
Tabla 14.21.2: Enfermedad previa: 0, HAS; 1, DM; 2, ICC; 3, EAC; 4, IM; 5, cardiomiopatía; 6, enf. vascular; 7, EVC; 8, renal; 9, enf. Pulmonar.

\begin{tabular}{|c|c|c|c|c|c|}
\hline & & n & $\%$ & $\%$ válido & $\%$ acumulado \\
\hline \multirow[t]{10}{*}{ Válido } & Hipertensión & 10 & 17.2 & 25.0 & 25.0 \\
\hline & Diabetes mellitus & 7 & 12.1 & 17.5 & 42.5 \\
\hline & Insuficiencia cardiaca & 1 & 1.7 & 2.5 & 45.0 \\
\hline & Enfermedad arterial coronaria & 1 & 1.7 & 2.5 & 47.5 \\
\hline & Infarto del miocardio & 1 & 1.7 & 2.5 & 50.0 \\
\hline & Cardiomiopatía & 2 & 3.4 & 5.0 & 55.0 \\
\hline & Enfermedad vascular periférica & 3 & 5.2 & 7.5 & 62.5 \\
\hline & Enfermedad renal & 10 & 17.2 & 25.0 & 87.5 \\
\hline & Enfermedad pulmonar & 5 & 8.6 & 12.5 & 10.0 \\
\hline & Total & 40 & 69.0 & 100.0 & \\
\hline Perdidos & Sistema & 18 & 31.0 & & \\
\hline Total & & 58 & 100.0 & & \\
\hline
\end{tabular}

Tabla 14.21.3: SCORE.

\begin{tabular}{|c|c|c|c|c|c|}
\hline & & n & $\%$ & $\%$ válido & $\%$ acumulado \\
\hline \multirow[t]{5}{*}{ Válido } & Riesgo bajo $<1 \%$ a 10 años & 7 & 12.1 & 12.3 & 12.3 \\
\hline & Riesgo moderado $>1-<5 \%$ a 10 años & 12 & 20.7 & 21.1 & 33.3 \\
\hline & Riesgo alto $>5 \%-<10 \%$ a 10 años & 22 & 37.9 & 38.6 & 71.9 \\
\hline & Riesgo muy alto $>10 \%$ de riesgo a 10 años & 16 & 27.6 & 28.1 & 100.0 \\
\hline & Total & 57 & 98.3 & 100.0 & \\
\hline Perdidos & Sistema & 1 & 1.7 & & \\
\hline Total & & 58 & 100.0 & & \\
\hline
\end{tabular}

Tabla 14.21.4: Resultado positivo para COVID-19.

\begin{tabular}{llrrrrr} 
& & n & \% & \% válido & \% acumulado \\
\hline Válido & Negativo & 14 & 24.1 & 24.6 & 75.4 & 100.0 \\
& Positivo & 43 & 74.1 & 100.0 & \\
Perdidos & Total & 57 & 98.3 & 1.7 & & \\
Total & Sistema & 1 & 100.0 & & \\
& & 58 & &
\end{tabular}

\subsection{Terapia fibrinolítica en trombosis de prótesis mitral previo a sustitución quirúrgica}

Mondragón Vargas Héctor, Hernández Santamaría Ismael Hospital Juárez de México.

Tipo de estudio: Reporte de casos clínicos con revisión de fuentes

Introducción: Hay cuatro mecanismos para disfunción valvular: trombosis protésica, crecimiento de pannus, degeneración valvular y endocarditis. Los factores de riesgo son: la superficie protésica, factores hemodinámicos (turbulencia, bajo flujo) y factores hemostáticos. Descripción del caso: Mujer de 36 años, antecedente de valvuloplastia mitral por embarazo de 36 semanas, posterior implante protésico mitral. Tratamiento acenocumarina $3 \mathrm{mg}$ alternados con $2 \mathrm{mg}$ cada 24 horas. Inició cuatro días previos a su ingreso con ausencia de click protésico mitral audible y deterioro de clase funcional establecido desde un mes previo con disnea progresiva y ortopnea. Metodología:
Para diagnosticar trombosis valvular hay que realizar ecocardiograma transtorácico (ECOTT) en el primer mes postimplante, después según el riesgo de complicaciones; pacientes de bajo riesgo ECOTT anual; pacientes de alto riesgo a los tres y seis meses y después anual; si se evidencia gradiente $>50 \%$ o alteraciones en grosor o movilidad de los velos se recomienda ecocardiograma transesofágico. Resultados: Se descartaría trombosis de implante protésico mitral complicada con insuficiencia cardiaca aguda (ICA). Se trombolizó a paciente con 29 mg de tenecteplasa, con mejoría clínica y hemodinámica, así como de parámetros ecocardiográficos de velocidad máxima y gradientes de presión medidos en dos rastreos ecocardiográficos. El tratamiento definitivo fue cambio valvular mitral. Discusión: Resulta de vital importancia el adecuado protocolo de abordaje diagnóstico y terapéutico de valvulopatía para la máxima optimización de la calidad de vida del paciente y del tratamiento definitivo, ya que ello conlleva una pertinente utilización de recursos hospitalarios. 


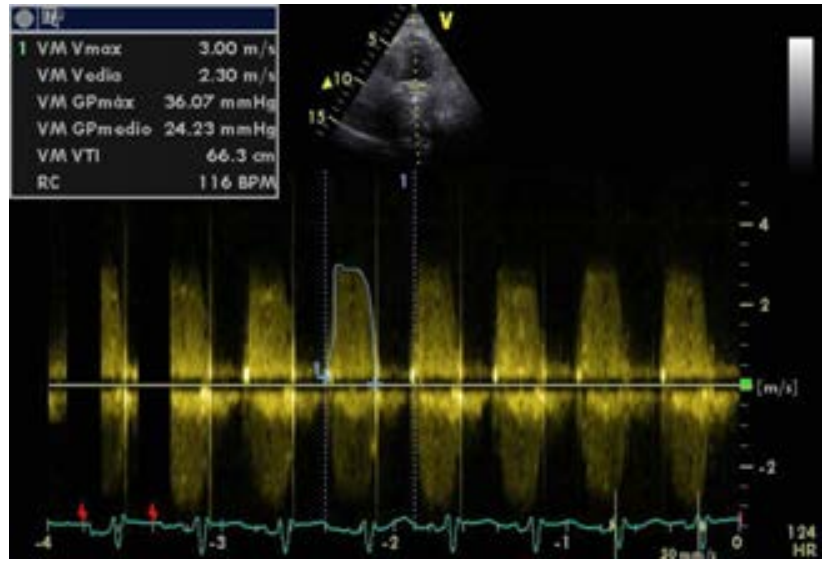

Figura 14.22.1.

\subsection{Aneurisma micótico de la arteria femoral como presentación de endocarditis infecciosa. Reporte de caso}

Quintero Panuco Jair Alexander, Delgado De Nicola Laura,

Almeida Gutiérrez Eduardo, Lupercio Mora Karina, Yáñez Serrano Agustín Hospital de Cardiología del Centro Médico Nacional Siglo XXI.

Tipo de estudio: Reporte de casos clínicos con revisión de fuentes

Introducción: Los aneurismas micóticos (AM) ocurren por embolismo séptico en endocarditis infecciosa, lo cual causa infiltración de la pared vascular a través del vaso vasorum; lo más común es por $S$. aureus. Se describe que los AM se localizan con mayor frecuencia en arterias intracraneales y menos comúnmente en vasculatura periférica, se presentan con dolor y masa palpable, el diagnóstico es por angiografía convencional. Descripción del caso: Mujer de 50 años con nefropatía diabética (hemodiálisis) y múltiples accesos vasculares; hace un mes con bacteriemia manejada con múltiples antimicrobianos, ingresa por disnea y fiebre. A la exploración: soplo holosistólico tricúspideo y lesiones vasculíticas cutáneas; ecocardiograma transesofágico: vegetación de $38 \times 15 \mathrm{~mm}$ en desembocadura de vena cava superior; tomografía; émbolos sépticos; Doppler: aneurisma micótico femoral derecho $17 \times 20 \mathrm{~mm}$; hemocultivos: S. aureus, se manejó con cefalotina y vegectomía. Metodología: A través de método booleano se realizó búsqueda

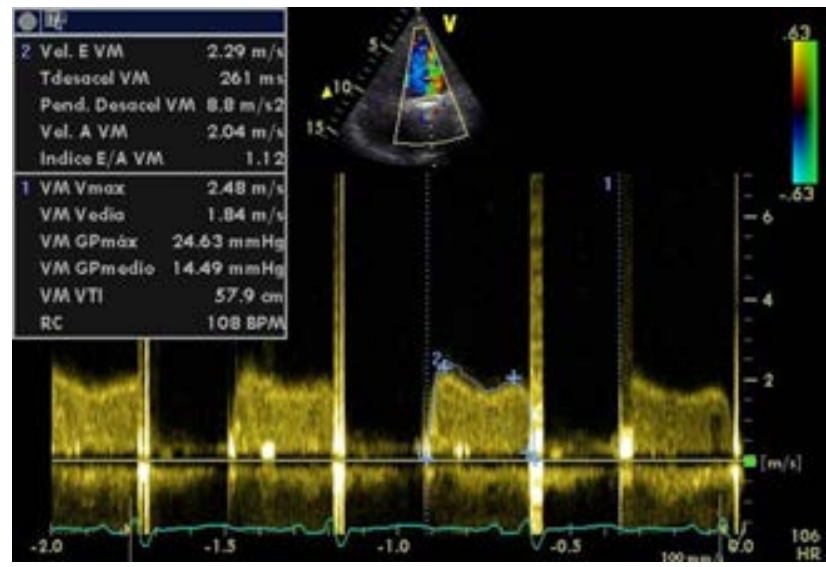

Figura 14.22.2.

de términos MeSH «aneurysm mycotic» [and] «endocarditis» en las bases de datos con repositorios de evidencia científica arbitrada indizada (PubMed) y no indizadas (Google Scholar). Resultados: El aneurisma micótico de la arteria femoral es una rara condición; es resultado de invasión y disrupción estructural de la arteria por agentes infecciosos, el desarrollo de embolismo séptico es condicionado por la exposición bacteriana en la circulación. Puede presentarse como trombosis o ruptura y sospechar de esta patología es primordial para su manejo con antibióticos y cirugía. Discusión: El aneurisma micótico periférico está descrito en $2 \%$ de los casos de endocarditis infecciosa y puede ser la primera manifestación o en el transcurso de la enfermedad; se describen en la literatura casos de aneurisma poplíteos; sin embargo, nuestro caso es una presentación inusual, por lo que su identificación es importante para reducir el riesgo de complicaciones.

\subsection{Metástasis cardiaca secundario a hepatocarcinoma}

Montoya Iribe Christi Dayana, González Orozco José Ángel, Machain Leyva Cyntia Z, Padilla Islas Luis Alejandro,

Zazueta Armenta Verónica, Saldaña García José H

Unidad Médica de Alta Especialidad, Hospital de Especialidades No. 2, IMSS, Ciudad Obregón.

Tipo de estudio: Reporte de casos clínicos con revisión de fuentes
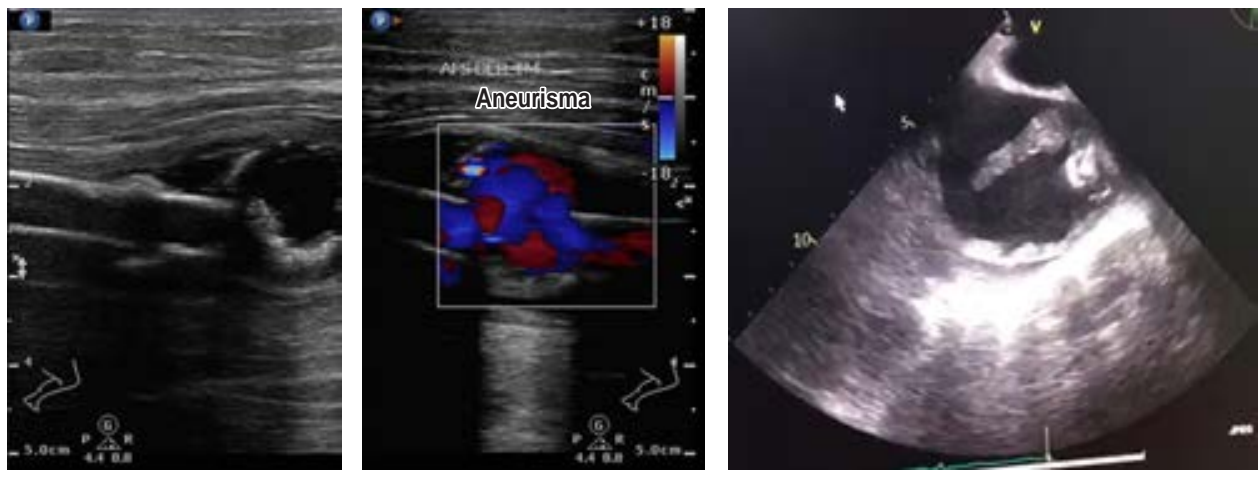

Figura 14.23.1. 

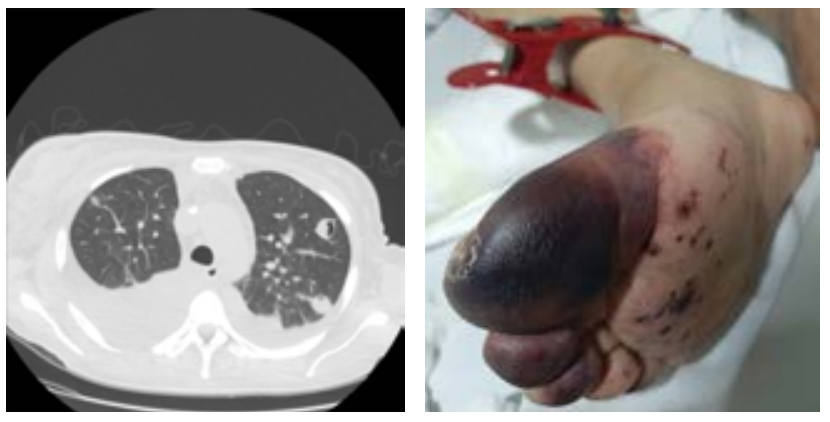

Figura 14.23.2.

Introducción: Los tumores cardiacos (TC) se clasifican según su origen en primarios o metastásicos y de acuerdo con su histología en benignos o malignos. La incidencia de enfermedad metastásica cardiaca (EMC) oscila entre $0.7-3.5 \%$ en la población general y 9.1\% en pacientes con cáncer metastásico. Los tumores con mayor frecuencia de EMC son de origen pulmonar, mama, hematológicos y melanoma. Descripción del caso: Mujer de 79 años, hipertensa, antecedente de carcinoma hepatocelular tratado mediante hepatectomía. Acude por hipertensión y disnea. Ecocardiograma muestra tumor heterogéneo, vascularizado que ocupa $80 \%$ del ventrículo derecho, la resonancia cardiaca (RMC) reveló una masa hipointensa de $7.6 \times 5.2 \times 6.5 \mathrm{~cm}$ con refuerzo al medio de contraste (Figura 14.24.1). La biopsia endomiocárdica determinó mediante inmunohistoquímica carcinoma hepatocelular moderadamente diferenciado (Figura 14.24.2). Metodología: Se realizó búsqueda bibliográfica en idioma inglés y español sobre tumores cardiacos, EMC e incidencia de carcinoma hepatocelular con afección cardiaca. Resultados: El carcinoma hepatocelular con metástasis cardiaca es poco común, el mecanismo principal es la extensión directa del tumor al corazón a través de la vena hepática y cava inferior. Con una incidencia de 2.7-4.1\% de metástasis a aurícula en autopsias según Kojiro M y colegas. El pronóstico con afección intracardiaca es muy pobre, con una supervivencia promedio de uno a cuatro meses. Discusión: La EMC es de 20 a 40 veces más común que los TC primarios. La apariencia varía de acuerdo con el tipo y la ubicación del tumor. El antecedente de un tumor conocido facilita el diagnóstico. El ecocardiograma es el estudio inicial y la RMC permite evaluar morfología, dimensión, ubicación y extensión. No existen pautas para el tratamiento quirúrgico, el caso expuesto recibió sorafenib.

\subsection{Adaptación hemodinámica benéfica en cardiopatías con gran daño cardiaco}

Acoltzin Vidal Cuauhtémoc, ${ }^{*}$ Rabling-Arellanos Elizabeth ${ }^{\ddagger}$

* Universidad de Colima. ${ }^{\ddagger}$ Clínica Cardiológica privada.

Tipo de estudio: Reporte de casos clínicos con revisión de fuentes

Introducción: La fracción de eyección del ventrículo izquierdo (FEVI) indica daño funcional importante e implica mal pronóstico. La respuesta hemodinámica ofrece mecanismos de adaptación. Existe correlación adecuada entre gasto cardiaco (QS) y resistencias vasculares sistémicas (RVS), no así con la FEVI. Descripción del caso: Cinco varones en sexta a octava décadas de vida, con cardiopatías crónicas de larga evolución y etiología variable, cuya FEVI es anormalmente baja pero las RVS han disminuido permitiendo aumentar el gasto dando por resultado que la capacidad física es normal (Tabla 14.25.1). Metodología: Información de PubMed como FEVI baja, QS normal. Se encontró 1,001 citas, la mayoría referentes a estenosis aórtica. Al agregar el término «ancianidad» sólo hubo 762, con semejante referencia. Resultados: Sólo dos citas aplican (en 10 años): una describe que después de desfibrilación ventricular, quienes tienen FEVI menor de 50\% muestran

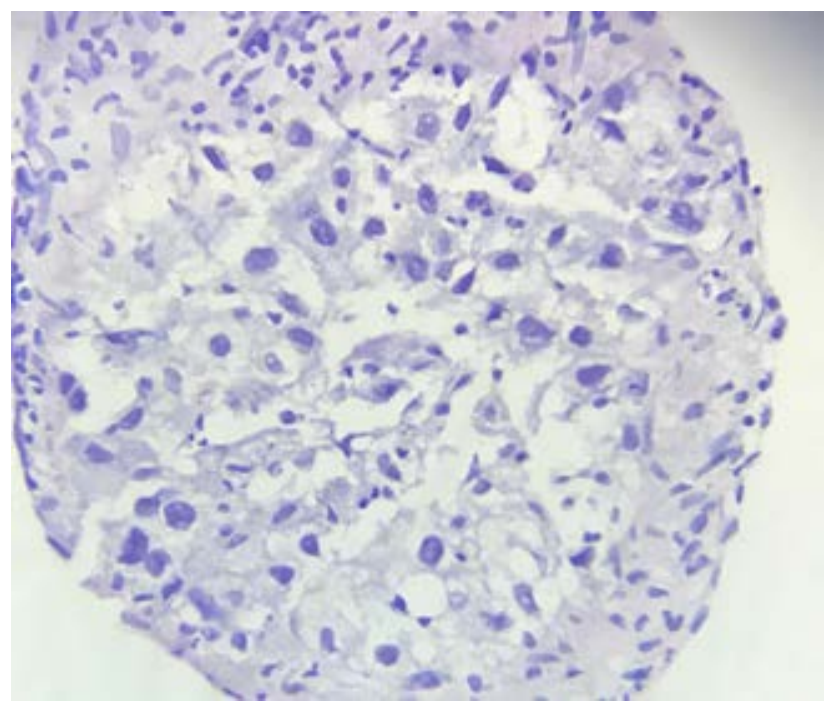

Figura 14.24.2.

Figura 14.24.1.
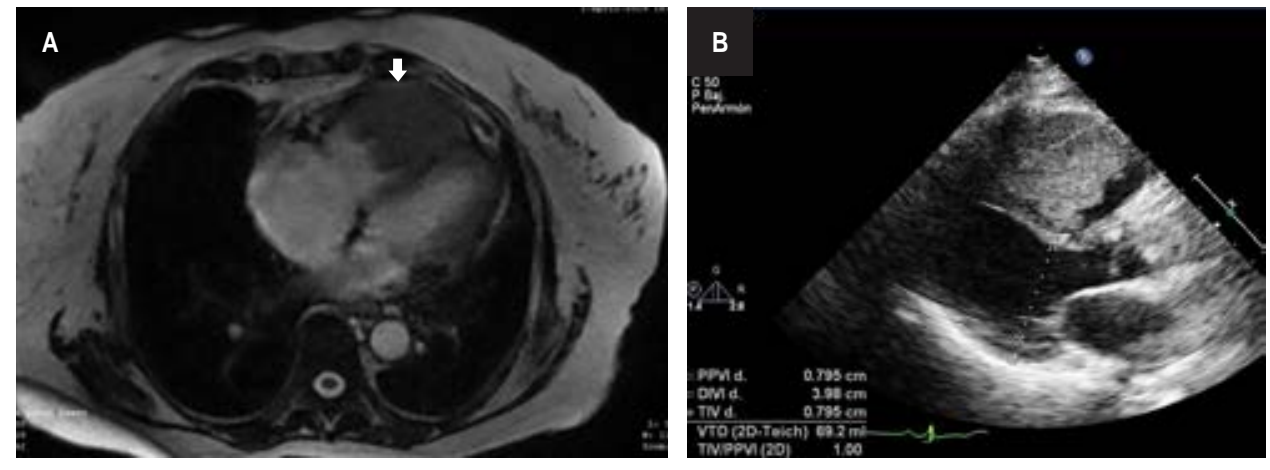
Tabla 14.25.1.

$\begin{array}{ccccr}\text { Clase funcional } & \text { Cardiomegalia } & \text { FEVI } & \text { Índice cardiaco } & \text { Resistencias totales } \\ \text { I } & \text { III } & 26.5 & 4.23 & 596 \\ \text { I, con ortopnea } & \text { I } & 29.0 & 5.46 & 629 \\ \text { II } & \text { II } & 31.9 & 4.08 & 1,171 \\ \text { I } & \text { II } & 35.0 & 5.25 & 764 \\ \text { II } & \text { III } & 43.0 & 5.10 & 810\end{array}$

aumento de gasto y tensión arterial. Otra en la cual el desempeño sistólico y diastólico ventricular está deteriorado en cardiópatas con FEVI normal que tengan limitación física, Ilenado ventricular aumentado y QS reducido. Discusión: En esta revisión se muestra que enfermos con cardiopatía crónica y FEVI baja han compensado hemodinámicamente disminuyendo de manera espontánea las RVS, aumentando el QS y mejorando la calidad de vida. Concepto novedoso según la bibliografía obtenida.

\subsection{Enfermedad de Whipple: una causa enigmática de endocarditis bacteriana con hemocultivos negativos}

Pacheco López Alejandro, Lupercio Mora Karina,

Almeida Gutiérrez Eduardo, Blanco Lemus B, Ramírez Sánchez Patricia,

Macossay Santiago Sigifredo, Esparza Pérez Denhi

Hospital de Cardiología del Centro Médico Nacional Siglo XXI.

Tipo de estudio: Reporte de casos clínicos con revisión de fuentes

Introducción: La enfermedad de Whipple ha sido considerada como una gran imitadora de un espectro amplio de enfermedades y por lo general se considera en pacientes con los siguientes síntomas cardinales: artralgias, diarrea, malestar abdominal y pérdida de peso. La presentación clínica en pacientes con diagnóstico de endocarditis fue de insuficiencia cardiaca, las características clínicas son inusuales a otras causas de endocarditis. Descripción del caso: Femenino de 49 años. Diabética. Tres meses previos presentó disnea, malestar general, artralgias y diarrea, antibioticoterapia con mejoría parcial. Arriba a urgencias con disnea; a la exploración: febril, escape en foco aórtico, Austin Flint; ecocardiograma muestra masa móvil en

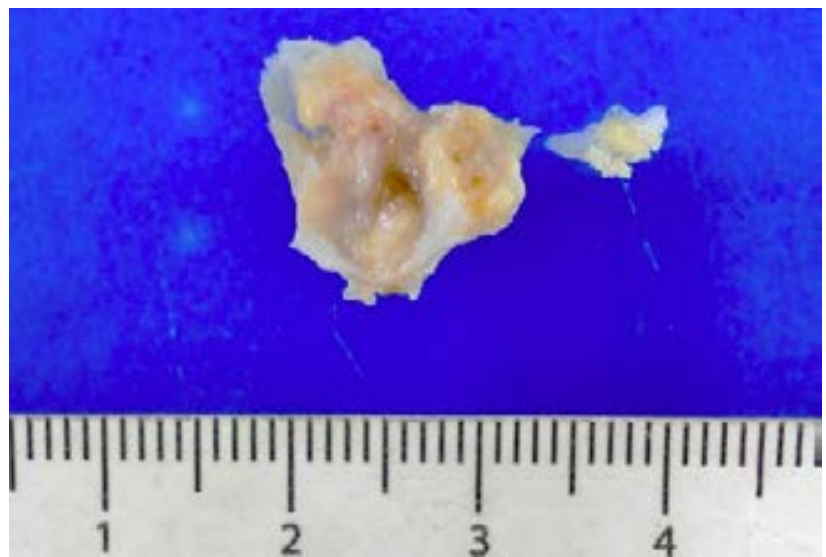

Figura 14.26.1: Imagen macroscópica de vegetación. la válvula mitral aórtica con insuficiencia grave. Reemplazo valvular mitral y aórtico con bioprótesis. Microscópicamente con ácido peryódico de Schiff con diastasa positivo, hemocultivos negativos. PCR positiva a Tropheryma whipplei. Metodología: A través del método booleano se realizó búsqueda de términos MeSH «Whipple» [and] «disease» en las bases de datos con repositorios de evidencia

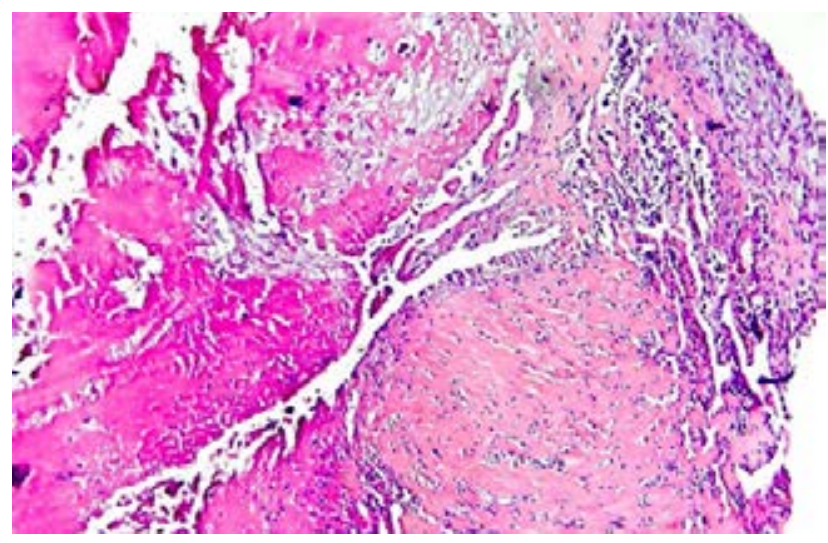

Figura 14.26.2: Corte transversal de valva con vegetación, infiltrado inflamatorio y restos celulares (H\&E, 100×).

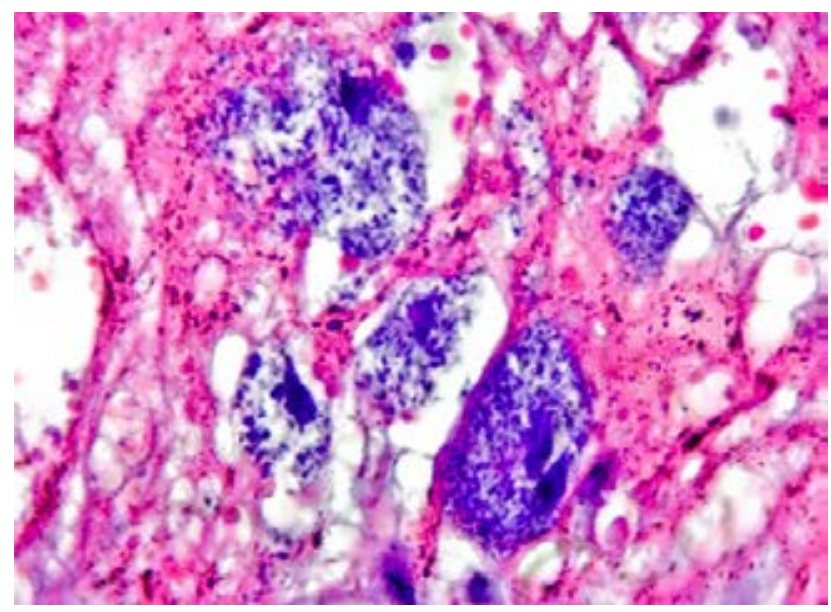

Figura 14.26.3: Zona de vegetación que muestra en detalle infiltración por macrófagos grandes con inclusiones intracitoplasmáticas granulares gruesas $(H \& E, 1000 \times)$. 


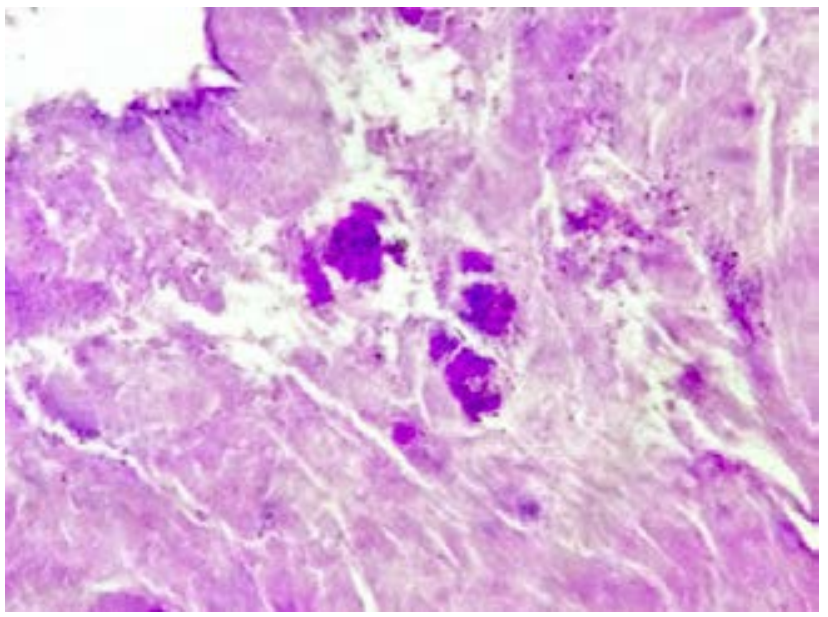

Figura 14.26.4: Tinción de ácido peryódico de Schiff (PAS) con distancia que muestra macrófagos con inclusiones granulares PAS positivas citoplasmáticas $(400 \times)$.

científica arbitrada indexadas (PubMed, EBSCO, Ovid, ClinicalKey) y no indexadas (Google Scholar). Resultados: El mayor desafío para el manejo de la endocarditis por T. whipplei sigue siendo el diagnóstico, agravado por su rareza, a pesar de los avances en técnicas moleculares. Estos pacientes a menudo son afebriles, con cultivos negativos, marcadores inflamatorios paradójicamente bajos a pesar de los signos de inflamación crónica, anemia e hipoalbuminemia. El diagnóstico a menudo se realiza después de la cirugía. Discusión: El tratamiento óptimo de estos pacientes a largo plazo sigue sin estar claro. Los médicos deben considerar el diagnóstico de endocarditis de Whipple en la endocarditis con cultivo negativo, especialmente si hay antecedentes de cualquier forma de artralgia o pérdida de peso con marcadores inflamatorios bajos o normales. La sospecha clínica sigue siendo la piedra angular para el diagnóstico.

\section{Trabajo ganador del premio Dr. Mariano Ledesma Velasco al Investigador Joven Tercer Lugar}

\subsection{Pronóstico de la hipertensión arterial sistémica y SCORE cardiovascular sobre mortalidad en COVID-19 o}

Mendieta Durán Dulce Angélica, ${ }^{*}$

García Méndez Rosalba Carolina, ${ }^{\ddagger}$ Hernández Jiménez Ernesto,*

Montiel Jarquín Álvaro José,* García Galicia Arturo*

* Unidad Médica de Alta Especialidad, Hospital de Especialidades

del Centro Médico Nacional «General de División Manuel Ávila

Camacho», IMSS, Puebla. ${ }^{\ddagger}$ UMAE Hospital de Cardiología del Centro Médico Nacional Siglo XXI, IMSS, Ciudad de México.

Tipo de estudio: Estudio pronóstico

Introducción: En la actualidad, COVID-19 es una enfermedad emergente de alta mortalidad. La hipertensión arterial es un predictor de mal pronóstico hasta en $40 \%$ de estos pacientes. La determinación del riesgo cardiovascular en la atención temprana de COVID-19 no se realiza. El SCORE cardiovascular constituye un instrumento predictor de complicaciones cardiovasculares a largo plazo; sin embargo, no ha sido evaluado en este contexto. Objetivo: Determinar si la hipertensión arterial sistémica y SCORE de riesgo cardiovascular constituyen predictores independientes de mortalidad en pacientes mayores de 40 años con COVID-19 sin cardiopatía y nefropatía subyacentes. Metodología: Estudio transversal analítico en pacientes mayores de 40 años con hipertensión arterial sistémica (HAS) y COVID-19 sin cardiopatía y nefropatía subyacentes, atendidos en la UMAE Hospital de Especialidades Puebla del 1 abril al 31 julio de 2020. Se realizó análisis estadístico descriptivo, inferencial y regresión logística multivariada para determinar predictores independientes de mortalidad. Se consideró significativo un valor alfa $\leq 0.05$. Resultados: Ciento trece pacientes: $54 \%$ sobrevivientes y $46 \%$ no sobrevivientes. Las diferencias respectivas fueron: edad $54.8 \pm 10.4$ vs $62.6 \pm 10.6$ años ( $\leq \leq 0.001)$; días de estancia intrahospitalaria (DEIH) 8 vs 6 días ( $p \leq 0.01)$; SCORE $1(0-1)$ vs $1(1-4.5)$ puntos $(p \leq 0.0001)$; HAS 16.3 vs $33 \%(p \leq 0.004)$; diabetes mellitus (DM) 14.7 vs $38 \%$ $(p \leq 0.004)$; bloqueadores del receptor de angiotensina II (BRAII) 16 vs 33\% ( $\leq$ 0.04); asistencia mecánica ventilatoria (AMV) ingreso 3 vs $23 \%(p \leq 0.001)$. Los predictores independientes de mortalidad: SCORE OR 1.6 IC 95\% (1.22-2.10); TAD OR 0.94 IC 95\% (0.89-0.98); DM OR 3.74 IC 95\% (1.35-10.5) y AMV ingreso OR 7.67 IC 95\% (1.4-42). Discusión y conclusiones: La hipertensión arterial se asoció con peor desenlace en COVID-19 como se ha descrito. La escala SCORE es un predictor independiente de mortalidad temprana e instrumento pronóstico novedoso en estos pacientes.

\subsection{Concretio cordis. Revisión de la fisiopatología y los hallazgos diagnósticos a propósito de un caso}

García Ruiz Carlos Alberto, Romero Zertuche Diana,

Becerril González Montecinos Alejandro, Lupercio Mora Karina, Almeida Gutiérrez Eduardo

Hospital de Cardiología del Centro Médico Nacional Siglo XXI.

Tipo de estudio: Reporte de casos clínicos con revisión de fuentes

Introducción: La pericarditis constrictiva calcificada (concretio cordis) tiene diversas etiologías que condicionan inflamación crónica del pericardio, evolucionando hacia esta entidad en un tiempo variable. La principal herramienta diagnóstica es el ecocardiograma transtorácico que revela la fisiopatología detrás de los síntomas. Existen otras herramientas como el cateterismo cardiaco y la resonancia magnética, que aportan información valiosa para la evaluación y el diagnóstico del paciente. Descripción del caso: Hombre de 39 años con antecedente de disnea progresiva y palpitaciones desde hace dos años. Se presenta a nuestro Servicio de Urgencias por nuevo episodio de disnea en reposo y palpitaciones. El electrocardiograma de ingreso evidencia flutter auricular con frecuencia cardiaca de 160 . Se realiza cardioversión sincronizada e ingresa posteriormente para estudio. La radiografía reveló calcificaciones proyectadas circundando al corazón. Metodología: Se realizó búsqueda de términos $\mathrm{MeSH}$ asociados en las bases de datos con repositorios de evidencia científica arbitrada indizada, se encontraron reportados en la literatura hallazgos de pericarditis constrictiva similares a los de nuestro paciente. El ecocardiograma mostró bounce septal, annulus reversus y dilatación atrial, entre otros. La resonancia evidenció engrosamiento pericárdico adyacente 
Tabla 14.27.1: Características demográficas y clínicas de acuerdo con el desenlace.

\begin{tabular}{|c|c|c|c|}
\hline & $\begin{array}{c}\text { Sobrevivientes, } N=61(54 \%) \\
\text { n (\%) }\end{array}$ & $\begin{array}{c}\text { No sobrevivientes, } \mathrm{N}=52(46 \%) \\
\mathrm{n}(\%)\end{array}$ & $\mathbf{p}$ \\
\hline Edad (años) & $54.8 \pm 10.4$ & $62.6 \pm 10.6$ & 0.001 \\
\hline Sexo & & & 0.44 \\
\hline Femenino & $23(38)$ & $16(31)$ & \\
\hline Masculino & $38(62)$ & $36(69)$ & \\
\hline Peso (kg) & 78 (72-85) & $75.5(70-88)$ & 0.70 \\
\hline Talla (m) & $1.64 \pm 0.10$ & $1.61 \pm 0.09$ & 0.16 \\
\hline IMC $\left(\mathrm{kg} / \mathrm{m}^{2}\right)$ & $28.7(27-33)$ & $29.1(26-33)$ & 0.72 \\
\hline Días de EIH & $8(6-10)$ & $6(1.5-11)$ & 0.01 \\
\hline SCORE (puntaje de riesgo) & $1(0-1)$ & $1(1-4.5)$ & 0.0001 \\
\hline TAS (mmHg) & $126.8 \pm 19.3$ & $124.5 \pm 25.8$ & 0.61 \\
\hline TAD (mmHg) & $76.9 \pm 9.1$ & $72.6 \pm 13.2$ & 0.05 \\
\hline HAS & $10(16.3)$ & 17 (32.6) & 0.041 \\
\hline $\mathrm{DM}$ & $9(1.6)$ & $20(38.4)$ & 0.004 \\
\hline Obesidad & $26(43)$ & $21(40.3)$ & 0.81 \\
\hline Dislipidemia & $1(1.6)$ & $4(7.7)$ & 0.12 \\
\hline Tabaquismo & $4(6.5)$ & $5(9.6)$ & 0.55 \\
\hline EPOC & $2(3.3)$ & $1(2)$ & 0.65 \\
\hline Cáncer & $2(3)$ & - & 0.18 \\
\hline Autoinmunidad & - & $1(2)$ & 0.27 \\
\hline IECA & $5(8)$ & $9(17)$ & 0.14 \\
\hline Bloqueadores ARA II & $10(16.4)$ & $17(33)$ & 0.14 \\
\hline TA controlada & $48(79)$ & $37(71)$ & 0.35 \\
\hline AMV ingreso & $2(3.3)$ & $12(23)$ & 0.001 \\
\hline
\end{tabular}

IMC = índice de masa corporal; EIH = estancia intrahospitalaria; TAS = tensión arterial sistólica; TAD = tensión arterial diastólica;

HAS = hipertensión arterial sistémica; DM = diabetes mellitus; EPOC = enfermedad pulmonar obstructiva crónica; IECA= inhibidores de la enzima convertidora de angiotensina; ARA II = antagonistas de los receptores de la angiotensina II; AMV = asistencia mecánica ventilatoria.

Tabla 14.27.2: Predictores independientes de mortalidad en población estudiada con COVID-19.

\begin{tabular}{lccccc} 
& OR & EE & $\mathbf{z}$ & $\mathbf{p}$ & IC 95\% \\
SCORE & 1.60 & 1.600 & 0.22 & 0.001 & $1.22-2.10$ \\
TAD & 0.94 & 0.021 & -2.67 & 0.008 & $0.89-0.98$ \\
DM & 3.74 & 1.940 & 2.54 & 0.011 & $1.35-10.3$ \\
AMV ingreso & 7.67 & 6.630 & 2.36 & 0.018 & $1.40-42.0$ \\
\hline
\end{tabular}

$\mathrm{TAD}$ = tensión arterial diastólica; $\mathrm{DM}$ = diabetes mellitus; $\mathrm{AMV}$ = asistencia mecánica ventilatoria; $\mathrm{OR}$ = odds ratio; $\mathrm{EE}$ = error estándar.
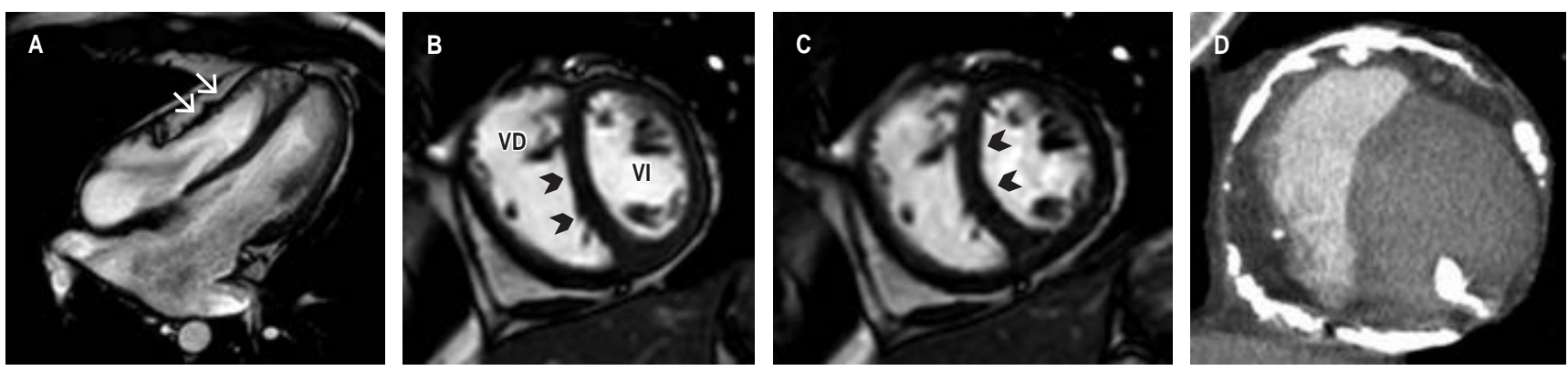

Figura 14.28.1: Imagen estática de secuencia en cine. A) En cuatro cámaras aspecto tubular de ambos ventrículos con compresión de la pared libre el ventrículo derecho durante la diástole (flechas blancas). B) En eje corto a nivel de tercio medio en inspiración y C) espiración, se observa el aplanamiento diastólico del septum interventricular durante la inspiración (cabezas de flechas) con configuración convexa hacia ventrículo derecho en espiración. D) Imagen tomográfica en eje corto donde se observan las calcificaciones que circundan a los ventrículos. VD = ventrículo derecho; VI = ventrículo izquierdo. 
Figura 14.28.2:

A) Proyección apical de cuatro cámaras. Se observa hiperrefringencia del pericardio (punta de flecha) con compresión del VD, así como dilatación del Al. B) Velocidades tisulares del anillo mitral que muestran el fenómeno de annulus revursus

( $E^{\prime}$ medial $>E^{\prime}$ laterial). Al = aurícula izquierda; $V D$ = ventrículo derecho.
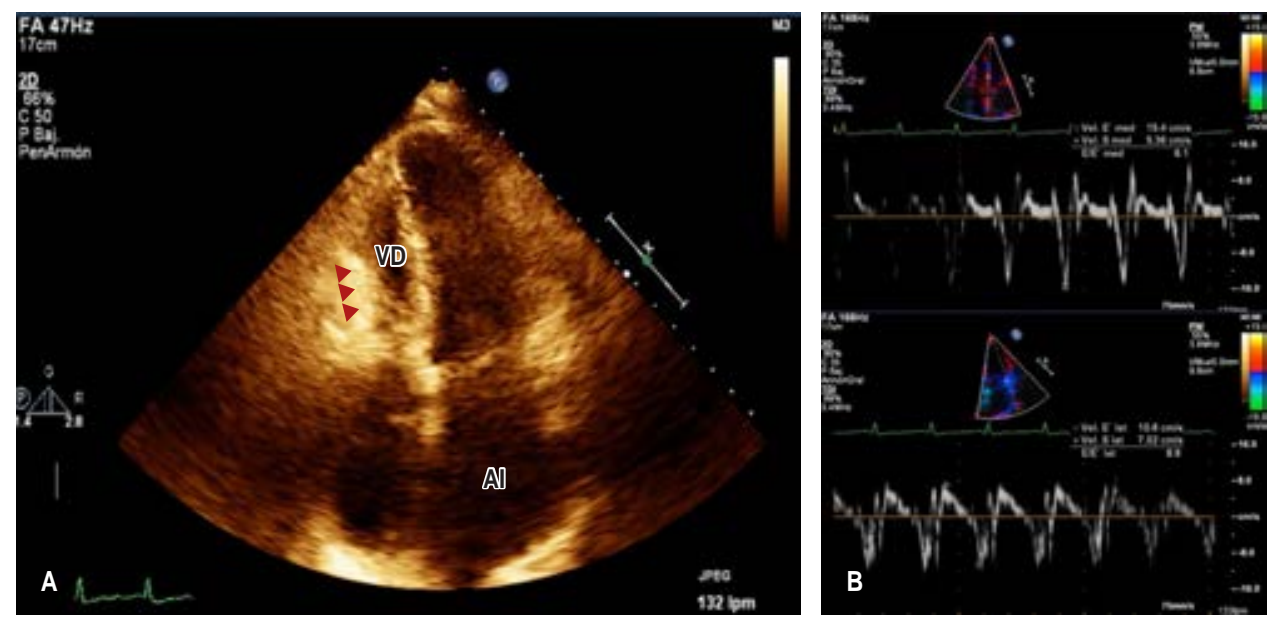
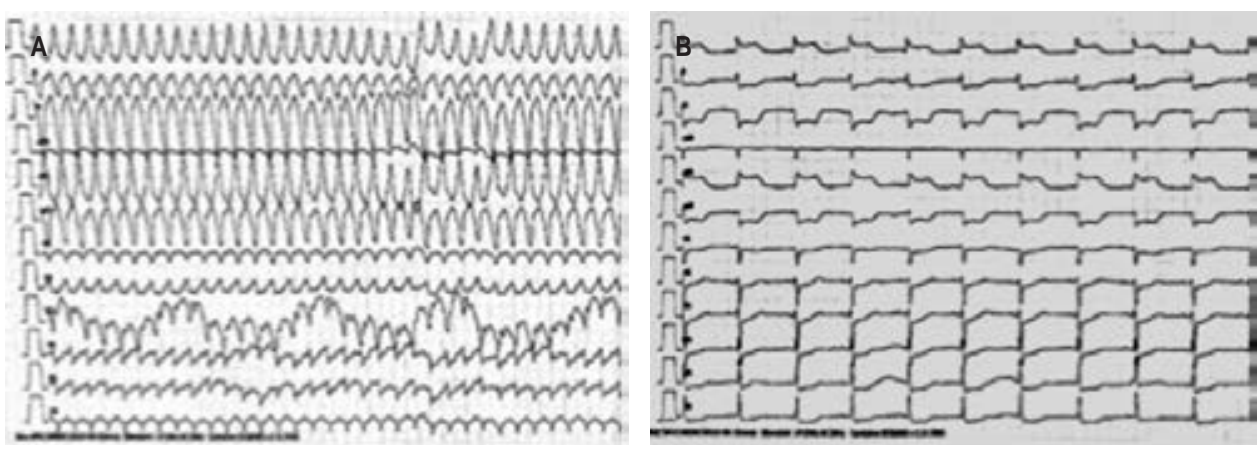

a atrios y dilatación biauricular. Resultados: El cateterismo documentó signo de raíz cuadrada y aumento de presión telediastólica del ventrículo izquierdo con una diferencia menor de $5 \mathrm{mmHg}$ con respecto al derecho. El paciente fue sometido a pericardiectomía. El examen histopatológico reportó calcificaciones distróficas multifocales. El paciente se egresó con manejo betabloqueador y anticoagulante oral directo, citado a rehabilitación cardiaca, con recuperación total al mes. Discusión: En un paciente con datos de falla cardiaca derecha y taquicardia supraventricular, la pericarditis constrictiva se encuentra dentro de los diagnósticos diferenciales. Los hallazgos se explican debido al pericardio rígido que impide la transmisión de la reducción de la presión intratorácica durante la inspiración hacia las cámaras cardiacas, con un llenado izquierdo menor y un llenado derecho mayor.

\subsection{Síndrome de Takotsubo complicado con taquicardia ventricular secundario a colecistitis aguda}

Carrillo Cázares María Betania, Cruz Montalvo Aníbal Eduardo,

Ramos García Marco Antonio, Almeida Gutiérrez Eduardo,

Lupercio Mora Karina

UMAE Hospital de Cardiología del Centro Médico Nacional Siglo XXI.

Tipo de estudio: Reporte de casos clínicos con revisión de fuentes

Introducción: La cardiomiopatía por estrés se caracteriza por la disfunción sistólica transitoria del ventrículo izquierdo frecuen-
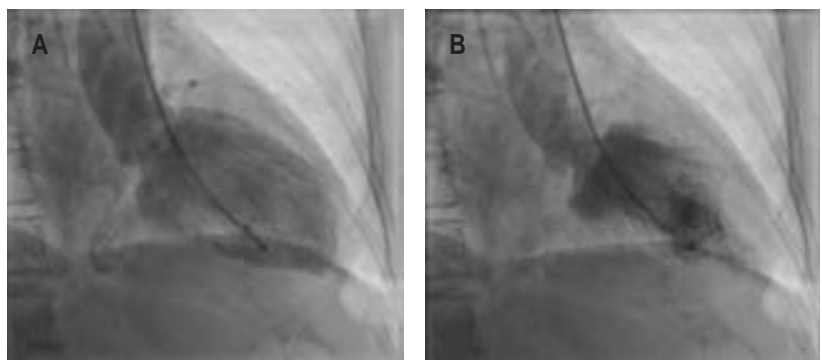

Figura 14.29.2: A) Ventriculograma en diástole. B) Ventriculograma en sístole con acinesia basal e hipercinesia medioapical.

temente relacionada con un evento estresante. Su diagnóstico puede representar un desafío al contar con una presentación muy variable que puede confundirse con síndrome coronario agudo. Se presenta el caso de una paciente con dolor abdominal y cambios electrocardiográficos sugestivos de infarto agudo de miocardio. Descripción del caso: Mujer de 83 años que acude por palpitaciones y dolor abdominal, con inestabilidad hemodinámica por taquicardia ventricular monomórfica. Posterior a cardioversión eléctrica QTprolongado y elevación del segmento-ST en DI, aVL; coronariografía con arterias sin lesiones obstructivas y ventriculograma con acinesia basal e hipercinesia apical. Presenta además colecistitis 
aguda (colecistectomía con resolución de síntomas). Metodología: A través del método booleano se realizó búsqueda de términos $\mathrm{MeSH}$ «Takotsubo syndrome» [and] «Stress cardiomyopathy» en las bases de datos con repositorios de evidencia científica arbitrada indizada (PubMed) y no indizadas (Google Scholar). Resultados: El síndrome de Takotsubo se caracteriza por alteraciones en la movilidad regional del ventrículo izquierdo desencadenados por estrés psicológico o físico. Típicamente son pacientes postmenopáusicas con dolor torácico, disnea, mareo, síncope. Es diagnosticado retrospectivamente al demostrar alteraciones reversibles de la movilidad del ventrículo izquierdo; sin embargo, hay datos electrocardiográficos, ecocardiográficos, con ventriculografía y resonancia magnética que lo sugieren. Discusión: La cardiomiopatía por estrés puede presentarse como síndrome coronario agudo. Este caso realza el considerar esta entidad ante la presentación de arritmias ventriculares y cambios de lesión subepicárdica. Aunque es un diagnóstico retrospectivo, se cuentan con herramientas como el ecocardiograma y la ventriculografía para realizarlo. Destaca la importancia de resolver la etiología subyacente, en este caso, un problema quirúrgico abdominal.

\subsection{Infección de vías urinarias como desencadenante de miocardiopatía de estrés}

Delgado De Nicola Laura, Quintero Pánuco Jair, Almeida Gutiérrez Eduardo, Lupercio Mora Karina Hospital de Cardiología del Centro Médico Nacional Siglo XXI. Tipo de estudio: Reporte de casos clínicos con revisión de fuentes

Introducción: El síndrome de Takotsubo se caracteriza por disfunción ventricular severa y está asociado a estrés emocional, es más frecuente en mujeres postmenopáusicas; clínica de síndrome coronario agudo (SCA), con alteración en la movilidad apical y en la angiografía evidencia de arterias coronarias sin lesiones con patrones
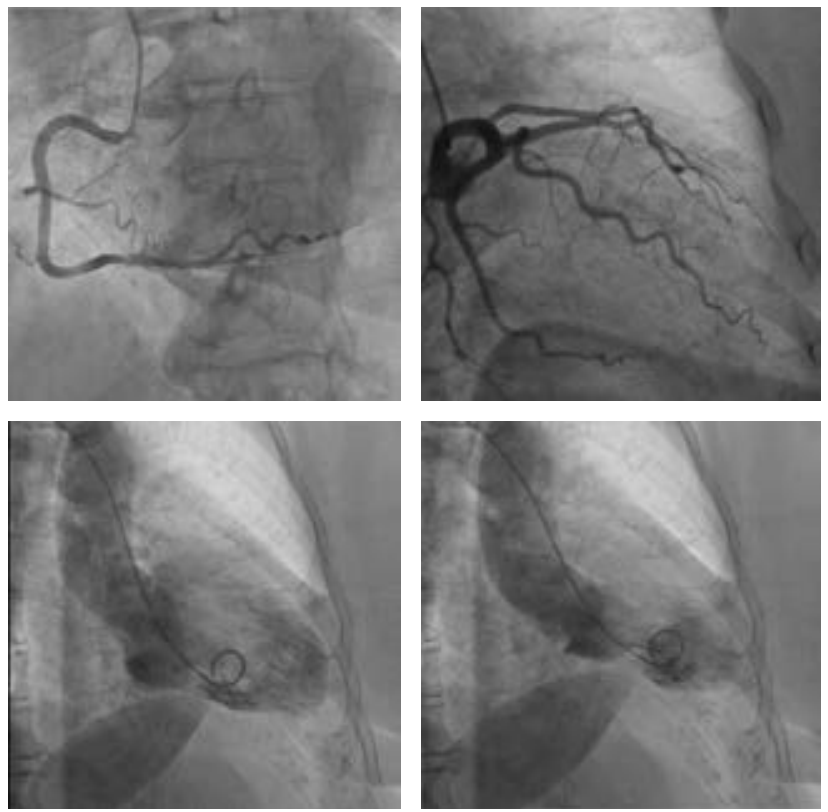

Figura 14.30.1.

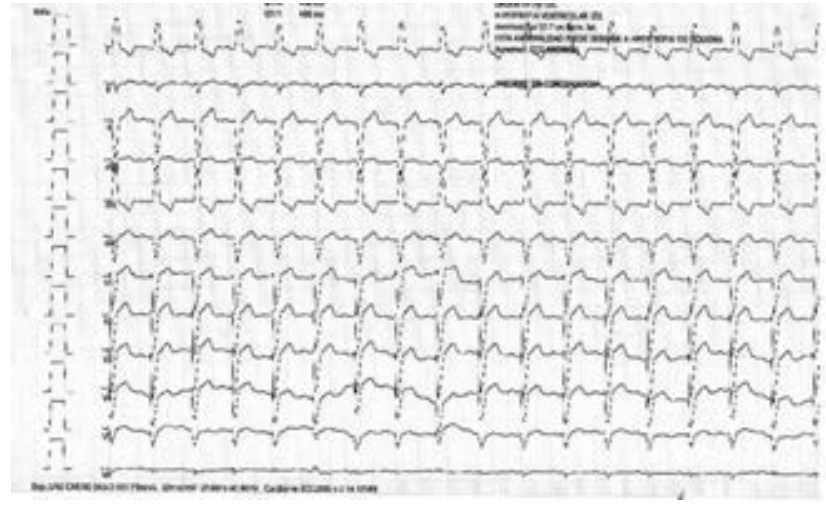

Figura 14.30.2.

de disfunción ventricular izquierda incluyendo la variante apical, medio ventricular, basal o la variante invertida. Descripción del caso: Mujer de 75 años, hipertensión arterial sistémica y bloqueo de rama izquierda del haz de $\mathrm{His}(\mathrm{BRIHH})$. Ingresa por angina típica y lipotimia; taquicardia sinusal y BRIHH sin criterios de Sgarbossa, troponina T-HS $378 \mathrm{ng} / \mathrm{dL}$, hipocinesia anterior basal y medio, FEVI 30\%; angiografía coronaria con arterias coronarias epicárdicas sin lesiones angiográficas, ventriculograma con acinesia apical; se concluye síndrome de Takotsubo; además, se documentó infección de vías urinarias. Metodología: A través del método booleano se realizó búsqueda de términos $\mathrm{MeSH}$ «takotsubo syndrome» [and] «sepsis» en las bases de datos con repositorios de evidencia científica arbitrada indizada (PubMed) y no indizadas (Google Scholar) Resultados: Las causas infecciosas se han reportado como etiología de cardiomiopatía de estrés en la que el sustento fisiopatológico se da por la liberación de citocinas, toxicidad por catecolaminas endógenas que condiciona espasmo de los vasos epicárdicos, disfunción microcirculatoria y cardiovascular. Discusión: El síndrome de Takotsubo inducido por sepsis y/o choque séptico es parte de los desencadenantes físicos descritos en la literatura hasta ahora de este síndrome, por lo que en el contexto de pacientes con perfil de riesgo para cardiomiopatía por estrés debe considerarse como diagnóstico diferencial de SCA, siendo descrito hasta en $2 \%$ de los casos.

\subsection{Pericarditis constrictiva secundaria a tuberculosis en paciente VIH positivo}

Chávez Félix Elsa Viridiana, Núñez Méndez José Gilberto, Silva García Marissa Anaid, Carrillo Muñoz Arturo, Almeida Gutiérrez Eduardo, Lupercio Mora Karina, Ramírez Arias Erick Instituto Mexicano del Seguro Social.

Tipo de estudio: Reporte de casos clínicos con revisión de fuentes

Introducción: La pericarditis constrictiva surge de un pericardio inelástico y enfermo que restringe la expansión diastólica ventricular, la tuberculosis es ahora una causa relativamente rara de pericarditis constrictiva, con informes que van desde menos de uno a $5.6 \%$ de los casos. Descripción del caso: Masculino de 37 años, tres años con VIH, cursa con disnea en reposo y uso de oxígeno, baciloscopias positivas para M. tuberculosis, tratado con DOTBAL, ECOTT: pericardio de $10 \mathrm{~mm}$, movimiento septal paradójico, flujo mitral E/a: 1.5, tiempo de desaceleración: 150 ms, TDI E medial 9 cm/ 

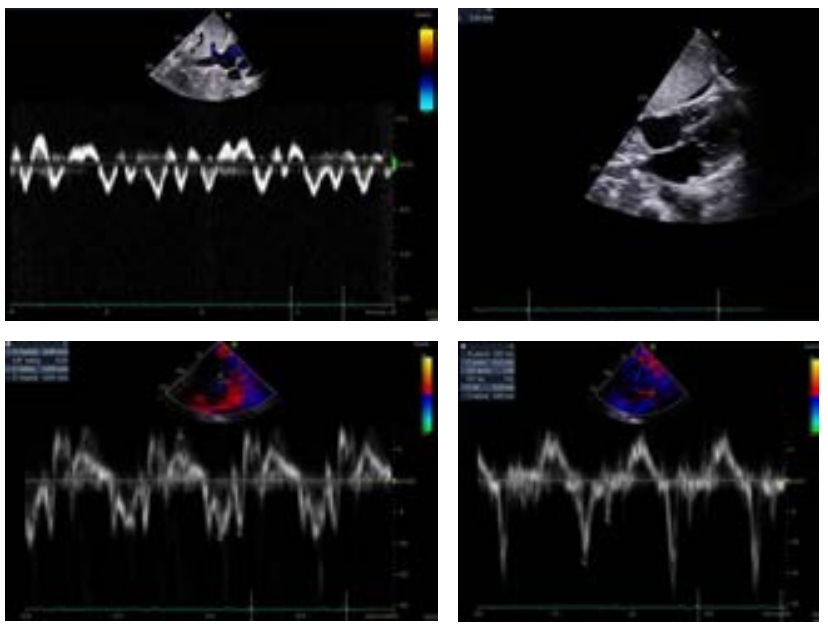

Figura 14.31.1.

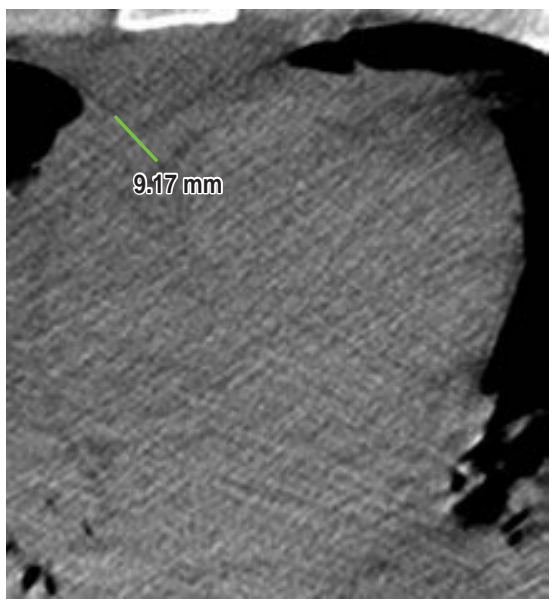

Figura 14.31.2.

seg, E/e': 5.2, flujo de vena suprahepática reversa. Biopsia muestra pericarditis crónica granulomatosa. Metodología: Se realizó una búsqueda en bases de datos de revistas indexadas con factor de impacto (PubMed, Cochrane) y en bases de datos de publicaciones arbitradas sin factor de impacto (Google Académico). Se eligieron los artículos de revisión, guías de práctica clínica y series de casos que mostraron información relacionada con nuestro caso. Resultados: El diagnóstico diferencial en ECOTT como flujo mitral e/a $<1.5$, tiempo de desaceleración de la onda e $<160$ ms, VCl dilatada, es pericarditis constrictiva vs miocardiopatía restrictiva, aunado al valor de la onda $E^{\prime}>8 \mathrm{~cm} / \mathrm{seg}$ con una onda $S^{\prime}>6 \mathrm{~cm} / \mathrm{seg}$ más un $T E^{\prime}-E<47$ mseg, la sensibilidad incrementa hasta $94 \%$. Discusión: La pericarditis constrictiva es una causa reversible de falla cardiaca. Hasta $60 \%$ de los casos de pericarditis constrictiva por $M$. tuberculosis responden a tratamiento farmacológico, en caso contrario la pericardiectomía está indicada. En regiones endémicas la pericarditis tuberculosa es la mayor causa de muerte cardiovascular y discapacidad, el diagnóstico oportuno está en pro de disminuir la morbimortalidad.

\subsection{Oclusión simultánea de dos vasos y síndrome coronario agudo con elevación del segmento ST}

Patricia Ramírez Sánchez, Macossay Santiago Sigifredo, Antezana Castro Javier, Pacheco López Alejandro, Hernández Pineda Axel Hiram, Almeida Gutiérrez Eduardo Hospital de Cardiología del Centro Médico Nacional Siglo XXI.

Tipo de estudio: Reporte de casos clínicos con revisión de fuentes

Introducción: La ruptura de una placa vulnerable con formación de trombo y la oclusión del vaso es la causa principal del infarto agudo de miocardio con elevación del segmento ST. Por lo general, se reconoce una sola arteria responsable del infarto; sin embargo, hasta en $2.5 \%$ de los pacientes se puede encontrar la oclusión simultánea de más de un vaso. Descripción del caso:

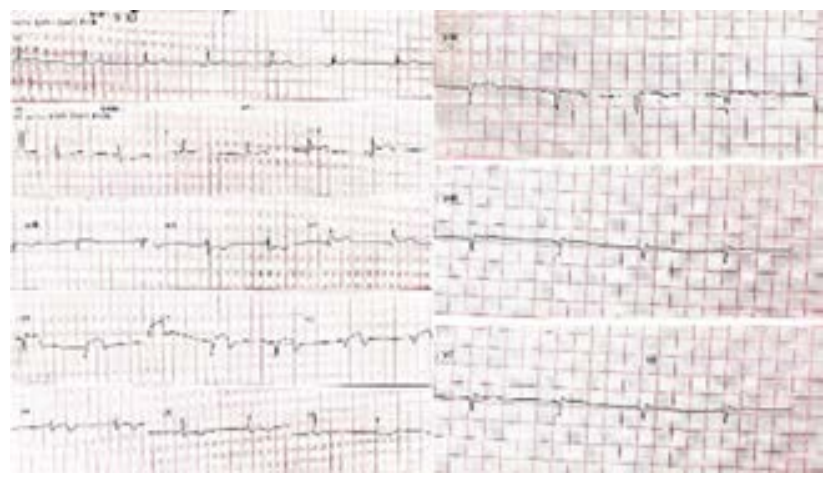

Figura 14.32.1.
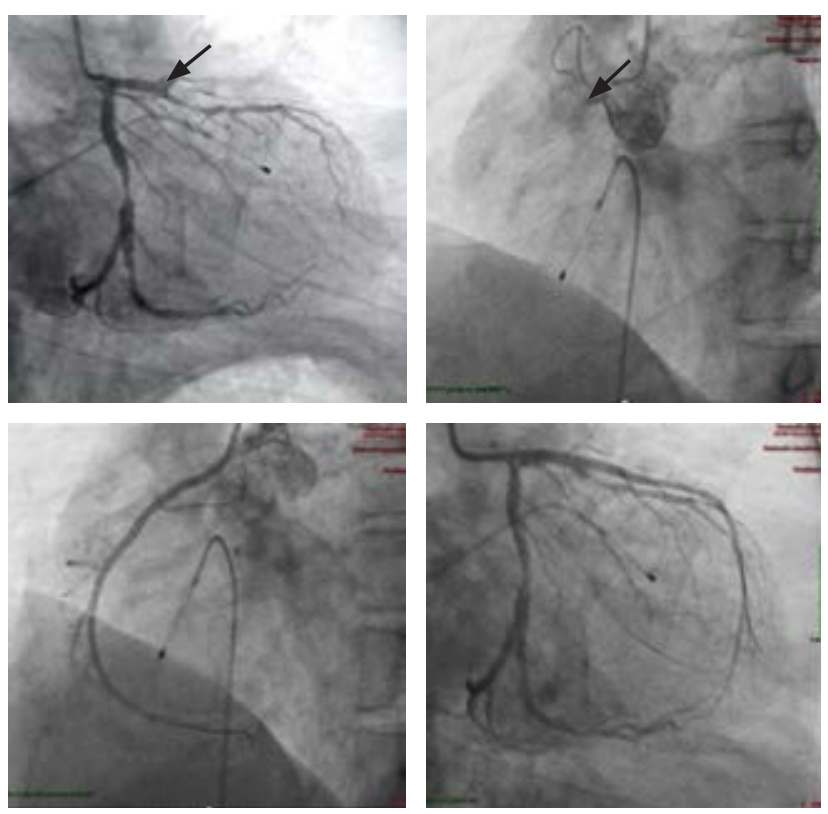

Figura 14.32.2. 
Masculino de 62 años; dislipidemia sin tratamiento y tabaquismo activo. Inicia con angina típica $>30 \mathrm{~min}$, acude a urgencias y el electrocardiograma muestra ritmo nodal, lesión subepicárdica en región inferior, derecha (V3R-V4R) y anteroapical (V1-V4). ICP-primaria: descendente anterior y coronaria derecha con oclusión total aguda desde proximal con trombo ambas; se decide intervenir ambos vasos. Metodología: A través del método booleano se realizó búsqueda de términos MeSH «simultaneous coronary occlusion» [and] «myocardial infarction» en las bases de datos con repositorios de evidencia científica arbitrada indizada (PubMed) y no indizadas (Google Scholar). Resultados: La trombosis aguda de más de una arteria es un hallazgo angiográfico infrecuente en el infarto del miocardio; sin embargo, representa un factor pronóstico para el desarrollo de choque cardiogénico. Se desconoce el mecanismo de la oclusión simultánea, pero se reconocen factores predisponentes como trombocitosis esencial, espasmo multivaso, embolismo coronario, hipercoagulabilidad y abuso de drogas. Discusión: Se trata de una presentación inusual del síndrome coronario agudo, en el que la elevación del segmento ST en sitios distintos debe alertar al clínico, ya que se trata de una entidad que requiere tratamiento de reperfusión inmediata por la gran cantidad de miocardio en riesgo que lleva a choque cardiogénico, arritmias ventriculares y muerte.

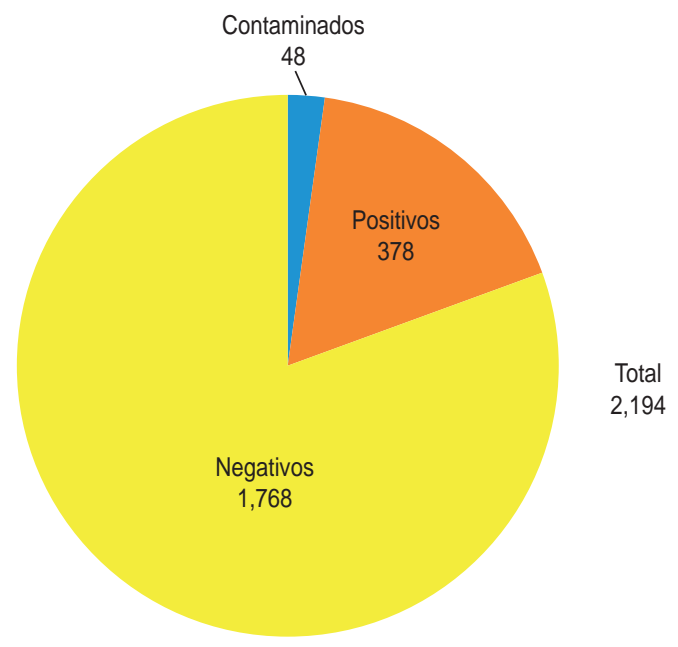

Figura 14.33.1: Muestras de hemocultivos.

\subsection{Agentes causales aislados con mayor frecuencia en hemocultivos durante el año 2019}

Chávez Del Monte Elizabeth, Escobar Sánchez Aldo

UMAE Hospital de Cardiología del Centro Médico Nacional Siglo XXI. Tipo de estudio: Estudio pronóstico

Introducción: En la actualidad, gracias a la transición epidemiológica, se han observado cambios en los agentes causales principales de las infecciones endovasculares debido a diferentes factores como aumento en la resistencia bacteriana resultado de hospitalizaciones prolongadas o tratamientos invasivos. Por ello, el diagnóstico oportuno con identificación del agente causal es primordial para el cardiólogo, actualizando de manera constante los microorganismos principalmente aislados. Objetivo: Determinación de los principales agentes causales encontrados en hemocultivos de población cardiópata durante el año 2019. Llevar una relación del resultado de hemocultivos y ayudar a la orientación del tratamiento Metodología: Se realizó un estudio observacional, retrospectivo, de 788 pacientes, se evaluaron variables como positividad de hemocultivos periféricos y centrales con microorganismos aislados a través del instrumento de medición Bact-Alert. Los datos obtenidos fueron analizados mediante estadística descriptiva. Resultados: Se analizaron 2,194 muestras, $17.22 \%$ fueron positivas ( $\mathrm{n}=378)$, una gran muestra de $80.58 \%$, negativas $(\mathrm{n}=1,768)$ y $2.18 \%$, contaminadas $(n=48)$. Los agentes aislados en primer lugar: S. epidermidis $29.36 \%$ ( $n=111$ ), en segundo lugar $E$. coli con $15.07 \%$ (57), tercer lugar S. aureus $14.02 \%$ (53), en cuarto lugar S. hominis con $6.08 \%(n=23)$, en quinto lugar K. pneumoniae y Serratia marcescens 4.49\% ( $n=17)$. Resto: $28.8 \%$ ( $n=100)$. Además, se encontró que S. epidermidis presentó resistencia a beta-lactámicos, lo que conlleva a la recurrencia de antibióticos de mayor espectro. Discusión y conclusiones: La evidencia en el cambio de la etiología en las infecciones vasculares, así como el aumento en las resistencias antimicrobianas de dichos agentes, reitera la importancia en su detección.

\subsection{Efecto de obesidad y SCORE cardiovascular como predictores de mortalidad en pacientes COVID-19}

Ahuja Casarín Alicia Carolina,* García Méndez Rosalba Carolina, ${ }^{\ddagger}$ Hernández Jiménez Ernesto,* García Galicia Arturo,* Montiel Jarquín Álvaro José*

* Unidad Médica de Alta Especialidad, Hospital de Especialidades del Centro Médico Nacional «General de División Manuel Ávila Camacho», IMSS, Puebla. ` UMAE Hospital de Cardiología del Centro Médico Nacional Siglo XXI, IMSS, Ciudad de México. Tipo de estudio: Reporte de casos clínicos con revisión de fuentes

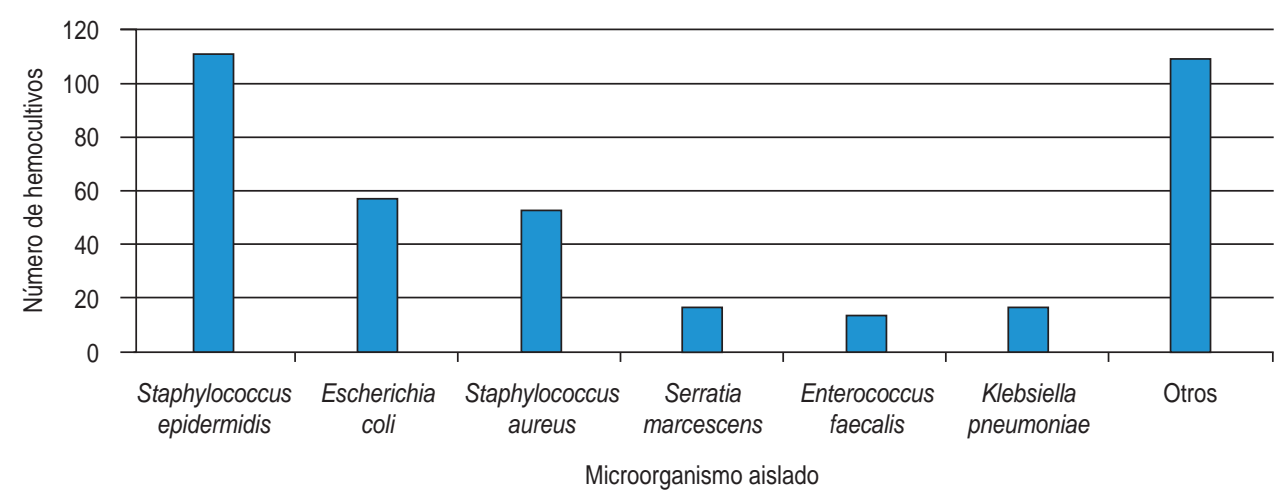

Figura 14.33.2. 
Tabla 14.34.1: Características demográficas y clínicas de acuerdo con el desenlace.

\begin{tabular}{|c|c|c|c|}
\hline & $\begin{array}{l}\text { Sobrevivientes, } \\
\begin{array}{c}\text { N = } 61(54 \%) \\
\text { n (\%) }\end{array}\end{array}$ & $\begin{array}{c}\text { No } \\
\text { sobrevivientes, } \\
\begin{array}{c}\mathrm{N}=52(46 \%) \\
\mathrm{n}(\%)\end{array}\end{array}$ & p \\
\hline Edad (años) & $54.8 \pm 10.4$ & $62.6 \pm 10.6$ & 0.001 \\
\hline Sexo & & & 0.44 \\
\hline Femenino & $23(38)$ & $16(31)$ & \\
\hline Masculino & 38 (62) & $36(69)$ & \\
\hline Peso (kg) & 78 (72-85) & $75.5(70-88)$ & 0.70 \\
\hline Talla (m) & $1.64 \pm 0.10$ & $1.61 \pm 0.09$ & 0.16 \\
\hline IMC (kg/m²) & $28.7(27-33)$ & $29.1(26-33)$ & 0.72 \\
\hline Días de EIH & $8(6-10)$ & $6(1.5-11)$ & 0.01 \\
\hline $\begin{array}{l}\text { SCORE (pun- } \\
\text { taje de riesgo) }\end{array}$ & $1(0-1)$ & $1(1-4.5)$ & 0.0001 \\
\hline TAS (mmHg) & $126.8 \pm 19.3$ & $124.5 \pm 25.8$ & 0.61 \\
\hline TAD (mmHg) & $76.9 \pm 9.1$ & $72.6 \pm 13.2$ & 0.05 \\
\hline HAS & 10 (16.3) & 17 (32.6) & 0.041 \\
\hline $\mathrm{DM}$ & $9(1.6)$ & $20(38.4)$ & 0.004 \\
\hline Obesidad & $26(43)$ & $21(40.3)$ & 0.81 \\
\hline Dislipidemia & $1(1.6)$ & $4(7.7)$ & 0.12 \\
\hline Tabaquismo & $4(6.5)$ & $5(9.6)$ & 0.55 \\
\hline EPOC & $2(3.3)$ & $1(2)$ & 0.65 \\
\hline Cáncer & $2(3)$ & - & 0.18 \\
\hline Autoinmunidad & - & $1(2)$ & 0.27 \\
\hline IECA & $5(8)$ & $9(17)$ & 0.14 \\
\hline $\begin{array}{l}\text { Bloqueadores } \\
\text { ARA II }\end{array}$ & $10(16.4)$ & 17 (33) & 0.14 \\
\hline TA controlada & 48 (79) & 37 (71) & 0.35 \\
\hline AMV ingreso & $2(3.3)$ & $12(23)$ & 0.001 \\
\hline
\end{tabular}

IMC = índice de masa corporal; EIH = estancia intrahospitalaria; TAS = tensión arterial sistólica; TAD = tensión arterial diastólica; HAS = hipertensión arterial sistémica; DM = diabetes mellitus; EPOC = enfermedad pulmonar obstructiva crónica; $\mathrm{IECA}=$ inhibidores de la enzima convertidora de angiotensina; ARA II = antagonistas de los receptores de la angiotensina II; AMV = asistencia mecánica ventilatoria.

Tabla 14.34.2: Predictores independientes de mortalidad en población estudiada con COVID-19.

\begin{tabular}{lccccc} 
& OR & EE & $\mathbf{z}$ & $\mathbf{p}$ & IC 95\% \\
SCORE & 1.60 & 1.600 & 0.22 & 0.001 & $1.22-2.10$ \\
TAD & 0.94 & 0.021 & -2.67 & 0.008 & $0.89-0.98$ \\
DM & 3.74 & 1.940 & 2.54 & 0.011 & $1.35-10.3$ \\
AMV ingreso & 7.67 & 6.630 & 2.36 & 0.018 & $1.40-42.0$ \\
\hline
\end{tabular}

$\mathrm{TAD}$ = tensión arterial diastólica; $\mathrm{DM}$ = diabetes mellitus; $\mathrm{AMV}$ = asistencia mecánica ventilatoria; $\mathrm{OR}=$ odds ratio; $\mathrm{EE}$ = error estándar.

Introducción: COVID-19 es una pandemia de alta mortalidad mundial. La obesidad ha mostrado probabilidad de 1.43 veces mayor para desarrollo de presentación grave en estos pacientes. La determinación del riesgo cardiovascular en la atención temprana de COVID-19 no se realiza. El SCORE cardiovascular constituye un instrumento predictor de complicaciones cardiovasculares a largo plazo; sin embargo, no ha sido evaluado en este contexto. Descripción del caso: Determinar si la obesidad y SCORE de riesgo cardiovascular constituyen predictores independientes de mortalidad en pacientes mayores de 40 años con COVID-19 sin cardiopatía y nefropatía subyacentes. Metodología: Estudio transversal analítico en pacientes mayores de 40 años con obesidad y COVID-19 sin cardiopatía y nefropatía subyacentes, atendidos en el Hospital de Especialidades Puebla del 1 abril al 31 julio de 2020. Se realizó análisis estadístico descriptivo, inferencial y regresión logística multivariada para determinar predictores independientes de mortalidad. Se consideró significativo un valor alfa $\leq 0.05$. Resultados: Se analizaron 113 pacientes: 54\% sobrevivientes y $46 \%$ no sobrevivientes. Las diferencias respectivas: edad $54.8 \pm 10.4$ vs $62.6 \pm 10.6$ años $(\mathrm{p} \leq 0.001)$; días de estancia intrahospitalaria (DEIH) 8 vs 6 días ( $p \leq 0.01)$; SCORE $1(0-1)$ vs $1(1-4.5)$ puntos $(p \leq 0.0001)$; hipertensión arterial sistémica (HAS) 16.3 vs $33 \%$ ( $\mathrm{p} \leq 0.004)$; diabetes mellitus (DM) 14.7 vs 38\% ( $\leq \leq 0.004$ ); bloqueadores del receptor de angiotensina II (BRAII) 16 vs 33\% ( $\leq \leq 0.04)$; asistencia mecánica ventilatoria (AMV) ingreso 3 vs 23\% ( $\leq \leq 0.001)$. Los predictores independientes de mortalidad: SCORE OR 1.6 IC 95\% (1.22-2.10); TAD OR 0.94 IC 95\% (0.89-0.98); DM OR 3.74 IC 95\% (1.35-10.5) y AMV ingreso OR 7.67 IC 95\% (1.4-4.2). Discusión: La obesidad no se asoció con peor desenlace en COVID-19 en este estudio. El SCORE constituyó un predictor independiente de mortalidad. Podría ser de utilidad pronóstica temprana en estos pacientes.

\subsection{Enfermedad de Kawasaki con afectación coronaria en adultos}

Chávez Ortíz Iván, De La O Durán Iris Melina,

Hernández Rangel Daniel Oswaldo, Agüero Castrejón Meredith

Instituto Mexicano del Seguro Social.

Tipo de estudio: Reporte de casos clínicos con revisión de fuentes

Introducción: La enfermedad de Kawasaki es una vasculitis autoinmune con afectación de vasos de pequeño y mediano

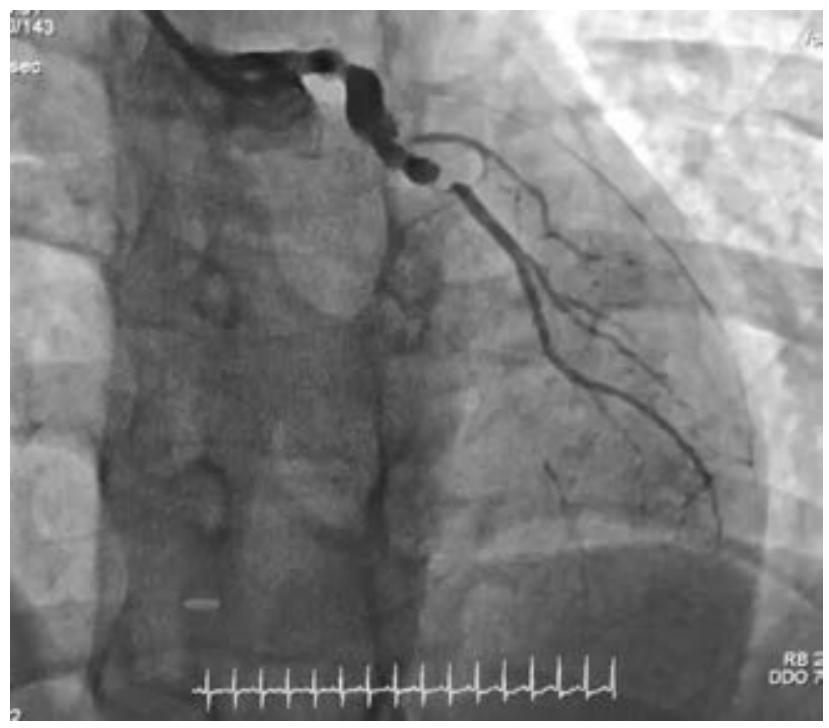

Figura 14.35.1. 


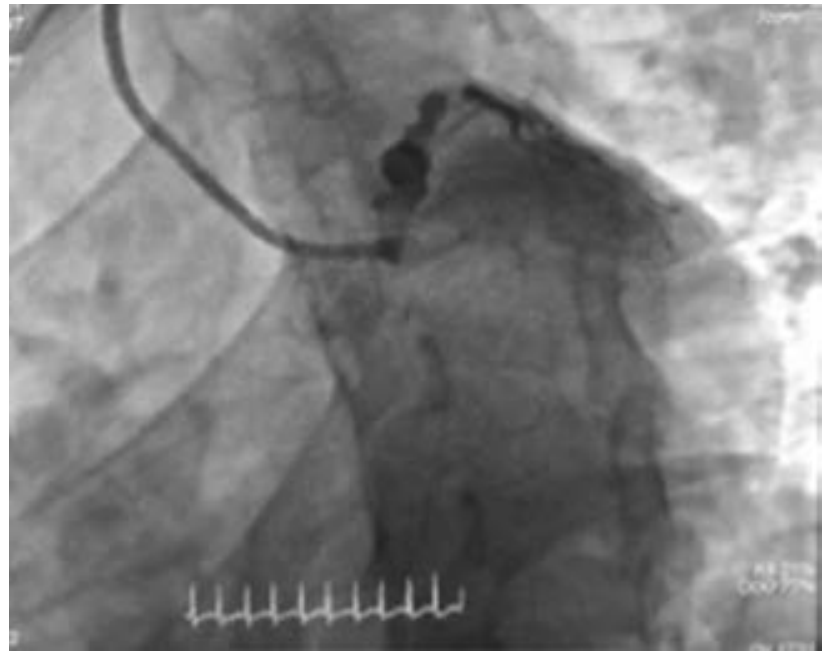

Figura 14.35.2.

calibre, especialmente de las arterias coronarias, y se manifiesta clínicamente por un evento agudo y autolimitado de fiebre alta, inflamación mucocutánea y linfadenopatías cervicales. Suele afectar a los niños, aunque también puede aparecer en la adolescencia y excepcionalmente en la edad adulta. Descripción del caso: Mujer de 27 años con antecedentes de fiebre autolimitada de 10 días de duración un año atrás. Seis meses después presenta dolor típico precordial; clase funcional III de la CCS. Se descartó cardiopatía estructural con ecocardiograma transtorácico y se confirmó la enfermedad arterial coronaria con angiografía invasiva con oclusión total crónica de arterias descendente anterior y circunfleja. Metodología: Se realizó una búsqueda de reportes de caso y de revisiones de la literatura actual en PubMed utilizando como palabras clave «Kawasaki's disease», «enfermedad de Kawasaki», «Coronary», «Kawasaki» y se revisaron al menos cuatro artículos relevantes, tres fueron de revisión y un reporte de caso. Resultados: No hay muchos casos de enfermedad de Kawasaki en la edad adulta reportados en la literatura como el de nuestra paciente, por lo que la evidencia sobre la evolución natural y el impacto de los factores de riesgo cardiovascular tradicionales en esta población es escasa. Discusión: El seguimiento y el manejo de individuos adultos con enfermedad de Kawasaki y afectación coronaria sigue siendo un área inexplorada, por lo que las decisiones clínicas, por el momento, deberán basarse en guías y lineamientos actuales de enfermedad arterial coronaria estable con la intención de buscar mejorar la calidad de vida y la supervivencia, también desconocida, en estos pacientes.

\subsection{Cumplimiento de metas de factores de riesgo cardiovascular en pacientes con diabetes mellitus}

Padilla Padilla Francisco Gerardo,* Vázquez Méndez Estefanía,

González Guillermo, ${ }^{\S}$ Silva Giordano Alejandra, ${ }^{\ddagger}$ Reyes Cisneros Fernando

* Centro de Investigación Cardiología Clínica e Intervencionista.

‡ AstraZeneca. ${ }^{\S}$ Hospital Civil de Guadalajara «Fray

Antonio Alcalde». " Hospital Puerta de Hierro.

Tipo de estudio: Registros locales o nacionales

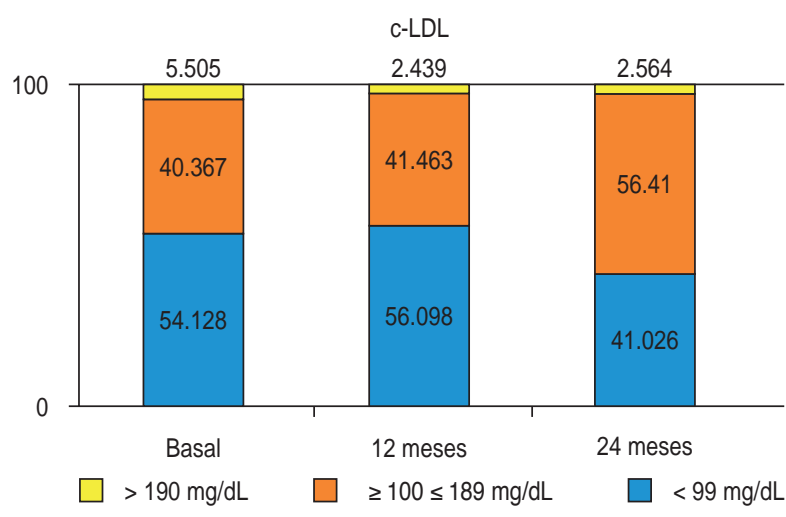

Figura 14.36.1.

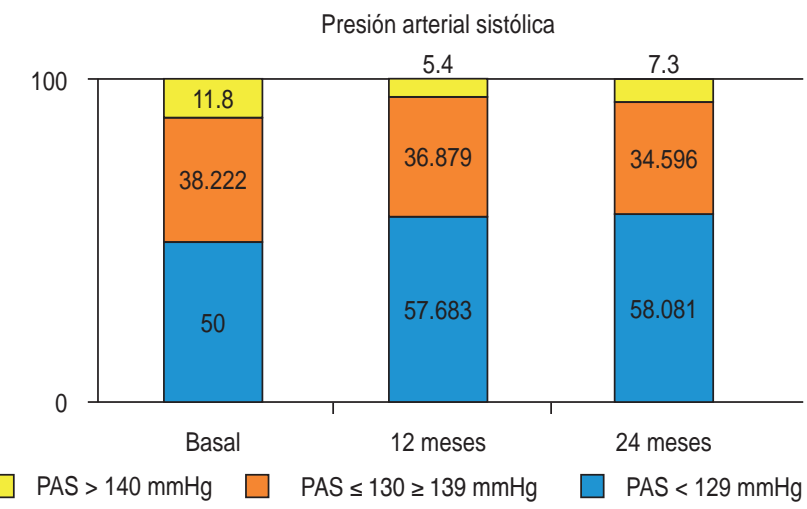

Figura 14.36.2.

Introducción: La diabetes mellitus tipo 2 (DMT2) es una enfermedad prevalente en México. El estudio DISCOVER DMT2 es un ensayo global, no intervencionista, prospectivo y observacional. En el presente estudio reportamos los datos basales de la cohorte mexicana. Se han realizado múltiples estudios transversales y longitudinales en México, pero nunca con tanta claridad. Objetivo: Mostrar el cumplimiento de metas de los factores de riesgo cardiovascular en los pacientes con diabetes mellitus tipo 2 en el registro DISCOVER cohorte México. Metodología: Incluimos a pacientes con antecedentes de diabetes mellitus tipo 2 en el momento de adicionar un segundo medicamento para el control de la glucosa. Se determinaron todos los factores de riesgo y se registraron todos los tratamientos para el control de los mismos. Se realizó un análisis descriptivo para las variables demográficas incluyendo media, mediana y desviación estándar. Resultados: Se reclutaron 455 pacientes en 15 centros a nivel nacional. El sexo fue femenino con $59.1 \%$, edad promedio 56.8 años. El $46.2 \%$ de los pacientes tenían hipertensión arterial y $40.7 \%$ tenían dislipidemia, así como obesidad en 81\%. En 24 meses de seguimiento logramos observar que $41.9 \%$ de los pacientes tuvieron una presión arterial sistólica por arriba de $130 \mathrm{mmHg}$ y $7.3 \%$ por arriba de $140 \mathrm{mmHg}$. En las cifras de colesterol LDL mayor de $100 \mathrm{mg} / \mathrm{dL}$ a 24 meses fue $59.0 \%$. Discusión y conclusiones: Es muy claro que la población mexicana con DMT2 tiene un franco descontrol de los factores 
de riesgo asociados. El resultado es un incremento en riesgo de eventos cardiovasculares.

\subsection{Cambios en el estilo de vida en pacientes con síndrome metabólico (estudio SILVIA)}

Padilla Padilla Francisco Gerardo,* Reyes Cisneros Fernando Antonio, ${ }^{*}$

Garza Marisol,* Ruiz Bernes Lina, ${ }^{\S}$ Fernández Mejía Silvia,"

Delgado Salinas Víctor Manuel ${ }^{\S}$

* Centro de Investigación Cardiología Clínica e

Intervencionista. ${ }^{\ddagger}$ Hospital Puerta de Hierro. ${ }^{\S}$ Cardiología

Clínica e Intervencionista. " Dermatología privada.

Tipo de estudio: Estudio terapéutico

Introducción: El síndrome metabólico es una entidad que es muy prevalente en México. Los cambios al estilo de vida con dieta, ejercicio, suspensión del tabaquismo y el tratamiento farmacológico es sumamente importante para el pronóstico de estos enfermos. Desarrollamos un estudio transversal que pretende evaluar el grado de cambios al estilo de vida en pacientes con síndrome metabólico. Objetivo: Determinar el porcentaje de pacientes que realizan cambios al estilo de vida en una cohorte mexicana. Metodología: En un centro de investigación se incluyeron 100 pacientes con síndrome metabólico para analizar mediante cuestionarios un estudio transversal de adherencia (estudio SILVIA) al tratamiento y también el apego a los cambios en el estilo de vida. Se utilizó el análisis estadístico descriptivo con medias, medianas, desviaciones estándar, porcentajes y conglomerado de respuestas tipo Likert.

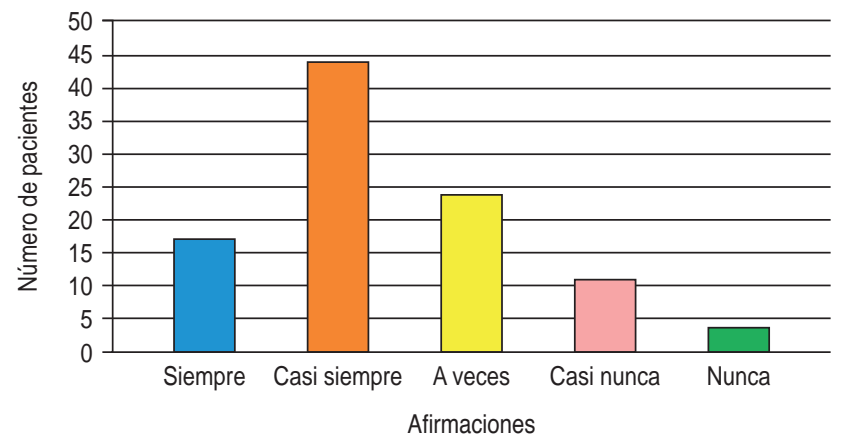

Figura 14.37.1: ¿Cumple las indicaciones relacionadas con la dieta?

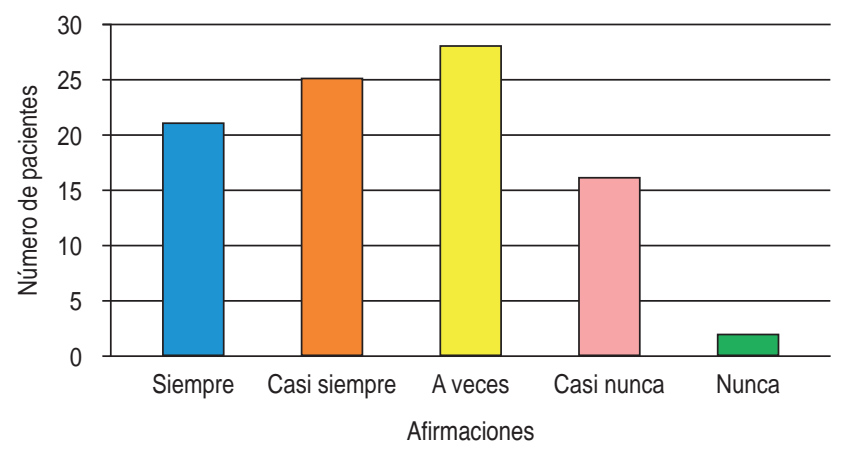

Figura 14.37.2: ¿Realiza los ejercicios físicos indicados?
Resultados: Se analizó el resultado de los cuestionarios de 100 pacientes mexicanos con síndrome metabólico y se encontraron los siguientes hallazgos: $24 \%$ de los pacientes hace la dieta a veces, $11 \%$ casi nunca y $4 \%$ nunca. En ejercicio y actividad física vigorosa sólo $21 \%$ de los pacientes lo hace siempre, $28 \%$ lo realiza a veces, $16 \%$ casi nunca y $10 \%$ nunca lo realiza. En cuanto a los demás parámetros como asistencia a citas, ajuste de horarios para su tratamiento, toma de decisiones junto con su médico, existe mucha variabilidad. Discusión y conclusiones: Los pacientes con síndrome metabólico son de una complejidad enorme para el tratamiento y cambio al estilo de vida. Influyen muchos factores, siendo la adherencia uno de los más importantes.

\subsection{Trombosis aurícula derecha/ vena cava superior y síndrome nefrótico. Reporte de un caso}

Romero Sánchez Javier Alberto, Yescaz Alemán Oscar, Jiménez Santos Moisés, Almeida Gutiérrez Eduardo, Lupercio Mora Karina, Saturno Chiu Guillermo Hospital de Cardiología del Centro Médico Nacional Siglo XXI. Tipo de estudio: Reporte de casos clínicos con revisión de fuentes

Introducción: La trombosis intracavitaria cardiaca asociada con síndrome nefrótico y patología glomerular tiene baja frecuencia e incidencia. El síndrome nefrótico es una constelación de características clínicas y de laboratorio caracterizadas por proteinuria severa, hipoalbuminemia y edema periférico, y con frecuencia se asocian a estados procoagulantes. Descripción del caso: Femenino de 22 años. Hipotiroidismo, aborto de 20 SDG. Inició un mes previo con edema facial y miembros inferiores, lumbalgia y náusea. Ecografía renal Doppler: trombosis en vena yugular derecha (VYD). Ecocardiograma transtorácico: masa en aurícula derecha (AD) 58 $\times 31 \mathrm{~cm}, \mathrm{FEVI} 57 \%$. Resonancia magnética cardiaca: trombo de $107 \times 19 \times 33 \mathrm{~mm}$ desde VYD a vena cava superior y AD hasta la unión cavo. Metodología: A través del método booleano se realizó búsqueda de términos $\mathrm{MeSH}$ «tumoración auricular derecha», «trombosis auricular» en las bases de datos con repositorios de evidencia científica arbitrada indizada (PubMed) y no indizadas (Google Scholar). Resultados: No se cumplieron criterios para

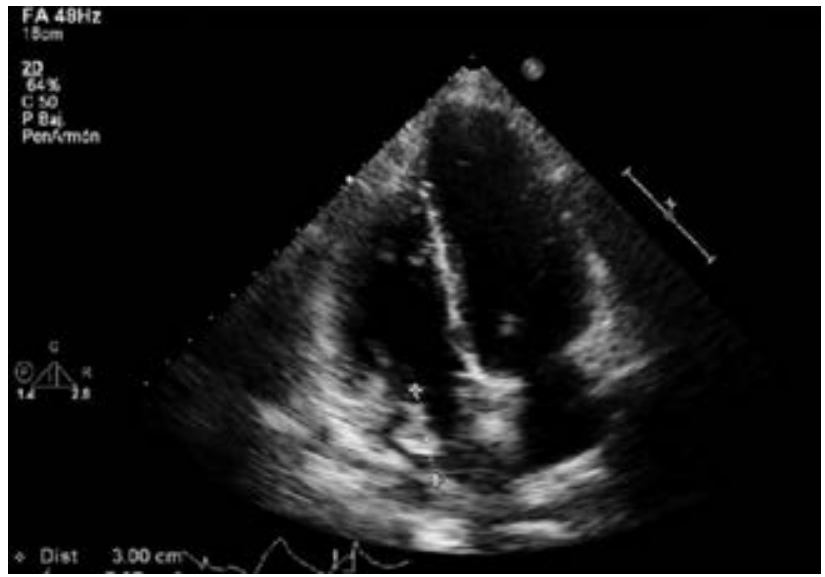

Figura 14.38.1. 
síndrome antifosfolípidos, lupus eritematoso sistémico (LES) o proceso neoplásico. Se enfatiza la importancia del ecocardiograma rutinario en pacientes con síndrome nefrótico debido al desarrollo de trombosis en lugares inusuales y asintomáticos. La paciente fue tratada con anticoagulación y trombectomía. En el seguimiento es necesaria la biopsia renal para determinar la etiología del síndrome nefrótico. Discusión: Kayali y colaboradores evaluaron una cohorte de pacientes con síndrome nefrótico ( $\mathrm{SN}$ ) con riesgo relativo (RR) 1.39 para tromboembolia pulmonar y 1.72 para trombosis venosa profunda (TVP). Pacientes de 18-39 años, el RR de TVP fue de 6.81. Otros factores de riesgo relacionados (cáncer, falla cardiaca) a RR de TVP con SN no fue mayor. La trombosis intracavitaria en paciente joven requiere asociación con estado procoagulante.

\subsection{Elevación del ST anterior como manifestación de oclusión proximal de la coronaria derecha dominante}

Ayón Ménez Vania Elizabeth, Espinosa Bravo Yasmín, Almeida Gutiérrez Eduardo, Lupercio Mora Karina Hospital de Cardiología del Centro Médico Nacional Siglo XXI. Tipo de estudio: Reporte de casos clínicos con revisión de fuentes

Introducción: La elevación del segmento ST en precordiales así como en DII, DIII y AVF puede favorecer el erróneo diagnóstico de enfermedad oclusiva de dos vasos: coronaria derecha (CD) y descendente anterior (DA); sin embargo, la lesión transmural del ventrículo derecho puede elevar el ST en derivaciones precordiales si existe oclusión proximal de la CD dominante, como en este caso. Descripción del caso: Masculino de 58 años, tabaquismo y diabetes. Presentó dolor precordial, electrocardiograma en ritmo nodal con elevación del ST en DII, DIII, con cambios recíprocos en DI y AVL AVF; V3R-V4R y anterior extenso. Ecocardiograma: disfunción del ventrículo derecho, fracción de expulsión del ventrículo izquierdo $41 \%$. Angiografía coronaria: CD con oclusión total proximal, sistema izquierdo sin lesiones significativas. Angioplastia exitosa en CD. Metodología: A través del método booleano se realizó búsqueda de términos MeSH «Acute Right Ventricular Infarction» [and] «Precordial Leads» en las bases de datos con repositorios de evidencia científica arbitrada indizada (PubMed) y no indizadas (Google Scholar). Resultados: Existe una fuerte correlación entre la magnitud de la elevación del ST y la extensión final del infarto; sin embargo, esto podría no ser aplicable en pacientes con elevación combinada anterior e inferior, en los que se presenta un infarto limitado por oclusión proximal de la CD, con sus implicaciones clínicas y pronósticas asociadas a un infarto del ventrículo derecho. Discusión: La oclusión de la coronaria derecha acompañada de cambios en el electrocardiograma que simulan un infarto anterior sugiere que la obstrucción fue proximal y se asocia a infarto del ventrículo derecho y a trastornos de la conducción eléctrica. La angiografía coronaria es la única técnica de diagnóstico de certeza para identificar los vasos culpables y establecer el mejor tratamiento intervencionista.

\subsection{Pericarditis postraumática asociada a disfunción ventricular transitoria}

Flores Oropeza Daniela Alejandra,

Olmos Temois Sergio Gabriel, Joya Delgado Javier

Hospital General Celaya.

Tipo de estudio: Reporte de casos clínicos con revisión de fuentes
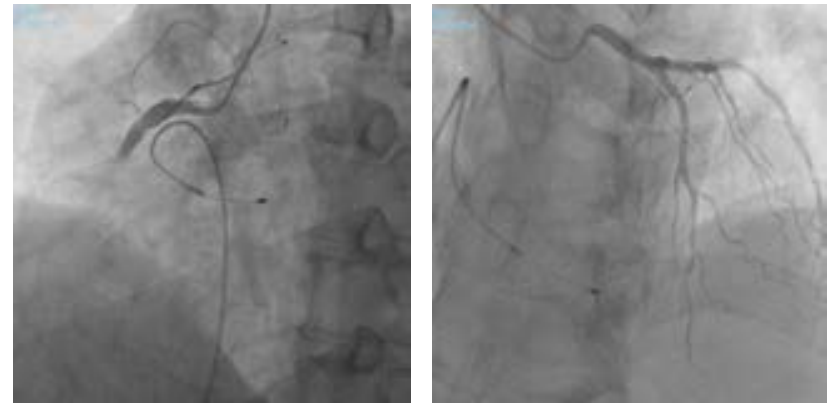

Figura 14.39.1.

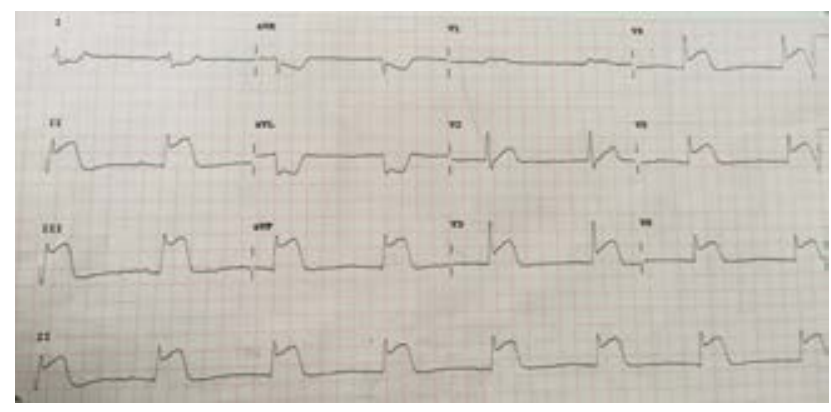

Figura 14.39.2.

Introducción: La pericarditis postraumática es una entidad bien conocida que forma parte del síndrome postlesión cardiaca (al igual que la pericarditis postinfarto y el síndrome postpericardiotomía). En el contexto de trauma torácico (tanto abierto como cerrado) es frecuente que se presente lesión miocárdica agregada a la afectación pericárdica. La presentación clínica es variable. Descripción del caso: Paciente de 38 años, consulta por cuadro de dolor torácico asociada a la inspiración profunda y a cambios de posición, disnea y mareo tras herida punzocortante precordial. Paraclínicos sin elevación de enzimas cardiacas. Por ecocardiografía se documenta derrame pericárdico con hipocinesia de pared ventricular izquierda, se hace diagnóstico de pericarditis postraumática y disfunción miocárdica. Se da manejo con analgésicos y antiinflamatorios. Metodología: Se realizó búsqueda en PubMed utilizando las palabras «pericarditis», «pericarditis postraumática», «síndrome post-lesión cardiaca», «pericarditis aguda». Resultados: La pericarditis postraumática es una entidad bien conocida, asociada frecuentemente a lesión miocárdica; la relevancia del presente estudio es el desarrollo de pericarditis posterior a un trauma torácico abierto sin evidencia de lesión pericárdica o miocárdica directa, atribuida a la cercanía de la lámina pericárdica parietal con el sitio de la lesión. Discusión: Se debe tener en consideración ante cualquier trauma torácico (aun cuando no haya datos de afectación directa) la posibilidad de desarrollar pericarditis y aún más, disfunción miocárdica, que puede constituir muchas veces el motivo de atención en los servicios de urgencias. El ecocardiograma es la herramienta de primera elección en este tipo de pacientes. 


\subsection{Patrones de adherencia en los pacientes mexicanos con síndrome metabólico}

Padilla Padilla Francisco Gerardo,* Reyes Cisneros Fernando Antonio ${ }^{\ddagger}$

* Centro de Investigación Cardiología Clínica e

Intervencionista. ${ }^{\ddagger}$ Hospital Puerta de Hierro.

Tipo de estudio: Estudio terapéutico

Introducción: El síndrome metabólico es una enfermedad poco estudiada, poco comprendida y que genera controversia en su diagnóstico, evaluación y tratamiento. No existen estudios en México que demuestren la adherencia al tratamiento farmacológico para el control del síndrome metabólico. Por tal motivo, contar con estudios que analizan la adherencia en un síndrome tan complejo son necesarios y útiles. Objetivo: Identificar el impacto en la adherencia al tratamiento farmacológico en pacientes con síndrome metabólico y describir las características del tratamiento. Metodología: Este es un estudio transversal para analizar la adherencia

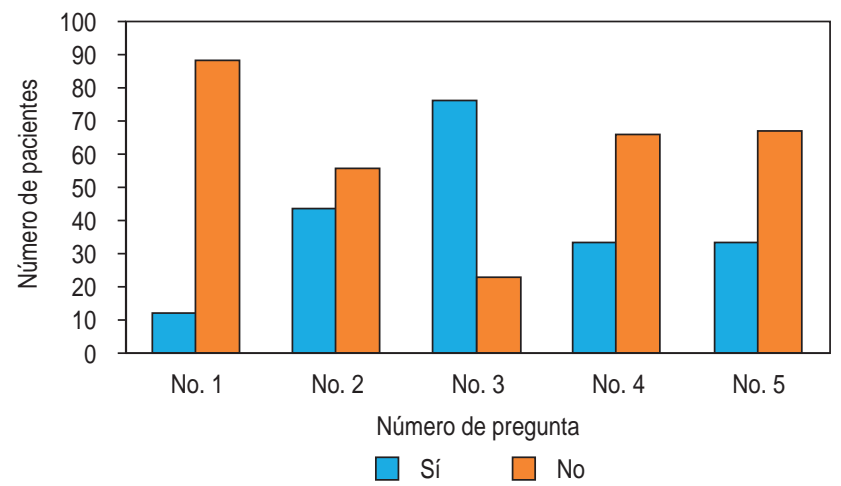

Preguntas:

No. 1: La mayoría de la gente tiene dificultad en seguir el tratamiento; ¿tiene verdadera dificultad para seguir con el suyo?

No. 2: ¿Se olvida alguna vez de tomar los medicamentos?

No. 3: ¿Toma los medicamentos a las horas indicadas?

No. 4: Cuando se encuentra bien, ¿deja alguna vez de tomarlos?

No. 5: Si alguna vez se siente mal al tomar los medicamentos, ¿deja de tomarlos?

Figura 14.41.1: Respuestas al cuestionario de apego al tratamiento.

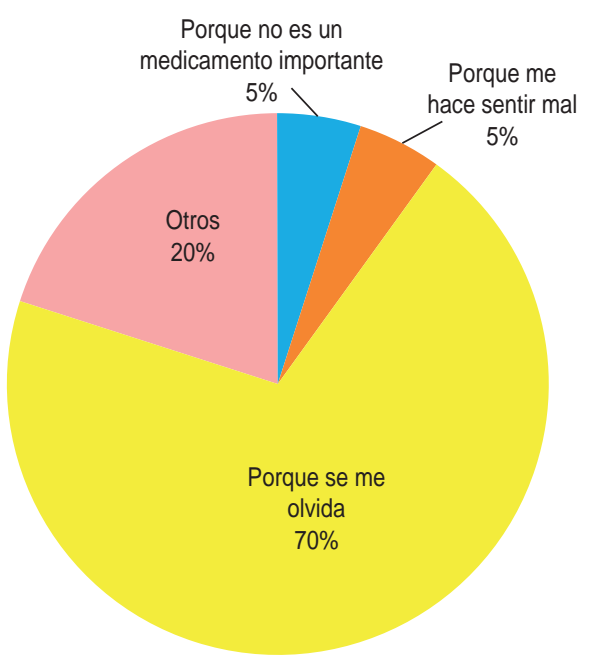

Figura 14.41.2: ¿Motivos por los que no toman bien algún medicamento?

al tratamiento farmacológico en 100 pacientes mexicanos en un centro de investigación. Dicho análisis se logró con reactivos en forma de cuestionario. Durante un periodo de seis meses se reclutaron a todos los pacientes con síndrome metabólico, se determinó el tratamiento que recibieron, número de tabletas y número de tomas. Resultados: En pacientes con síndrome metabólico 44\% de los pacientes olvidan tomar el medicamento ocasionalmente. Además, 34\% de los pacientes abandonan el tratamiento cuando se sienten bien. De igual forma, en pacientes que no se sienten bien suspenden los fármacos hasta en $33 \%$ de las ocasiones al no sentir mejoría. Es importante destacar que los pacientes que no toman de manera correcta el tratamiento indicado hasta en $77 \%$ es por olvido al mismo. La edad media del estudio fue de 60 años y la mayoría fueron mujeres. Discusión y conclusiones: No existen referencias de estudios mexicanos de adherencia en síndrome metabólico. En este estudio demostramos la pobre adherencia al tratamiento. La reducción de tomas y medicamentos combinados puede solucionar problemas. 